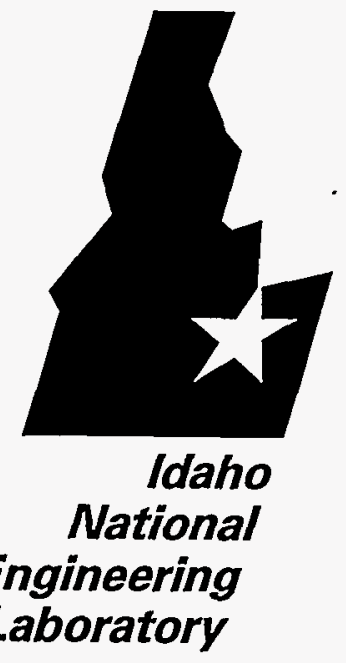

Engineering Laboratory

\title{
Ocean Current Observations near McMurdo Station, Antarctica, 1993 to 1994: Relation to Wastewater Discharge Dispersal
}

\section{J. P. Barry}

\section{DISCLAIMER}

This report was prepared as an account of work sponsored by an agency of the United States Government. Neither the United States Government nor any agency thereof, nor any of their employees, makes any warranty, express or implied, or assumes any legal liability or responsibility for the accuracy, completeness, or usefulness of any information, apparatus, product, or process disclosed, or represents that its use would not infringe privately owned rights. Reference herein to any specific commercial product, process, or service by trade name, trademark, manufacturer, or otherwise does not necessarily constitute or imply its endorsement, recommendation, or favoring by the United States Government or any agency thereof. The views and opinions of authors expressed herein do not necessarily state or reflect those of the United States Government or any agency thereof.

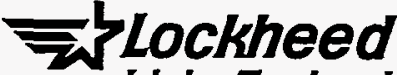 Idaho Technologies Company}


INEL-95/0362

\title{
Ocean Current Observations near . McMurdo Station, Antarctica, 1993 to 1994: Relation to Wastewater Discharge Dispersal
}

\author{
J. P. Barry
}

Published September 1995

\section{J. P. Barry Consulting}

889 Jefferson St.

Monterey, California 93940

\section{Prepared for Lockheed Martin Idaho Technologies}

Under Subcontract C93-134040 and for the

National Science Foundation Office of Polar Programs

Under DOE Idaho Operations Office

Contract DE-AC07-94ID13223

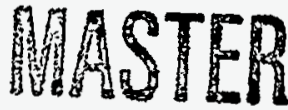

DISTRIBUTION OF THIS DOCUMENT IS UNLHMIED 


\section{ABSTRACT}

This report presents analyses of current measurements from McMurdo Sound, Antarctica during December, 1993 to November, 1994, in relation to dispersal of the McMurdo Station wastewater plume. Data collected from 1991 to 1993 (Barry 1994) are also discussed here. Six current meters were deployed near McMurdo Station, Antarctica, from December 1993 to November 1994. Five functioned properly throughout the observation period, and one failed. Analyses of 5 data series include: 1) summaries of current speed and direction, 2) directional analyses of flow, 3) time series current vectors averaged over $1,3,6,12$, and $24 \mathrm{~h}, 4$ ) principal axes of flow, 5) maps of mean seasonal flow, 6) progressive vector plots, 7) spectral analyses, and 8) low-pass filtered ( $30 \mathrm{~h}$ ) time series of currents at McMurdo Station. Observations of flow near McMurdo Station during 1994 were generally similar to 1993 . Flow varied greatly in speed and direction near McMurdo Station, over periods of hours to months. Short term variation in flow was related principally to diurnal tidal motions. Longer period oscillations in flow such as seasonal shifts, and non-periodic changes in current speed and direction were likely related to changes in ice cover and wind stress in the vicinity of McMurdo Station or over much larger scales or both. Three distinct oceanographic 'seasons' were apparent in time series from 1992 to 1994, from stations furthest offshore, where the effects of local topography are minimal. The spring-summer (Oct. - Jan.) period of both years was dominated by regional southward flow, which generates a counter-clockwise eddy (McMurdo Gyre) adjacent to McMurdo Station. This pattern was strong in 1992-93, but in early spring of the following year (Oct.-Nov. 1993), flow was not yet consistently southward, and included significant northward flow, perhaps related to anomalously high regional ice cover during that year. From summer to fall (Feb.-May) of 1993 and 1994, lower ice cover appeared related to a current pattern including episodes of hours to days of alternating northward and southward flow. In fall to winter (Jun.-Sep.), northward flow dominated the region, but this pattern persisted for a shorter time in 1994, and currents were more similar to the summer - fall pattern for much of the time. With regard to dispersal of the wastewater plume from McMurdo Station, observations of currents during 1994 generally corroborate those from 1993, and the recommendation that the outfall pipe should be repositioned

offshore of the McMurdo Gyre is supported. 



\section{CONTENTS}

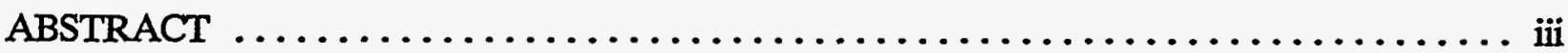

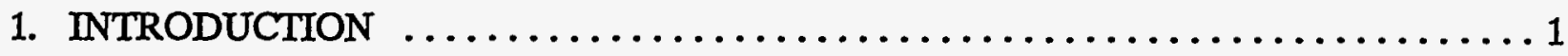

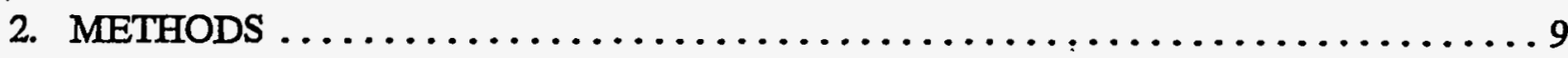

2.1 Current Meter Placement and Deployment $\ldots \ldots \ldots \ldots \ldots \ldots \ldots \ldots \ldots \ldots$

2.1.1 1991 - 1994 Current Observations .......................... 9

2.1.2 1993 - 1994 Year-round Current Meter Deployment .................. 9

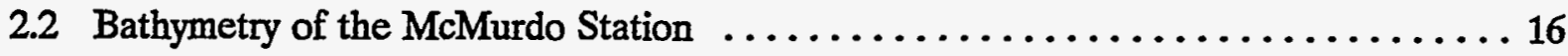

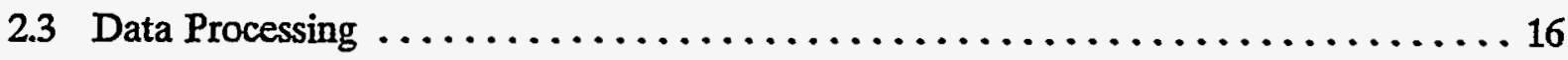

2.4 General Flow Characteristics near McMurdo Station $\ldots \ldots \ldots \ldots \ldots \ldots \ldots \ldots$



2.6 Periodic Characteristics near McMurdo Sound Currents $\ldots \ldots \ldots \ldots \ldots \ldots \ldots$

2.7 Aperiodic Characteristics near McMurdo Sound Currents .............. 17

2.8 Low-pass Filtering of Current Records $\ldots \ldots \ldots \ldots \ldots \ldots \ldots \ldots \ldots \ldots \ldots \ldots \ldots \ldots \ldots$

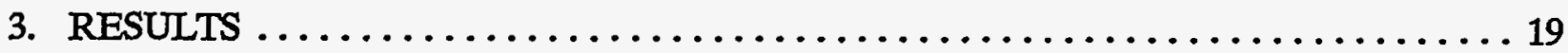



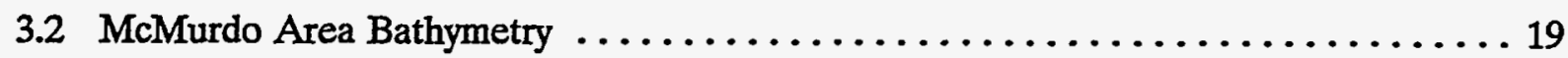

3.3 Regional Scale Pattern of Flow near McMurdo Station $\ldots \ldots \ldots \ldots \ldots \ldots$

3.4 General Pattern of McMurdo Station Currents $\ldots \ldots \ldots \ldots \ldots \ldots \ldots \ldots \ldots \ldots$

3.5 Principal Axes of Current Flow $\ldots \ldots \ldots \ldots \ldots \ldots \ldots \ldots \ldots \ldots \ldots \ldots \ldots \ldots \ldots \ldots \ldots \ldots \ldots$

3.6 Temporal Variation in Regional Flow $\ldots \ldots \ldots \ldots \ldots \ldots \ldots \ldots \ldots \ldots \ldots \ldots \ldots$

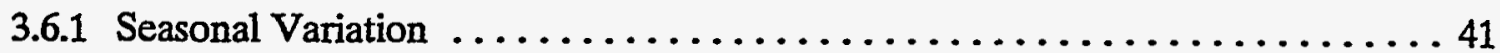

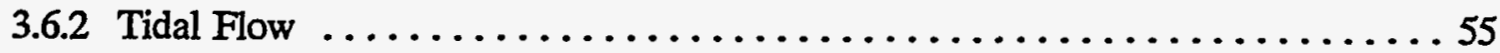

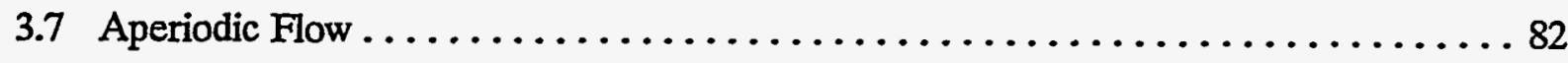

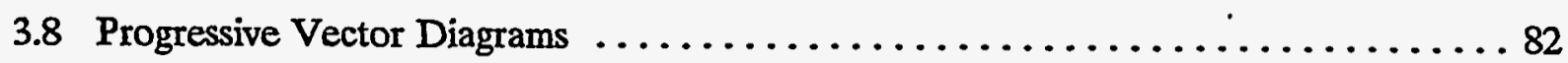


4. DISCUSSION ....................................... 99

4.1 Relationship of Current Patterns to Wastewater Plume Dispersal . . . . . . . . . 99

4.2 Recommendations for Wastewater Outfall Relocation . . . . . . . . . . . . 101

5. REFERENCES $\ldots \ldots \ldots \ldots \ldots \ldots \ldots \ldots \ldots \ldots \ldots \ldots \ldots \ldots \ldots \ldots \ldots \ldots \ldots$

Appendix A-Computer-Based Time Series of McMurdo Sound Current Vectors . . . . . . . A-1 FIGURES

1. Map of Ross Sea Region $\ldots \ldots \ldots \ldots \ldots \ldots \ldots \ldots \ldots \ldots \ldots \ldots \ldots \ldots \ldots \ldots$

2. Map of McMurdo Sound, indicating regional flow pattern $\ldots \ldots \ldots \ldots \ldots \ldots \ldots \ldots$

3. Location of current meters stations in McMurdo Sound $\ldots \ldots \ldots \ldots \ldots \ldots \ldots \ldots$

4. Schematic of current meter deployment in McMurdo Sound $\ldots \ldots \ldots \ldots \ldots \ldots \ldots$

5. Bathymetry of McMurdo Sound near McMurdo Station, Antarctica ........... 21

6. Overall net flow for current meter stations from 1991 to 1994 . . . . . . . . . . . . 25

7. Net flow at all current observation stations from 1991 to 1994 . . . . . . . . . . . . . 31

8. Net flow at all current observation stations during summer to fall $\ldots \ldots \ldots \ldots \ldots \ldots$

9. Net flow at all current observation stations during fall to winter $\ldots \ldots \ldots \ldots \ldots \ldots$

10. Straw diagram time series of 1 hour average current vectors for all stations $\ldots \ldots \ldots \ldots 45$

11. Straw diagram time series of 3 hour average current vectors for all stations $\ldots \ldots \ldots . \ldots 47$

12. Straw diagram time series of 6 hour average current vectors for all stations $\ldots \ldots \ldots . \ldots 49$

13. Straw diagram time series of 12 hour average current vectors for all stations $\ldots \ldots \ldots \ldots 51$

14. Straw diagram time series of 24 hour average current vectors for all stations $\ldots \ldots \ldots . \ldots 53$

15. Straw diagram time series of 12 hour average current vectors for Stations $\mathrm{Q}$ and $\mathrm{N}$ from 1992-93, and nearby Stations $V$ and $W$ from $1993-1994 \ldots \ldots \ldots \ldots \ldots \ldots$

16. Straw diagram time series of $6 \mathrm{~h}$ average current vectors for December, 1993 - February, 1994 
17. Straw diagram time series of $6 \mathrm{~h}$ average current vectors for March - May, $1994 \ldots \ldots 1$

18. Straw diagram time series of $6 \mathrm{~h}$ average current vectors for June - August, 1994 . . . . . 63

19. Straw diagram time series of $6 \mathrm{~h}$ average current vectors for September - November, 1994 . 65

20. Power spectra for periodic flow at Station $T \ldots \ldots \ldots \ldots \ldots \ldots \ldots \ldots \ldots \ldots \ldots$

21. Power spectra for periodic flow at Station $V \ldots \ldots \ldots \ldots \ldots \ldots \ldots \ldots \ldots \ldots \ldots$

22. Power spectra for periodic flow at Station $w \ldots \ldots \ldots \ldots \ldots \ldots \ldots \ldots \ldots \ldots \ldots$

23. Power spectra for periodic flow at Station $\mathrm{X} \ldots \ldots \ldots \ldots \ldots \ldots \ldots \ldots \ldots \ldots$

24. Power spectra for periodic flow at Station $Y \ldots \ldots \ldots \ldots \ldots \ldots \ldots \ldots \ldots \ldots \ldots$

25. Time series of $1 \mathrm{~h}$ low-pass filtered and unfiltered average current speeds at Station $\mathrm{T} \ldots \mathrm{73}$

26. Time series of $1 \mathrm{~h}$ low-pass filtered and unfiltered average current speeds at Station $V \ldots 75$

27. Time series of $1 \mathrm{~h}$ low-pass filtered and unfiltered average current speeds at Station W .. 77

28. Time series of $1 \mathrm{~h}$ low-pass filtered and unfiltered average current speeds at Station X ... 79

29. Time series of $1 \mathrm{~h}$ low-pass filtered and unfiltered average current speeds at Station $\mathrm{Y} \ldots 81$

30. Progressive vector plot for current vectors $(3 \mathrm{~h}$ means) at Station $\mathrm{V}$

a. Overall .................................. 44



31. Progressive vector plot for current vectors ( $3 \mathrm{~h}$ means) at Station $\mathrm{Y}$

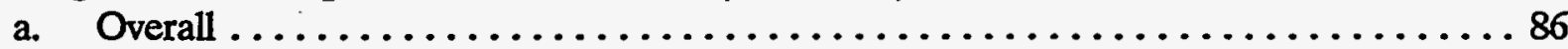

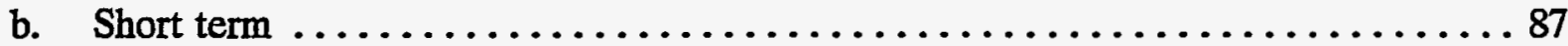

32. Progressive vector plot for current vectors ( $3 \mathrm{~h}$ means) at Station $\mathrm{X} \ldots \ldots \ldots \ldots . \ldots 8$

33. Progressive vector plot for current vectors ( $3 \mathrm{~h}$ means) at Station $\mathrm{W}$

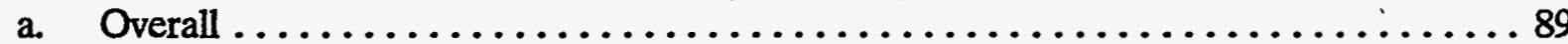

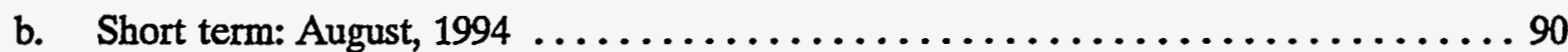

c. Short term: October, $1994 \ldots \ldots \ldots \ldots \ldots \ldots \ldots \ldots \ldots \ldots \ldots \ldots \ldots \ldots$

34. Progressive vector plot for current vectors ( $3 \mathrm{~h}$ means) at Station $\mathrm{T}$



b. Short term $\ldots \ldots \ldots \ldots \ldots \ldots \ldots \ldots \ldots \ldots \ldots \ldots \ldots \ldots \ldots \ldots \ldots \ldots \ldots$

35. Proposed outfall pipe relocation map of McMurdo Sound $\ldots \ldots \ldots \ldots \ldots \ldots$ 


\section{TABLES}

1. List of current meter station characteristics $\ldots \ldots \ldots \ldots \ldots \ldots \ldots \ldots \ldots \ldots \ldots$

2. Flow characteristics for current stations during December, 1993 to November, 1994 . . . . 27

3. Seasonal flow patterns in McMurdo Sound, December, 1993 to November, 1994 . . . . . . 33

4. Principal axes of flow at stations during December, 1993 to November, 1994 . . . . . . . 43 


\section{Ocean Current Observations near McMurdo Station, Antarctica, 1993 to 1994: Relation to Wastewater Discharge Dispersal}

\section{INTRODUCTION}

Ocean currents in the vicinity of McMurdo Station, Antarctica undoubtedly have a large role in the transport and dispersal of wastewater from the McMurdo Station sewage outfall pipe. Observations of ocean currents during the initial phases of this study have been presented by Howington et al. (1992), McFeters (1993), and McFeters, Barry, and Howington (1993), and Barry (1994). These studies, using coliform bacterial counts as an indicator of dispersion of the wastewater plume, and current meters to measure flow patterns, indicated that dispersal of the plume by local currents does not effectively remove the plume from the vicinity of McMurdo Sound, under the present outfall pipe location. Moreover, these studies suggest that although the flow pattern is generally consistent with transport of the plume away from McMurdo Station, episodes of current reversal are sufficient to transport the wastewater plume along-shore toward the southeast, eventually overlapping the sea water intake area near the McMurdo jetty. Concerns including 1) impacts of wastewater inputs to nearshore benthic and pelagic habitats adjacent to McMurdo Station (heavily utilized sites for basic scientific research), 2) effects of wastewater input to the McMurdo Station fresh water intake source, and 3) reduction in human impacts on the McMurdo Sound ecosystem, motivated studies to characterize nearshore currents more extensively, in relation to dispersal of the wastewater plume. This report summarizes analyses of current observations near McMurdo Station from December 1993 to November 1994, and compares data from this period to earlier observations, and in particular to the prior one year observation period (1992-1993).

Ocean currents are generated from a variety of sources including wind stress, planetary motions inducing gravitational tides and tidal currents, density gradients, flexure of ice shelves, and other sources, all of which are superimposed to produce the flow field detected by current sensors. Observations of currents are often divided into periodic and aperiodic (or net) motions to dissect at least some potential factors regulating the flow field. Periodic motions are currents that vary in speed or direction or both, over specific periods associated most often with known planetary motions (e.g. diurnal or semi-diurnal tidal motions). Aperiodic flow is the residual (or net) motion remaining after periodic oscillatory flow is filtered from current patterns. Aperiodic motions may consist of actual net transport arising from various sources, but may also be related to unidentified periodic motion. For example, observations over a 3 month period are not sufficient to detect periodic patterns of flow with cycles greater than 3 months. Thus, long period cycles $(>3 \mathrm{~m})$ would be measured as net aperiodic flow. Any record of current observations includes both aperiodic and periodic motions superimposed upon one another. Periodic motions are detected using spectral analyses to identify the dominant frequencies discernable in any set of 
current observations. Data filters are then used to 'filter out' periodic motions so that aperiodic, or net, motions can be assessed. Net motion is also evident from overall averages of flow throughout the observation period.

Flow patterns near McMurdo Station should first be considered in the context of larger scale currents, which must have profound effects on small scale features of concern in this study. Though few regional studies of currents are available for the SW Ross Sea, calculations of geostrophic flow from hydrographic data and limited current measurements have been used to generate a synoptic characterization of the regional flow field. Generally, a clockwise gyre prevails in the Ross Sea, with a westward flowing quadrant found in the southern Ross Sea (Figure 1). This gyral flow likely contributes to the prevailing westward flow observed along the Ross Shelf Barrier edge. Westward coastal flow may be enhanced by wind-driven Ekman transport driven by northward katabatic atmospheric flow off the Antarctic continent in the western Ross Ice Shelf region (Bromwich et al. 1993). Ultimately, this coastal current flows towards Ross Island along the Ross Shelf Barrier, and turns south as it flows westward around Cape Bird, but also may flow around the southern boundary of Ross Island under the Ross Ice Shelf, only to emerge in southern McMurdo Sound as a northward flowing current. The relative dominance of southward flow from the Cape Bird region, or northward flow from under the Ross Ice Shelf may depend upon presently unknown factors. Hypotheses to explain interannual variation in flow observed directly (Barry et al. 1990, Dunbar and Leventer 1991, Dunbar et al. unpublished data), and indirectly (Barry 1988, Barry and Dayton 1988, Dayton 1989), include variation in zonal winds (e.g. El Niño Southern Oscillation [ENSO] events) and variation in ice cover extent, which may regulate wind driven current transport. Superimposed on these factors, ventilation of the cavity beneath the Ross Ice Shelf appears to result in a net transport from the central shelf cavity region to the northwest in the vicinity of Ross Island, based upon the salinity signature of waters in the region (Jacobs et al. 1985, Pillsbury and Jacobs 1985, McFeters et al. 1993). Thus, a variety of large scale, perhaps even global scale, processes may influence current patterns near McMurdo Station.

Ocean currents in McMurdo Sound, Antarctica have been investigated by several researchers from 1907 to the present, with most observations made very near McMurdo Station. Early current observations in McMurdo Sound were made over very short periods (hours to days) and indicated that currents varied in both magnitude and direction near McMurdo Station (Hodgson 1907, Gilmour et al. 1960, 1962). Other studies suggested seasonal shifts in flow direction (Tressler and Ommundsen 1962, Littlepage 1965), in addition to shorter term periodic motions. More recent studies including data collected over periods up to 2 months during the austral spring (Barry and Dayton 1988, Barry et al. 1990, Heath 1971, 1977, Lewis and Perkin 1985, Raytheon Service Co. 1983, Barry 1994) indicate that flow adjacent to McMurdo Station is dominated by diumal periodic motions. Heath (1977), Barry and Dayton (1988), and Barry (1994) showed that oscillations in flow speed and direction were associated mainly with diurnal tidal constituents related to specific planetary motions. The dominant constituents were the principal lunar diurnal (O1), principal solar diurnal (K1), and luni-solar diurnal (P1) constituents with periods of $25.82,24.07$, and $23.93 \mathrm{~h}$, respectively. Semi-diurnal components (M2, K2, S2, 
Figure 1

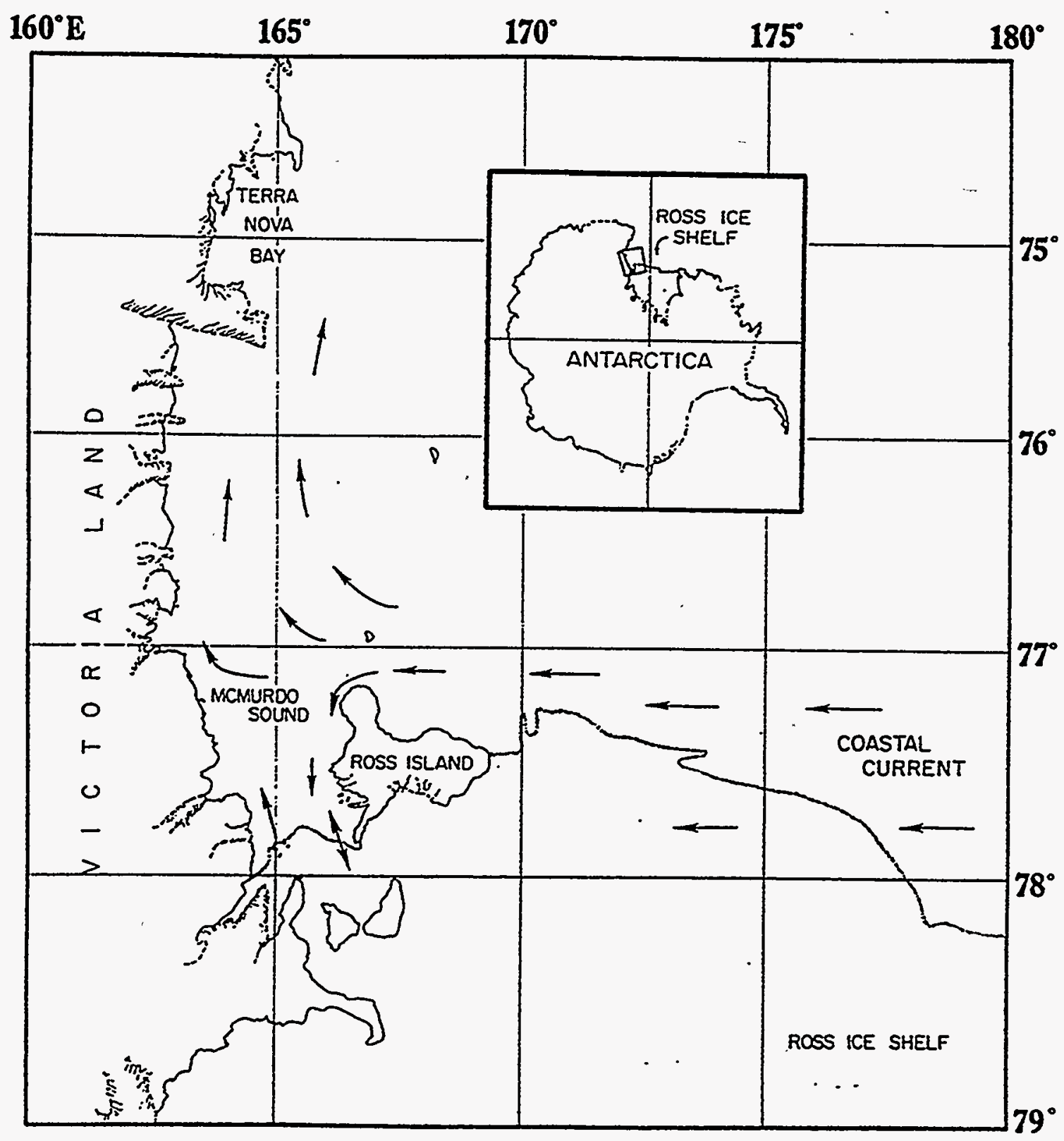

Figure 1 Map of Ross Sea Region, showing large scale current pattern 
N2) were of secondary importance in McMurdo Sound. Tidally-induced flow in McMurdo Sound is thought to be generated directly by equilibrium tidal motions and perhaps by tidallyinduced flexing of the Ross Ice Shelf (Holdsworth 1977, Doake 1978, MacAyeal 1984), which may accentuate or damp local currents. Barry (1994) summarized many current observations from 1991 to 1993, including a year-long data series from 6 stations adjacent to McMurdo Station, focusing on the local current field, and its role in the dispersal of the wastewater plume from McMurdo Station. Barry's results corroborate the observation that diurnal tidal flow was the dominant periodic motion in McMurdo currents. and the predominance of southward flow near McMurdo Station during spring and summer. Observations during winter and fall, however, showed that strong seasonal shifts in the principal direction of flow were dramatic, resulting in strong northward flow near McMurdo Station during winter months.

Measurements of net transport (aperiodic flow) throughout McMurdo Sound are somewhat complex, with southward transport in the eastern Sound, particularly in deeper waters, and northward in the western Sound (Barry and Dayton 1988; Figure 2). Flow in shallow waters (c. $100 \mathrm{~m}$ ) of the eastern Sound was more variable in both speed and direction, than that observed in deeper water $(c .500 \mathrm{~m})$. Coastal topography can have important effects on flow speed and direction, particularly near McMurdo Station. Short term studies performed during the late 1970s to early 1980s (Raytheon Service Co. 1983) included current measurements for 5 stations in this area, and suggested that a counter-clockwise gyre was positioned south of Hut Pt., approximately directly offshore of the present outfall site. Later studies, and particularly studies focussing on the local current field (Barry 1994), confirmed the presence of the 'McMurdo Gyre', and partially characterized its location and temporal persistence.

The McMurdo Gyre occurs principally during periods of consistent southward flow. During such periods, the prominence of Hut Pt. interrupts the flow field and modifies flow speed and direction, particularly downstream of the point. This results in a counter-clockwise eddy positioned adjacent to McMurdo Station. Flow accelerates adjacent to Hut Pt., reaching speeds of nearly $50 \mathrm{~cm} / \mathrm{s}$ towards the south. The main flow stream continues south to southeastward past McMurdo Station and towards Cape Armitage, but a smaller current branches off and turns toward shore adjacent to McMurdo Station at about the position of the 'ice transition' area below the helicopter hanger. Flow along the shore north of the transition is generally sluggish and northward towards Winter Quarters Bay. Flow turns northwestward toward Hut Point just south of Winter Quarters Bay and meets the rapid southward flow at Hut Point to complete the gyre. A smaller clockwise gyre may occasionally occur in Winter Quarters Bay, driven by the McMurdo Gyre, but no current observations are available to evaluate this idea.

If the McMurdo Gyre is temporally persistent, it may effectively transport much of the wastewater plume from the outfall pipe away from McMurdo Station by advecting the plume away from the outfall pipe and into the mainstream flow passing Hut Point. Some of the plume may be entrained in the gyre, however, and distributed throughout the McMurdo Station vicinity. Moreover, decay of the gyre, as suggested by McFeters, Barry and Howington (1993) and Barry (1994) may be responsible for episodes of wastewater retention near McMurdo Station. 


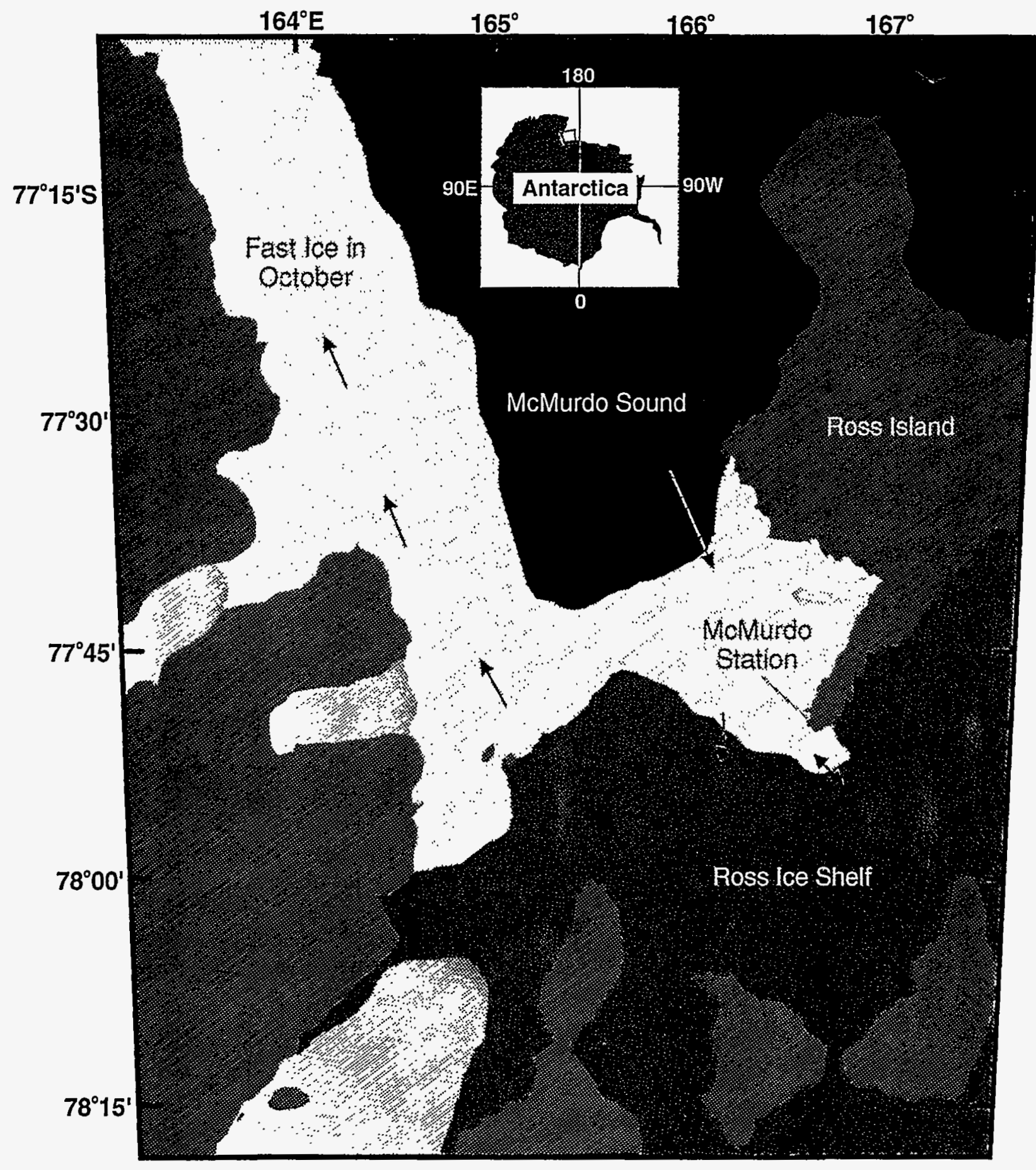

Figure 2 Map of McMurdo Sound, indicating regional spring-summer flow pattern. 
Optimal design and positioning of the wastewater outfall pipe is contingent upon knowledge of the average flow field in the vicinity of the plume during wastewater plume dilution and dispersal. In addition, information concerning the magnitude and pattern of variation in the flow field, and their effect on plume dispersal, are of interest. Thus, it is desirable to identify the existence, position, extent, and persistence of the McMurdo Gyre adjacent to McMurdo Station. The optimal position for relocation of the McMurdo Wastewater Outfall pipe is likely within or beyond the outer quadrant of this gyre. Thus, the wastewater plume would be entrained in the prevailing regional mainstream current (on a spatial scale incorporating the Ross Island coast, rather than simply the McMurdo Station vicinity. When the McMurdo Gyre is active the plume would be swept away from McMurdo Station toward the south. Observations of currents from 1991 to 1993 indicate that the plume would continue towards the south during much of the summer, while in winter, strong northward flow would carry the plume northward beyond Hut Point, and away from the McMurdo Station vicinity. Flow during fall and early winter of 1993 (Mar. - May) was more variable in direction than other seasons, and would have greater potential for retention of the wastewater plume near McMurdo Station, especially if the outfall pipe was positioned near the station (i.e. within the McMurdo Gyre). The direction and distance of plume transport during periods when the McMurdo Gyre has decayed are less predictable, but current observations during 1991 to 1993 (Barry 1994) suggest that the plume transport is variable. Shortly after decay of the McMurdo Gyre, local flow can retain the plume along the shoreline and carry it to the seawater intake pipe. During periods of strong regional northward flow, the plume may be effectively removed from the McMurdo vicinity.

In this study, results are presented of current observations collected from December 1993 to November 1994 at 5 stations adjacent to McMurdo Station. Results from the prior 1 year observation period (December 1992 to November 1993) were discussed by Barry (1994). These observations include all seasons, both with and without significant ice coverage, and provide an interesting comparison to the prior year-long observation period, which were the first extensive winter current data available near McMurdo Station. Several maps showing locations of all current stations used from 1991 to 1994, with average current vectors from these stations for each season, are presented for comparison with results from 1993 to 1994 . Recommendations for outfall pipe relocation are discussed in relation to results of current observations. 


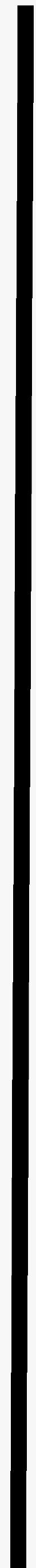




\section{METHODS}

\subsection{Current Meter Placement and Deployment}

\subsubsection{1 - 1993 Current Observations}

Current meters were deployed at several stations adjacent to McMurdo Station (Figure 3) during the austral spring for periods of 1 to 3 months in 1991 and 1992 at various locations (Stations A to M), and throughout the year between December 1992 to November 1993 (Stations $\mathrm{N}$ to $\mathrm{S}$ ), to characterize the pattern and variation of the flow field impacting the wastewater plume from the McMurdo Station wastewater outfall. These studies were performed in conjunction with a sampling program to determine concentrations of fecal coliform bacteria in surface waters and sea ice in this area (Howington et al. 1992, McFeters et al. 1993). Current stations were located throughout the area identified as a gyre by the Raytheon Service Company Report (1983), and also included sites adjacent to Hut $\mathrm{Pt}$, assumed to be indicative of prevailing regional flow patterns. Details of these current measurements are discussed by Barry (1994).

Current meters were suspended from the sea ice and deployed through 48 inch diameter access holes drilled through the sea ice (Figure 4). Meters were positioned approximately 30 to 50 feet above the sea floor, depending upon water depth. Current measurements were programmed on each meter to calculate the mean flow direction and speed over a 5 minute period and record each 5 minute average. Intervals between 5 minute averages ranged from continuous ( 1 average each $5 \mathrm{~min}$. interval) to 1 hour ( 1 five min. average per hour), and depended upon current meter memory and deployment duration. Deployment dates, grid locations (McMurdo ASA Location Grid [MLG], station characteristics, and sampling specifications are listed in Table 1. Results of these initial studies confirmed the presence and approximate position of the McMurdo Gyre, and temporal scales of persistence of the gyre.

\subsubsection{3-1994 Year-round Current Meter Deployment}

Six current meters (InterOcean Model S4) were deployed for a one year period (December 1993 to November 1994) to identify spatial and temporal characteristics of the McMurdo Gyre, particularly with respect to transport and dispersal of the wastewater plume. Station locations were established based upon results from spring-summer observations during 1991-1992 and year-long observations during 1992-1993. Specifically, station configuration was planned to bracket the McMurdo Gyre, and identify the transition zone between the inner quadrant (northwestward coastal flow) and outer quadrant (mainstream southward flow) of the gyre. Three stations were established along a transect extending from the present outfall location $(\sim$ Station W) in an offshore direction crossing the gyre (Figure 3 ). Station J is in a central location in the gyre, presumably near the transition zone into the main southward quadrant. Station $\mathrm{Y}$ is in the outer southward quadrant or in the prevailing regional flow. Station $\mathrm{X}$, the most southerly station, was positioned in an area thought to be near the southern extent of the 
Figure 3 Map of McMurdo Sound showing locations of current meter stations for observations. Letters indicate locations of current meter stations from 1991 to 1994. 


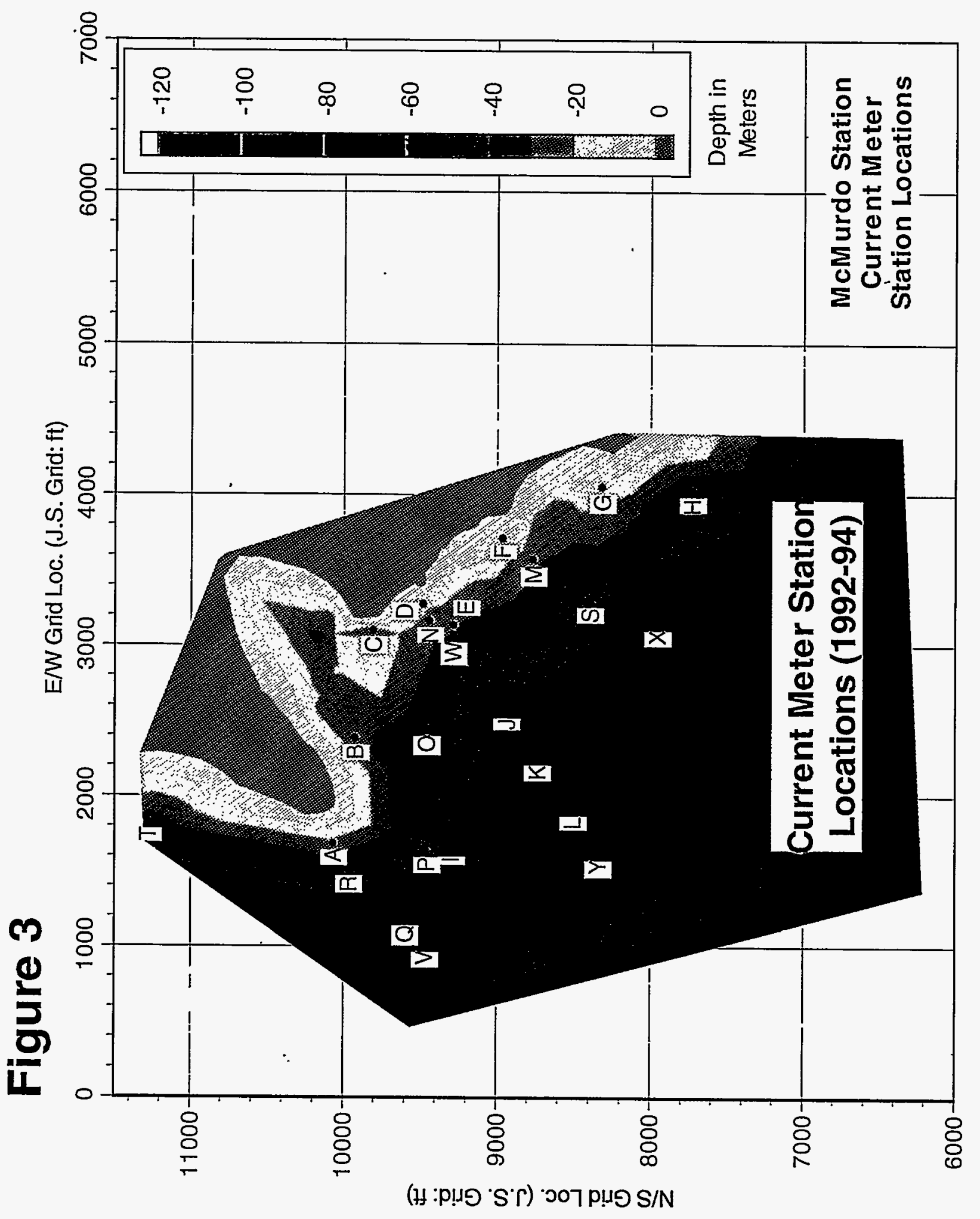




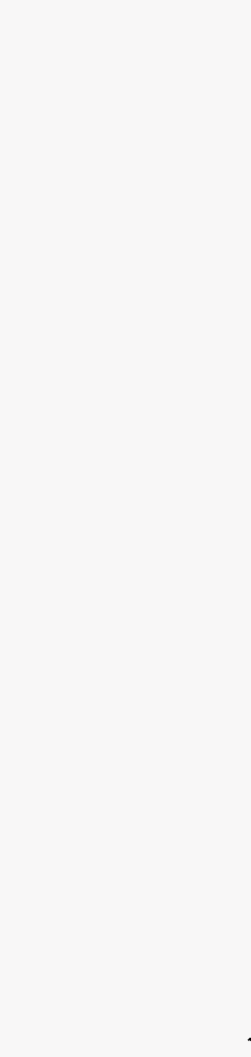


Sea lce

Benthos Float

(1) S4 Current Meter

Figure 4. Schematic of InterOcean Model S4 current meter deployment in McMurdo Sound, December 1993 to November 1994. 
. 
- Table 1 List of station characteristics, grid coordinates, deployment dates and sample specifications for current meter observations in McMurdo Sound during 1993 to 1994. NS Grid and EW Grid are McMurdo Local Grid Coordinates (feet). Period is the duration of current observations (days). Cycle time is cycle period for the current meter observations, in minutes. Average is the number of minutes of per current average within each cycle time. $\mathrm{N}$ is the total number of averages (current vectors) recorded during the observation period.

\begin{tabular}{|c|c|c|c|c|c|c|c|c|c|c|}
\hline STATION & NS GRID & EW GRID & START DATE & START TIME & END DATE & END TIME & PERIOD & CYCLE & AVERAGE & $N$ \\
\hline$\vec{G} \quad T$ & 11305 & 1833 & 17 Dec 93 & 1752 & 18 Nov 94 & 1052 & 335.75 & 15 & 2 & 32232 \\
\hline V & 9491 & 1017 & 17 Dec 93 & 1719 & 18 Nov 94 & 1119 & 335.79 & 15 & 2 & 32236 \\
\hline W & 9307 & 3079 & $17 \operatorname{Dec} 93$ & 1517 & 18 Nov 94 & 0717 & 335.71 & 15 & 2 & 32238 \\
\hline $\mathrm{X}$ & 7973 & 3156 & $17 \operatorname{Dec} 93$ & 1443 & 18 Nov 94 & 0943 & 335.83 & 15 & 2 & 32240 \\
\hline$Y$ & 8362 & 1628 & $17 \operatorname{Dec} 93$ & 1047 & 18 Nov 94 & 0347 & 335.75 & 15 & 2 & 32232 \\
\hline
\end{tabular}


gyre, where flow has turned toward shore. One additional station (Station T) was positioned in the bight north of Hut Point, where another gyre is hypothesized to form during periods of northward regional flow. Current measurement schedules were programmed on each meter to calculate the mean flow direction and speed during a 2 minute period, every 15 minutes. Deployment of current meters were performed by ASA personnel under the direction of Ms. Holly Issackson. Current meters (InterOcean model S4) deployed through access holes drilled in the ice were anchored by steel weights at the bottom of the array and buoyed by a benthos $16^{\prime \prime}$ glass sphere float at the top (Figure 4). Meters were positioned to be approximately mid-way between the surface and sea floor. Station locations were surveyed by ASA personnel (Jeff Scanniello) and located on the McMurdo Local Grid Map. Meters were recovered during November 1994 by ASA personnel (Ms. Holly Issackson) after relocating stations sites by surveying (J. Scanniello: ASA) and acoustic search methods (Furuno echo sounder). Divers attached recovery lines, and meters were pulled to the surface using a tracked vehicle (Spryte) and pulley system.

\subsection{Bathymetry of the McMurdo Station Coast}

Water depth was determined at many sites during the 1992-1993 summer season to enable creation of a bathymetric chart of the nearshore region adjacent to McMurdo Station. Bottom depth was measured to the nearest meter with a Furuno depth sounder (ASA-Crary Science Facility), or with a weight and line for most Winter Quarters Bay stations. Each site was surveyed (ASA surveyor) to provide MLG coordinates or McFeters (T-325) grid coordinates (converted to MLG coordinates). Grid coordinates and depths, along with a compilation of grid coordinates for the McMurdo coastline (digitized from an aerial photograph by Barry and Dayton) were contoured using Deltagraph 3.0.

\subsection{Data Processing}

Upon recovery of current meters, data was downloaded to disk storage as soon as possible. General flow characteristics were inspected using InterOcean S4 application software to assess current data for obvious sensor failure or error. Binary files stored on diskettes to mailed to J. Barry in Monterey, California, where there were converted to ASCII files and processed by a fortran program (J. Barry) used to average the data over specified intervals $(1,3,6,12$, and $24 \mathrm{~h}$ periods). One hour averages (of 15 minute data observations) were used for spectral analyses, progressive vector plots, and principal component analyses.

\subsection{General Flow Characteristics near McMurdo Station}

Overall, mean flow direction and speed for each station were calculated as the average of all 1 hour vector averages, corrected for compass variation. Similarly, seasonal averages were 
calculated for 3 'oceanographic seasons', including spring-summer (Dec. through Jan.), summèrfall (Feb. through May), and fall-winter (Jun. through Sep.). Station V near Hut Point was assumed to be most representative of the 'mainstream' or regional flow field in the vicinity of McMurdo Station. Time series of current vectors (straw diagrams) were calculated from raw data ( 2 minute averages every 15 minutes) over $1,3,6,12$, and 24 hour averages.

\subsection{Principal Axes of Flow}

Principal axes of flow were estimated from three hour current vector averages by identifying the compass axis containing the maximum mean absolute flow speed for each station. Thus, the major axis was the compass heading accounting for the greatest average flow, and the minor axis was orthogonal to the major axis.

\subsection{Periodic Characteristics of McMurdo Sound Currents}

Current vectors averaged over 1 hour were separated into NS and EW components and analyzed using spectral analyses for the dominant frequencies of flow. Analyses consisted of a fast fourier transform (Matlab), using a data string length of 2048, Hanning window, and overlap of 1024. Power spectra for each flow component at each station were standardized to a maximum of 1.0, and plotted versus frequency (cycles per hour), to illustrate the dominant frequencies of the flow field for each data string.

\subsection{Aperiodic Characteristics of McMurdo Sound Currents}

Net current speeds and directions were calculated for the entire data record from each station, and within three oceanographic seasons (defined above). Current vectors ( $3 \mathrm{~h}$ means) were separated into NS and EW components, and averaged over total, or seasonal intervals. Progressive vector plots were prepared using cumulative NS and EW components of flow through the observation period.

\subsection{Low-pass Filtering of Current Records}

East-west and NS components of flow ( $1 \mathrm{~h}$ averages) were low-pass filtered to remove tidal variations on frequencies of 30 hours or less. Filtered time series were plotted with unfiltered data to enable comparisons of tidal motion with aperiodic or low frequency motions, which may affect transport of the waste-water plume. 


\section{RESULTS}

\subsection{Deployment Information}

Six current meters were deployed at 6 stations (J, T, V, W, X, Y) in McMurdo Sound, adjacent to McMurdo Station (Figure 3). These meters collected current observations . . continuously from mid-December, 1993 to mid-November, 1994. Five of six current meters functioned properly throughout the deployment period. Although the current meter at Station J operated during the deployment period, all current speeds were unrealistically high (mean speeds greater than $300 \mathrm{~cm} / \mathrm{s}$ ), and thus data from this station were deleted from all analyses. Details of the deployment schedule are presented in Table 1.

\subsection{McMurdo Area Bathymetry}

A bathymetric contour map of the vicinity of McMurdo Station is presented in Figure 5. Each red dot denotes a position of known depth. Together, these points were used to created the contours shown. The bottom slopes rapidly to deep water off McMurdo, particularly Near Hut Point. A small basin near $30 \mathrm{~m}$ depth is present in Winter Quarters Bay is bounded by a sill at the outer edge.

\subsection{Regional Scale Pattern of Flow near McMurdo Station}

As discussed in the Introduction, local variation in currents is allied quite strongly to regional (i.e. SE McMurdo Sound) and larger scale (i.e. SW Ross Sea) processes. Variation on even global scales may be manifested as changes in flow adjacent to McMurdo Station. Thus, it is important to first consider regional patterns of flow during 1993-94, and evaluate local patterns with respect to regional flow.

Flow measurements in the vicinity of the Hut Point Peninsula serve as the best proxy for 'mainstream' or regional flow near McMurdo Station which is then modified by local topography (e.g. Hut Pt) to generate local patterns of flow. During spring and early summer, regional flow, identified in other studies (e.g. Barry and Dayton 1988, Barry 1994) and corroborated by data reported here, includes fairly consistent southward transport in eastern McMurdo Sound, flowing generally southward past Hut Point. The local flow pattern arises largely from the effects of coastline configuration and local bathymetry. Projection of Hut Pt. into southward flow along the Hut Point Peninsula creates a downstream eddy, positioned adjacent to McMurdo Station, that may persist as long as the regional southward flow. Regional currents, however, vary over several temporal scales (see below) and thus, have important consequences for local flow. Even during spring and summer when southward regional flow is most consistent, it pulses with the 
Figure 5 Bathymetry of McMurdo Sound in the vicinity of McMurdo Station, Antarctica. Red dots indicate locations of known depth. Contours on $10 \mathrm{~m}$ intervals. 


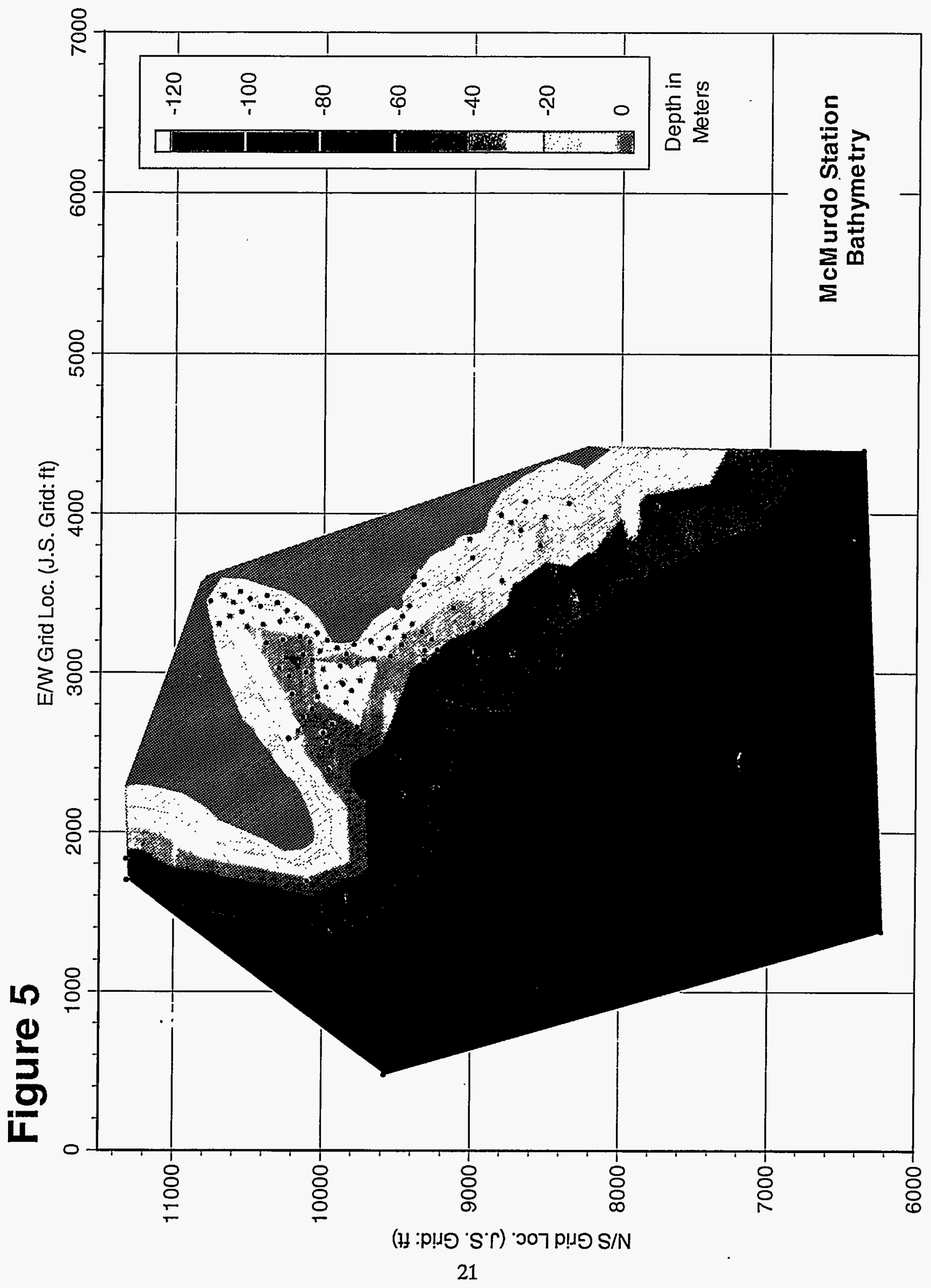


daily tide, and occasionally reverses in direction towards the north for short periods (e.g. hours). During other seasons, regional currents can be either generally northward (winter) or highly variable in speed and direction. During periods of southward regional flow, local currents, such as the McMurdo Gyre, may be dramatically different than when northward regional flow dominates. For example, the McMurdo Gyre was absent during periods of strong northward flow in.winter 1993, at which time a clockwise gyre may have formed north or Hut Pt.

For this study, regional flow can be estimated only from current meters at stations least affected by shoreline topography. Thus, stations offshore from Hut Pt. (Station V), even though they are still quite close to Hut Pt. (c. $100-300 \mathrm{~m}$ ) are most representative of regional flow. The major effects of Hut Pt. on current station V probably include intensification of current speed owing to 'compression' of along-shore flow as it approaches Hut Pt. from the north or south, and .alignment of flow in an along-shore direction. Current patterns at stations $(X, W, T)$ nearer shore or within the McMurdo bight (i.e. within a line from Hut Pt. to the McMurdo jetty), are more representative of local scale circulation.

\subsection{General Pattern of McMurdo Station Currents}

Although the current pattern measured during 1993-1994 near McMurdo Station showed several strong similarities to the 1992-1993 observation period, there were significant differences in the flow field which strengthen recommendations to relocate the wastewater outflow pipe further offshore. The general pattern of variation in flow was quite similar, with strong tidal variation in speed or direction of flow over periods near $24 \mathrm{~h}$. In addition, the general seasonal trend in net transport was fairly similar between years, with south to southeastward flow at offshore stations during summer, and net north to northwestward flow during winter. An overall average of current records for year-long stations (1992-1993 and 1993-1994) and shorter term spring and summer observations (data from 1991-1992) provides a composite view of flow near McMurdo Station (Figure 6), in which the counter-clockwise flow of the McMurdo gyre is evident. Current vectors for the 1993-1994 period are shown in red, while all other data are shown in yellow. Station A, at Hut Point, differs from Stations $P, Q, R$, and V owing to the yearlong observations at the latter stations, and spring observations at the fórmer. Mean overall current speeds for 1993 to 1994 observations are presented in Table 2. Overall, the mean flow field would transport the wastewater plume generally away from McMurdo Station. However, on short time periods (1-3 hours), and during occasional episodes lasting days or longer, flow along the shore at McMurdo Station was towards the jetty, and could transport the wastewater plume to the seawater intake area near the jetty (see below).

Average regional flow near McMurdo Station, estimated from the current meter at Station $V$ near Hut Pt., shifted from strong southward to southeastward flow in late spring and summer (Dec. 1993 to Jan. 1994) to northward to northwestward flow in winter (July 1994). The transition between these periods was somewhat gradual, with periods of tidally-shifting current directions from north to south, and episodes of a few to several days dominated by flow in one 
Figure 6 Overall net flow for all current observations at stations near McMurdo Station from 1991 to 1994, superimposed on a map of McMurdo bathymetry. Red dots indicate locations of Stations. Yellow current vectors indicate the direction and speed of flow for the entire observation period for each station from 1991 to 1993. Red vector represent year-long observations from 1993-1994. Scale bar at bottom. Current vectors are for different lengths of observations among stations. Note the general counter-clockwise gyre formed by all vectors. 


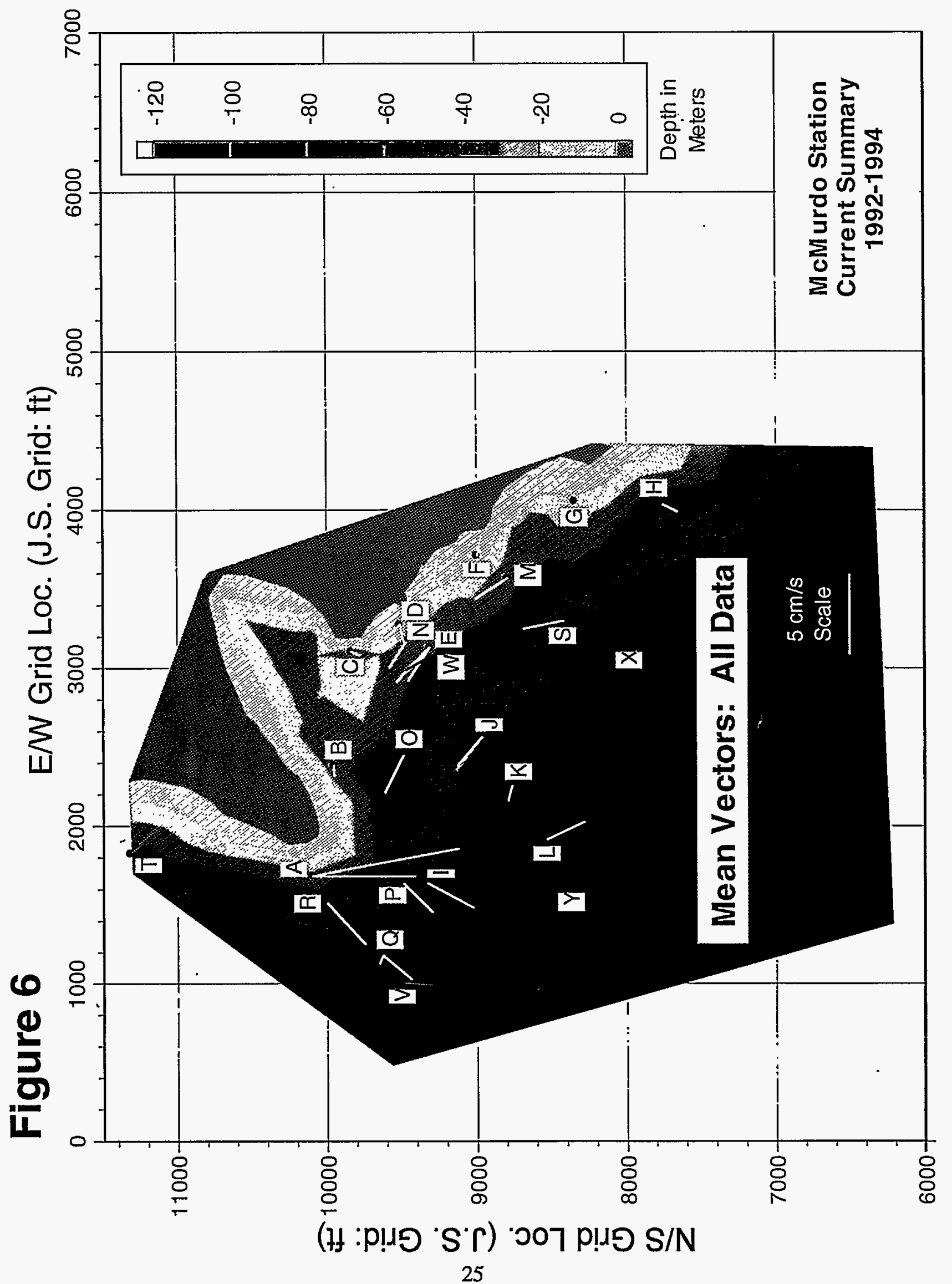



Table 2 Flow characterlstlcs for current observation stations occupled during 1993 to 1994, based on 3h average data. Overall net and absolute current speeds for east-West (EW) and north-south (NS) components of llow are listed with standard devlatlons (St. Dev.), mean net speed, heading (angle), and sample size (N). File lists the data code lor each station as statlon-year-data serles number. Eastward and northward net llow are positive values. Westward and southward net flow are negative. Absolute speeds represent the average current speed along EW and NS axes. Averages are derived from $3 \mathrm{~h} \mathrm{EW}$ and NS current vectors averages. $Z$ (bot.) is bottom depth for each statlon in melers. $Z(C M)$ is depth of the current meter (m).

\begin{tabular}{|c|c|c|c|c|c|c|c|c|c|c|c|c|c|c|}
\hline \multirow[b]{2}{*}{ STATION } & \multirow[b]{2}{*}{ FILE } & \multirow{2}{*}{\multicolumn{2}{|c|}{$z$ (BOT.) $z(\mathrm{CM})$}} & \multicolumn{6}{|c|}{ NET SPEED } & \multicolumn{5}{|c|}{ ABSOLUTE SPEED } \\
\hline & & & & EW & St. Dov. & NS & St. Dov. & SPEED & ANGLE & EW & St. Dov. & NS & SI. Dov. & $N$ \\
\hline $\begin{array}{l}T \\
V \\
W \\
X \\
Y\end{array}$ & $\begin{array}{l}94 \quad T \text { all } \\
94 V_{\text {all }} \\
94 W_{\text {all }} \\
94{ }_{\mathrm{X}} \text { all } \\
94 Y_{\text {all }}\end{array}$ & $\begin{array}{l}33 \\
78 \\
29 \\
63 \\
74\end{array}$ & $\begin{array}{l}16 \\
39 \\
15 \\
32 \\
37\end{array}$ & $\begin{array}{r}1.73 \\
\cdot 0.15 \\
\cdot 0.80 \\
0.87 \\
2.42\end{array}$ & $\begin{array}{l}1.99 \\
7.87 \\
2.79 \\
2.44 \\
7.66\end{array}$ & $\begin{array}{r}\cdot 1.95 \\
\cdot 2.01 \\
1.56 \\
0.44 \\
\cdot 2.99\end{array}$ & $\begin{array}{r}3.03 \\
11.61 \\
2.91 \\
4.18 \\
11.11\end{array}$ & $\begin{array}{r}3.6 \\
11.7 \\
3.6 \\
4.1 \\
3.8\end{array}$ & $\begin{array}{c}138 \\
184 \\
333 \\
63 \\
141\end{array}$ & $\begin{array}{l}2.05 \\
6.18 \\
2.19 \\
1.88 \\
5.95\end{array}$ & $\begin{array}{l}1.66 \\
4.88 \\
1.91 \\
1.78 \\
5.40\end{array}$ & $\begin{array}{l}2.7 .3 \\
9.2 . \\
2.66 \\
3.31 \\
8.16\end{array}$ & $\begin{array}{l}2.29 \\
9.27 \\
2.08 \\
2.59 \\
8.12\end{array}$ & $\begin{array}{l}8058 \\
8059 \\
8057 \\
8060 \\
8058\end{array}$ \\
\hline
\end{tabular}




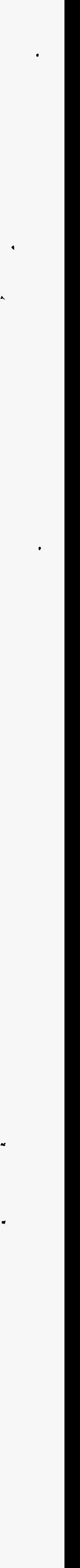


direction. Seasonal changes in prevailing flow during 1993-94 were similar to that of 1992 to 1993, with three generalized 'seasons' of flow. Figure 7 illustrates the pattern of flow at all stations occupied during the spring to summer period (Oct. to Jan.) from 1991 to 1994. Strong southward flow along Hut $\mathrm{Pt}$., which ended in early February 1993, persisted into early March during 1994, suggesting that large scale factors controlling flow (e.g. ice cover) may have differed between years. Table 3 lists the means speeds and directions of flow at each station during 3 seasonal periods. The McMurdo Gyre was well-developed during spring and summer of both years, and clearly evident in the composite mean current vectors for the season (Figure 7), even though episodes of decay and disappearance of the eddy occurred frequently. In the summer to fall seasons (February through May) of 1993 and 1994, regional flow was more oscillatory in direction with lower net southward transport, but the McMurdo Gyre is still evident in mean flow vectors for this season (Figure 8). Dominance of north to northwestward flow during late fall and winter (June through September) of 1993 was less evident during 1994 (Figure 9). Although northward flow dominated over southward flow at Station $Y$ in fall-winter, northwestward flow was persistently strong only during July 1994, compared with June, July, and September of 1993. Stations $\mathrm{Y}, \mathrm{X}$, and $\mathrm{W}$ show evidence gyral circulation characteristic of the McMurdo Gyre, even during winter. North to northwestward flow at other inshore stations reflect the regional northward flow during winter 1992-93, rather than eddy formation by the McMurdo Gyre, which was rare during winter 1992-93. These differences between years may be a manifestation of interannual differences in regional ice cover. Cover during 1993 was lower than 1994, which was one of the most extensive ice cover years on record. The apparent opposing flow at Station A, adjacent to Hut Point, is related to the southward flow at this station during September 1992, compared to the northwestward net flow there averaged from June through September 1993, show for Stations O, P, Q, and V.

Mean flow at Station T, north of Hut Pt. was southeastward throughout the year. This pattern appears to reflect the regional southward flow in spring and summer, during which generally southward flow approaches Hut Point from the north. In addition, southeastward flow at Station $T$ may represent the southeastward quadrant of a clockwise gyral circulation pattern which may develop north of Hut Point during periods of north to northwestward regional flow.

Shifts in flow direction and speed were evident at all stations, and were more extensive than observed during 1992 to 1993 , and are very important in the local dispersal of the wastewater plume. Episodes of southward flow along McMurdo Station appear related to decay of the McMurdo Gyre, or to deflection of regional flow from the SW by Hut Pt. Even with the greater variability in flow at 'regional' stations (Station V, Y) than observed in 1992-93, mean flow at Station W (near the wastewater outfall) was consistently northwestward. For both 19921993, and 1993-1994, the major sources of variability for periodic, or cyclic, flow, occurred on diurnal and, to a lesser degree, semi-diurnal and shorter tidal periods (see below), even though seasonal changes in average flow were detected. 
Figure 7 Net flow at all current observation stations occupied during the spring to summer season (October through January). Symbols as in Figure 6. 
Figure 7

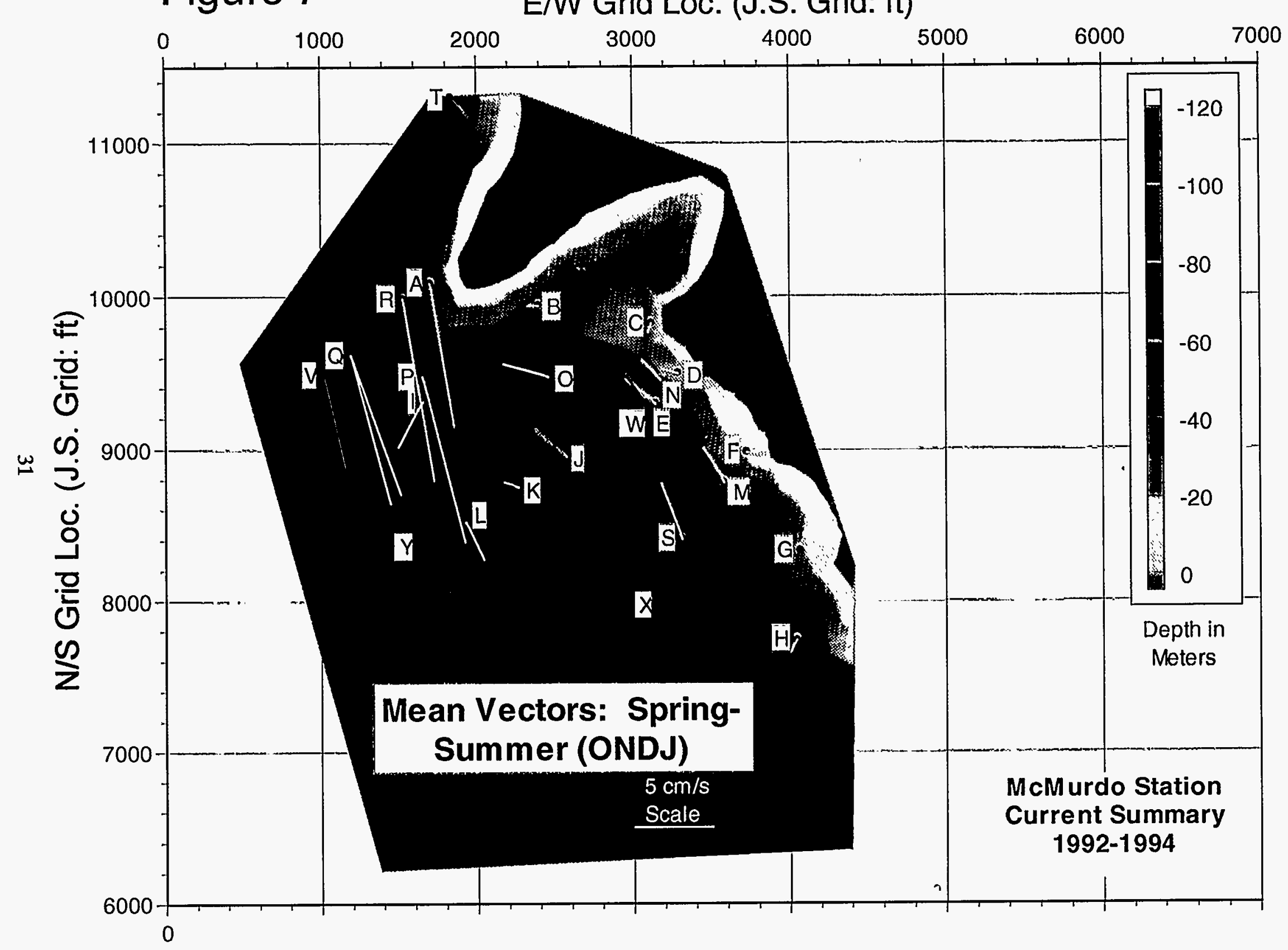




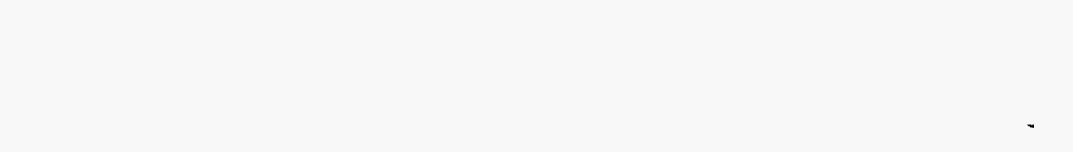


Table 3. Seasonal patterns of flow for Stations in McMurdo Sound. Three hour mean vectors were averaged within specific seasons (listed). Net flow, standard deviation, and sample size (N) are listed for EW and NS How, for all available data at each station.

\begin{tabular}{|c|c|c|c|c|c|c|c|c|c|}
\hline \multirow[t]{2}{*}{ STATION } & \multirow[t]{2}{*}{ SEASON } & \multirow[t]{2}{*}{ MONTHS } & \multicolumn{2}{|c|}{ EW SPEED } & \multicolumn{2}{|c|}{ NS SPEED } & \multicolumn{2}{|c|}{ OVERALL } & \multirow[t]{2}{*}{$N$} \\
\hline & & & $\mathrm{cm} / \mathrm{s}$ & St. Dev. & $\mathrm{cm} / \mathrm{s}^{\circ}$ & St. Dev. & Angle & $\mathrm{cm} / \mathrm{s}$ & \\
\hline$T$ & $\begin{array}{l}\text { Sp-Sum } \\
\text { Sum-Fal } \\
\text { Fal-Win }\end{array}$ & $\begin{array}{l}\text { ONDJ } \\
\text { FMAM } \\
\text { JJAS }\end{array}$ & $\begin{array}{l}1.52 \\
1.69 \\
1.93\end{array}$ & $\begin{array}{l}2.22 \\
1.78 \\
1.98\end{array}$ & $\begin{array}{l}-1.87 \\
-1.93 \\
-2.01\end{array}$ & $\begin{array}{l}3.28 \\
3.03 \\
2.82\end{array}$ & $\begin{array}{l}141 \\
139 \\
136\end{array}$ & $\begin{array}{l}2.41 \\
2.57 \\
2.79\end{array}$ & $\begin{array}{l}2250 \\
2880 \\
2928\end{array}$ \\
\hline v & $\begin{array}{l}\text { Sp-Sum } \\
\text { Sum-Fal } \\
\text { Fal-Win }\end{array}$ & $\begin{array}{l}\text { ONDJ } \\
\text { FMAM } \\
\text { JJAS }\end{array}$ & $\begin{array}{r}1.35 \\
0.57 \\
-2\end{array}$ & $\begin{array}{l}9.52 \\
6.29 \\
7.49\end{array}$ & $\begin{array}{r}-6.13 \\
-1.82 \\
0.98\end{array}$ & $\begin{array}{r}13.51 \\
9.88 \\
10.63\end{array}$ & $\begin{array}{l}168 \\
163 \\
296\end{array}$ & $\begin{array}{l}6.28 \\
1.91 \\
2.23\end{array}$ & $\begin{array}{l}2251 \\
2880 \\
2928\end{array}$ \\
\hline$w$ & $\begin{array}{l}\text { Sp-Sum } \\
\text { Sum-Fal } \\
\text { Fal-Win }\end{array}$ & $\begin{array}{l}\text { ONDJ } \\
\text { FMAM } \\
\text { JJAS }\end{array}$ & $\begin{array}{l}-1.29 \\
-0.55 \\
-0.68\end{array}$ & $\begin{array}{l}2.71 \\
2.68 \\
2.92\end{array}$ & $\begin{array}{l}1.84 \\
1.35 \\
1.55\end{array}$ & $\begin{array}{l}2.81 \\
2.82 \\
3.06\end{array}$ & $\begin{array}{l}325 \\
338 \\
336\end{array}$ & $\begin{array}{l}2.25 \\
1.46 \\
1.69\end{array}$ & $\begin{array}{l}2249 \\
2880 \\
2928\end{array}$ \\
\hline$x$ & $\begin{array}{l}\text { Sp-Sum } \\
\text { Sum-Fal } \\
\text { Fal-Win }\end{array}$ & $\begin{array}{l}\text { ONDJ } \\
\text { FMAM } \\
\text { JJAS }\end{array}$ & $\begin{array}{r}0.4 \\
0.81 \\
1.28\end{array}$ & $\begin{array}{r}2.5 \\
2.09 \\
2.63\end{array}$ & $\begin{array}{r}1.37 \\
0.46 \\
-0.29\end{array}$ & $\begin{array}{l}4.11 \\
3.86 \\
4.39\end{array}$ & $\begin{array}{r}16 \\
60 \\
103\end{array}$ & $\begin{array}{l}1.43 \\
0.93 \\
1.31\end{array}$ & $\begin{array}{l}2252 \\
2880 \\
2928\end{array}$ \\
\hline$Y$ & $\begin{array}{l}\text { Sp-Sum } \\
\text { Sum-Fal } \\
\text { Fal-Win }\end{array}$ & $\begin{array}{l}\text { ONDJ } \\
\text { FMAM } \\
\text { JJAS }\end{array}$ & $\begin{array}{l}5.01 \\
1.21 \\
1.61\end{array}$ & $\begin{array}{r}9.4 \\
6.51 \\
6.68\end{array}$ & $\begin{array}{l}-8.11 \\
-0.15 \\
-1.85\end{array}$ & $\begin{array}{r}13.07 \\
8.41 \\
10.47\end{array}$ & $\begin{array}{r}148 \\
96.9 \\
138.9\end{array}$ & $\begin{array}{l}9.53 \\
1.22 \\
2.45\end{array}$ & $\begin{array}{l}2250 \\
2280 \\
2928\end{array}$ \\
\hline
\end{tabular}


Figure 8 Net flow at all current observation stations occupied during the summer to fall season (February through May). Symbols as in Figure 6. 


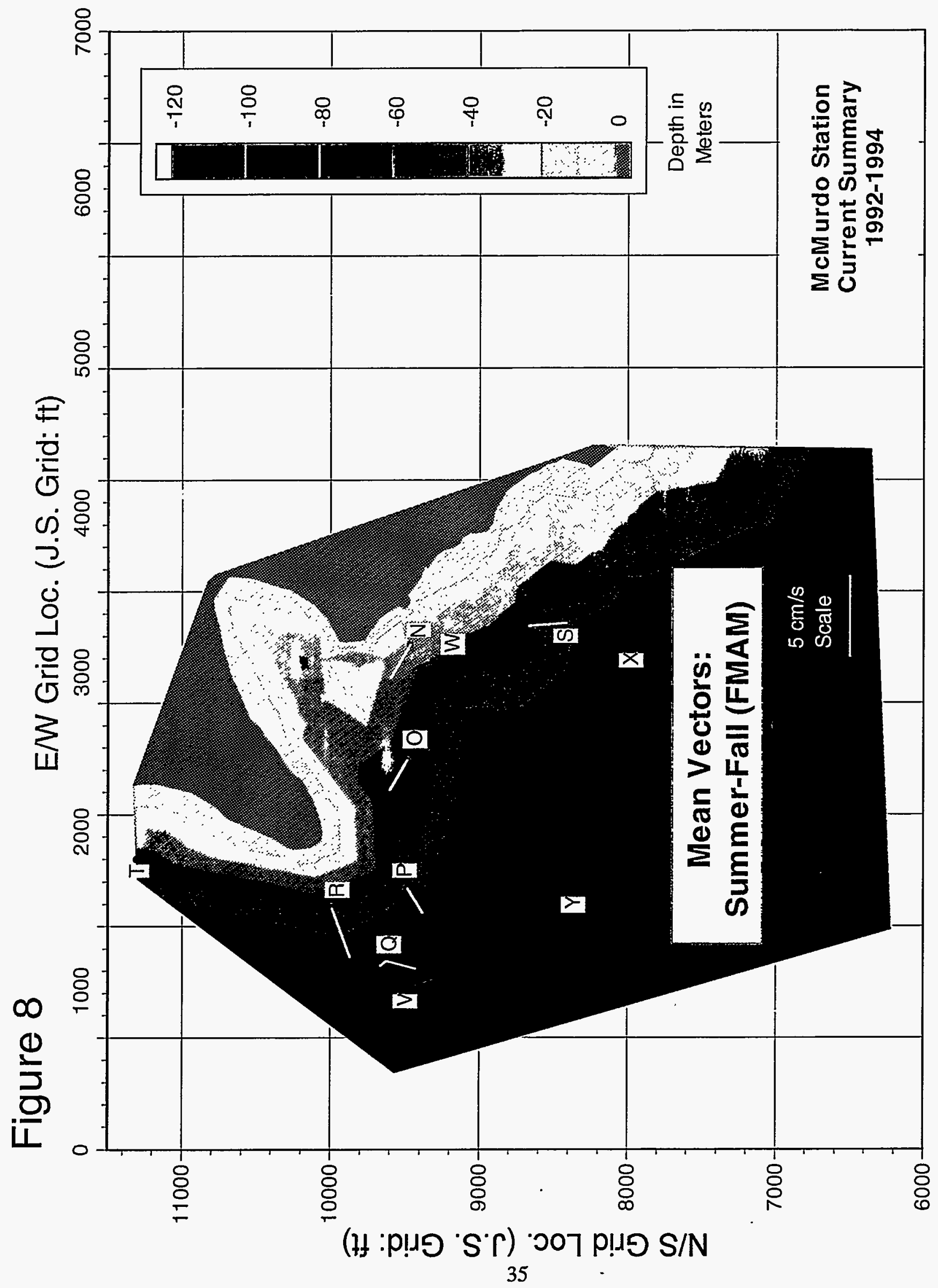


Figure 9 Net flow at all current observation stations occupied during the fall to winter season (June through September). Symbols as in Figure 6. 



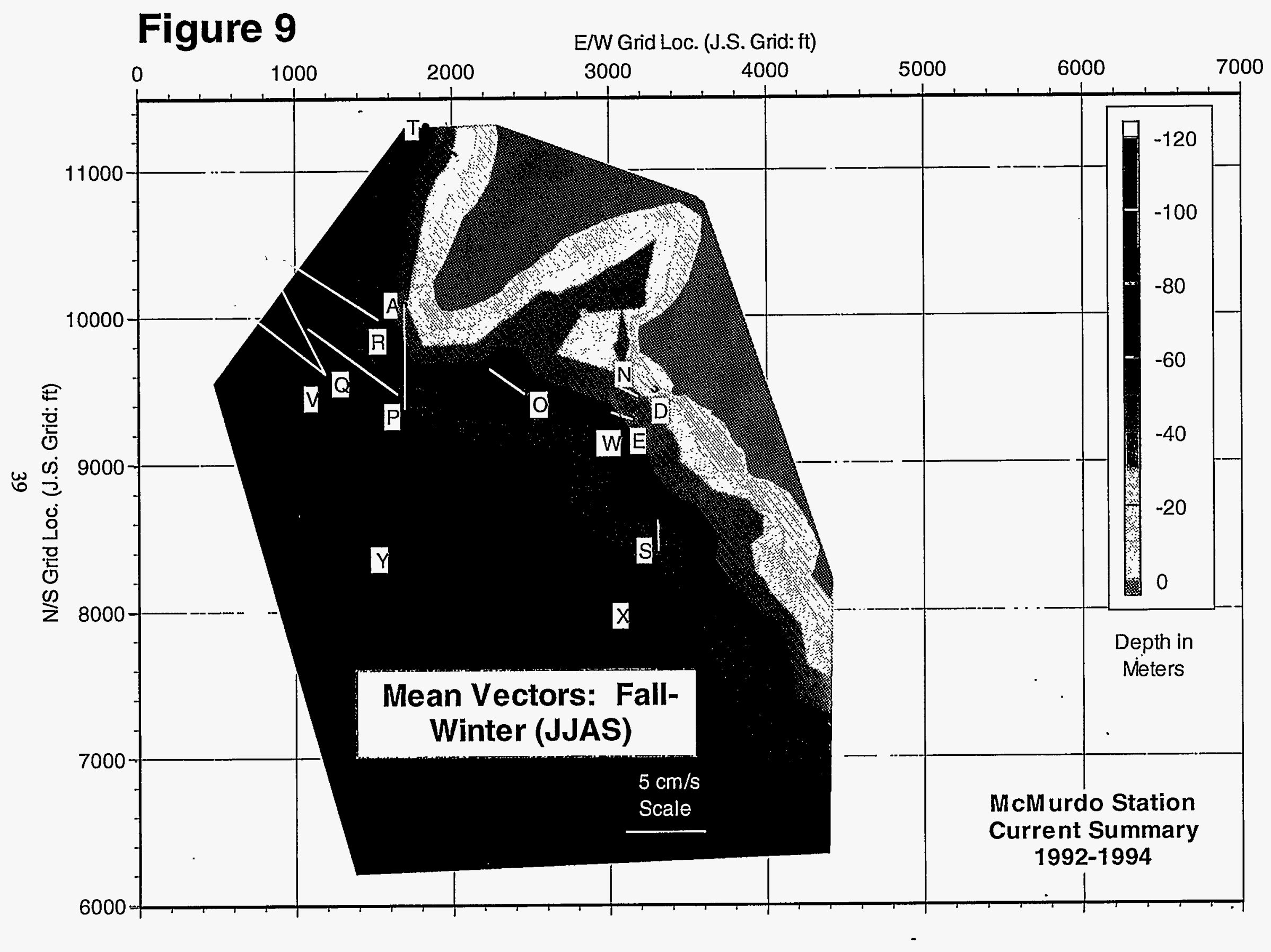




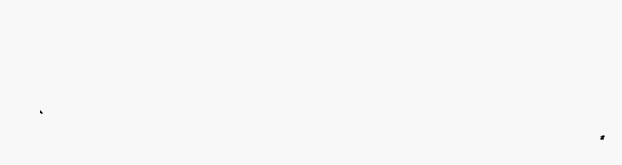




\subsection{Principal Axes of Current Flow}

The principal axes of motion at each station during the 1993-94 period were fairly similar to each other and similar to those calculated for the prior year's observations. The major axes of flow were generally oriented on along-shore, rather than cross-shore, and ranged from 320 to 337 degrees (Table 4). There was very little variation among stations, and less than during the prior year. The close similarity reflects the constraining influence of shoreline topography, and also the general alongshore switching in direction over tidal periods, particularly during 1993-94. Stations $\mathrm{V}, \mathrm{Y}$, and $\mathrm{T}$ were most similar among stations observed in 1993-94. Stations $\mathrm{V}$ and $\mathrm{Y}$ are fairly near one another and positioned furthest offshore in the regional flow field, and are least impacted by topographic effects. Flow at Station $T$ was undoubtedly constrained by the shoreline north of Hut Point, and was fairly consistent towards the southeast. The principal axis of flow at Station $\mathrm{W}$, near the present outfall, like Stations $\mathrm{T}$ and $\mathrm{Y}$, were aligned closely with the direction of overall net flow. At Stations $V$ and $X$, principal axes of flow were not as strongly coupled to the axis of net transport (Table 4). Tidal or longer period oscillations in current direction can result in differing degrees of current deflection by coastal topography, depending upon which direction the flow is moving, leading to an imbalance in oscillatory flow, and a decoupling of net transport from the principal axes of motion. For example, flow at Station $\mathrm{X}$ was nearly due north when regional flow was northward, but when regional flow switched to southward, flow at Station $X$ was deflected towards the SE or ESE by the McMurdo Gyre. Thus, net flow was shoreward (63\%), and differed $94^{\circ}$ from the principal axis of motion (Table 4; Figure 6). It is important to recall, however, that net transport does not usually represent the most energetic direction of flow. Nor do net transport vectors represent the major direction of dispersal of the wastewater plume, particularly over time scales shorter than used to calculate net transport vectors.

\subsection{Temporal Variation in Regional Flow}

\subsubsection{Seasonal Variation}

As during the 1992 to 1993 , currents at all stations varied considèrably over daily, monthly, and seasonal periods during 1993 to 1994 . Some periods of motion were related clearly to known tidal motions controlled by planetary motions (see periodic flow below). Time-series plots illustrate a year-long plot of individual current vectors for each station, averaged over 1,3 , 6,12 , and 24 hours. Figure 10 shows 1 hour average for each current meter, including data for the entire year, and illustrates the great variation in both speed and direction from hourly to seasonal temporal scales. Although it is difficult to discern amidst the considerable variation shown on $1 \mathrm{~h}$ average time series, the data from 1993-94 are generally more variable on short time scales (i.e. 1-12 h) and less variable on seasonal time scales, than the 1992-93 period. Time series plots over 1, 3, and 6 hour averages (Figures 10,11,12) from most stations measured during 1993-94 (especially St. V, Y, X) show fairly strong oscillations in flow, when compared with observations during 1992-93 (Barry 1994). Long term (e.g. monthly to seasonal) patterns of variation are evident from time series averaged over longer periods (12 and $24 \mathrm{~h}$; Figures 13,14$)$. 

- Table 4 Summary of principal axes of flow at each station during 1993 to 1994

\begin{tabular}{|c|c|c|c|c|c|c|}
\hline \multirow[b]{2}{*}{ STATION } & \multicolumn{4}{|c|}{ PRINCIPAL ÄẌES } & \multicolumn{2}{|c|}{ NET FLOW } \\
\hline & $\begin{array}{l}\text { Major } \\
\text { Axis }\end{array}$ & $\begin{array}{l}\text { Speed } \\
\mathrm{cm} / \mathrm{s}\end{array}$ & $\begin{array}{l}\text { Minor } \\
\text { Axis }\end{array}$ & $\begin{array}{l}\text { Speed } \\
\mathrm{cm} / \mathrm{s}\end{array}$ & Heading & $\begin{array}{c}\text { Speed } \\
\mathrm{cm} / \mathrm{s}\end{array}$ \\
\hline$T$ & 327 & 3.2 & 57 & 1.1 & 138 & 2.6 \\
\hline V & 328 & 10.8 & 58 & 3.0 & 184 & 20 \\
\hline $\mathbf{W}$ & 320 & 3.3 & 50 & 0.7 & 323 & 1.8 \\
\hline$x$ & 337 & 3.6 & 67 & 1.5 & 63 & 1.0 \\
\hline $\mathbf{Y}$ & 326 & 9.6 & 56 & 2.9 & 141 & 3.8 \\
\hline
\end{tabular}


Figure 10 Straw diagram illustrating a year-long time series of 1 hour average current vectors for current stations occupied in.McMurdo Sound from December 1993 to November 1994. Individual 'sticks' represent single average vectors indicating the speed (length of stick) and direction of flow (direction of stick): Note the considerable variation over hours to seasons. 


\section{Current Vector Time Series Figure 10}

McMurdo Sound, ih Means
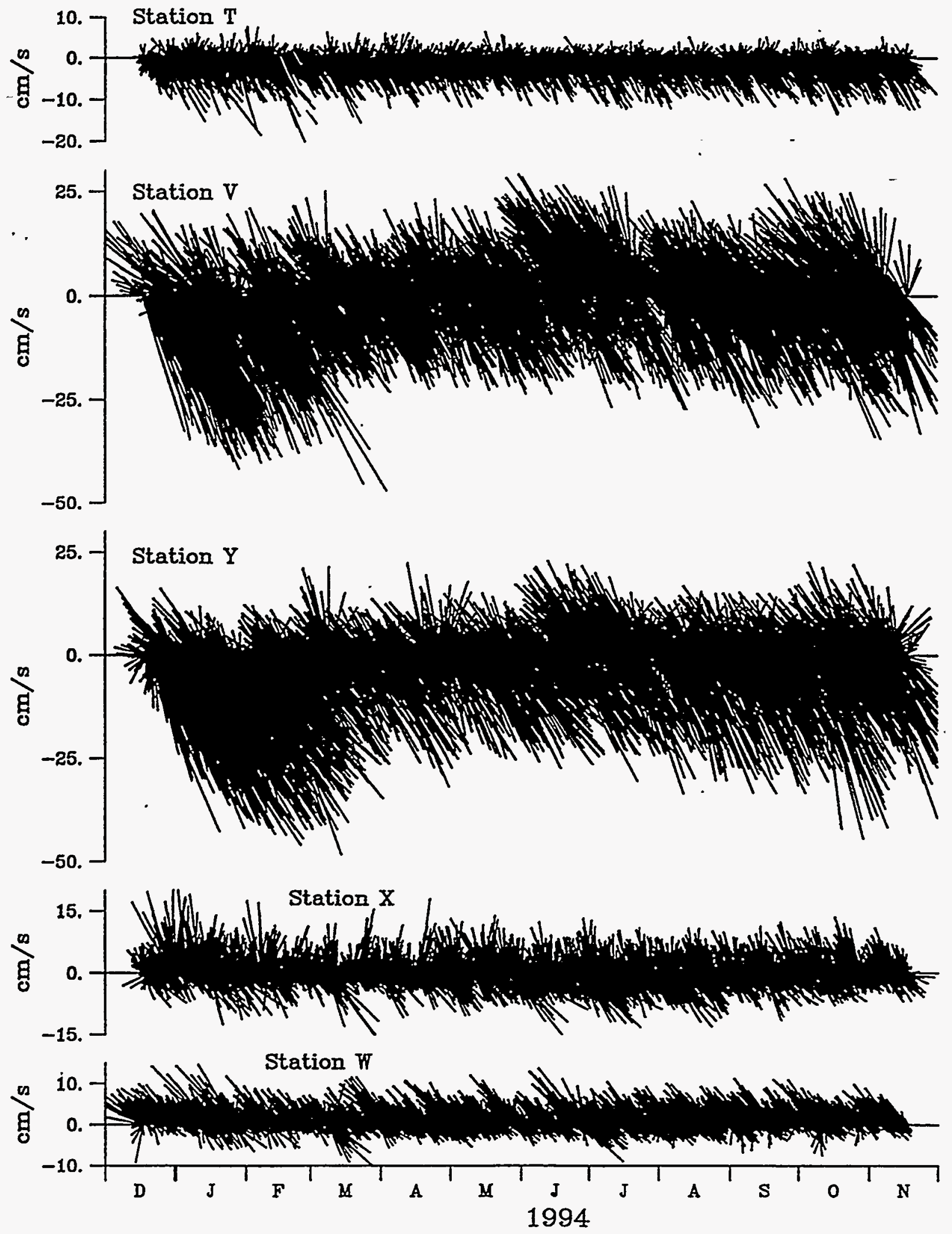
Figure 11 Straw diagram illustrating a year-long time series of 3 hour average current vectors for current stations occupied in McMurdo Sound from December 1993 to November 1994. 


\section{Current Vector-Time Series McMurdo Sound, 3h Means}
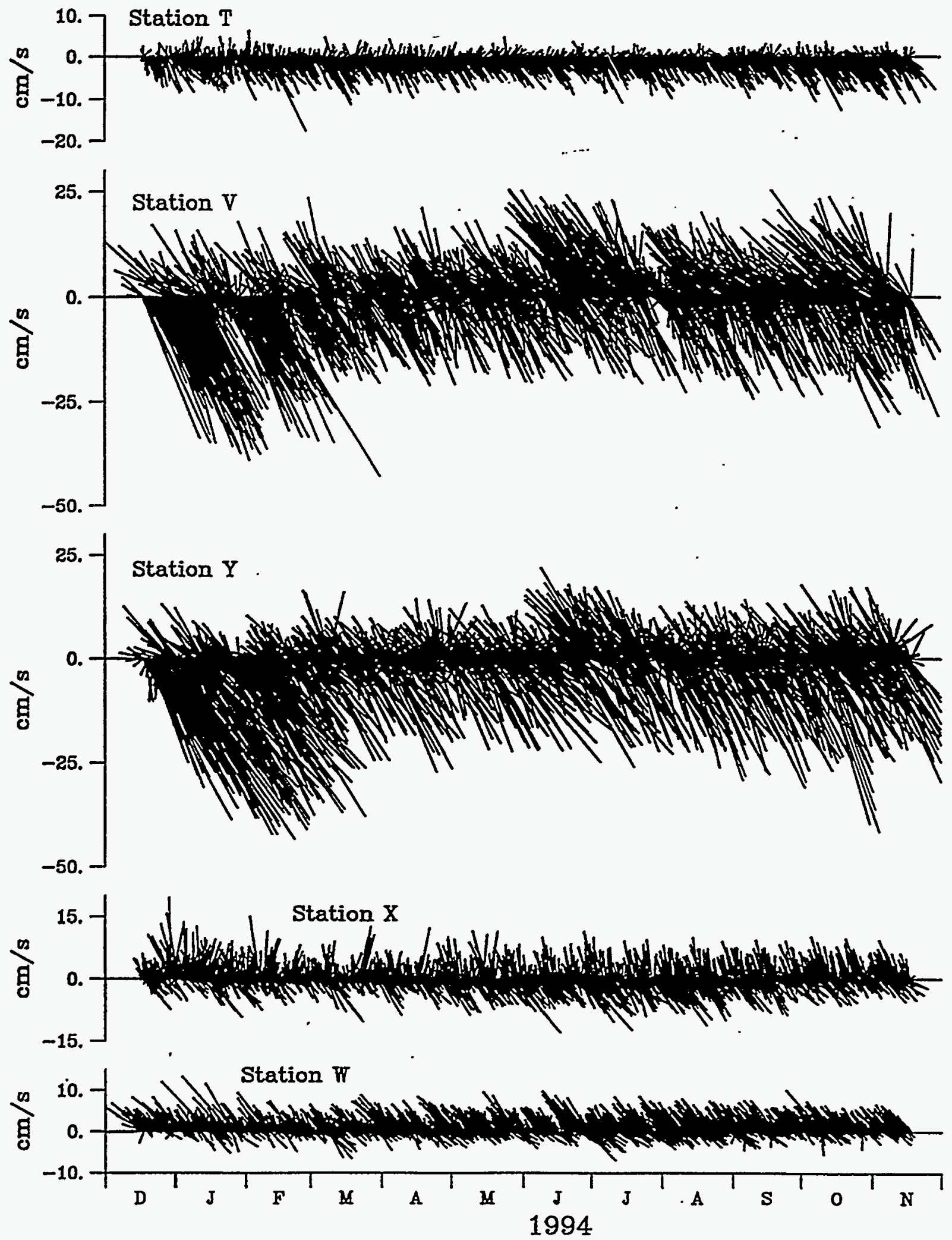
Figure 12. Straw diagram illustrating a year-long time series of 6 hour average current vectors for current stations occupied in McMurdo Sound from December 1993 to November 1994. 


\section{McMurdo Sound, 6h Means}

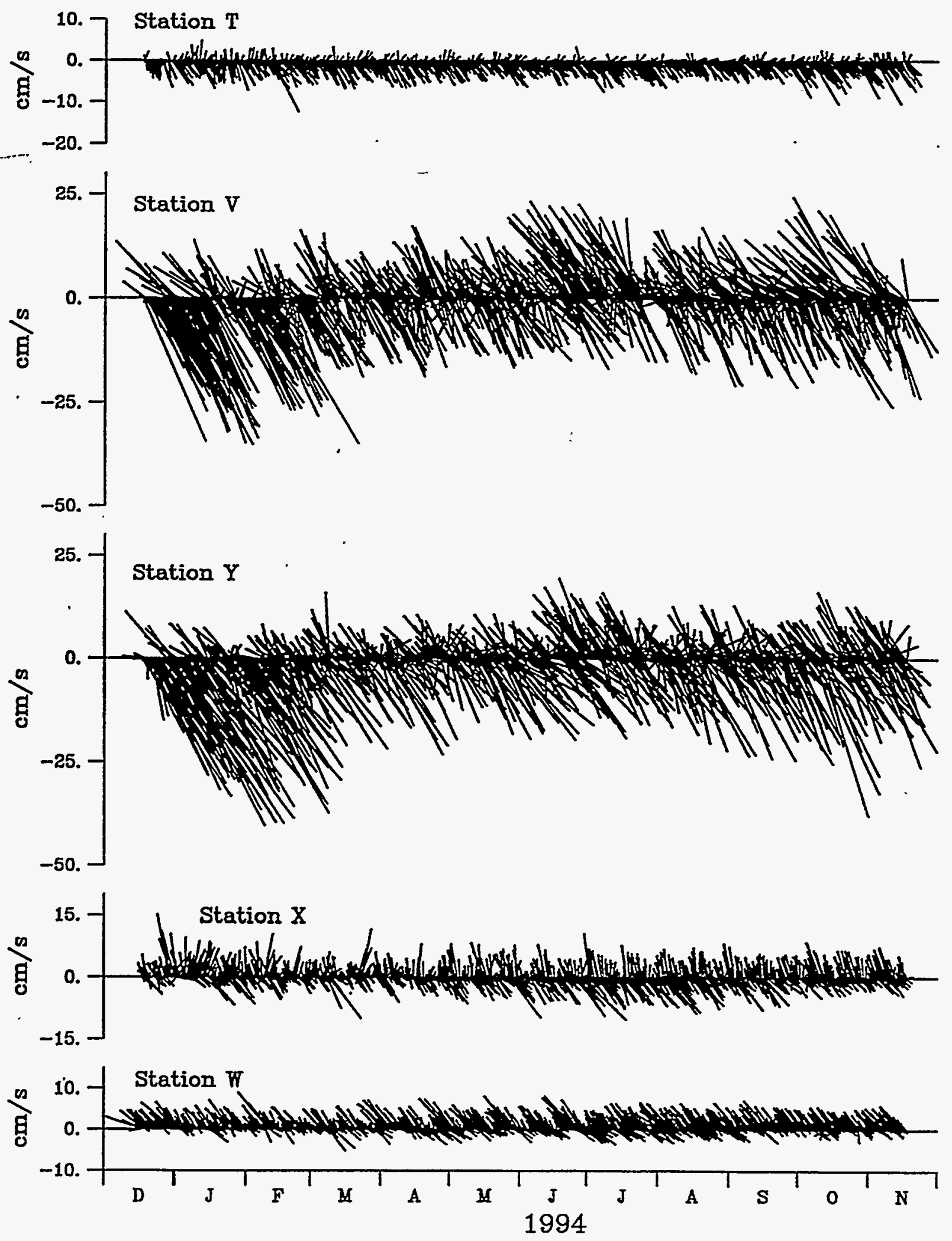


Figure 13 Straw diagram illustrating a year-long time series of 12 hour average current vectors for current stations occupied in McMurdo Sound from December 1993 to November 1994. 


\section{McMurdo Sound, 12h Means}
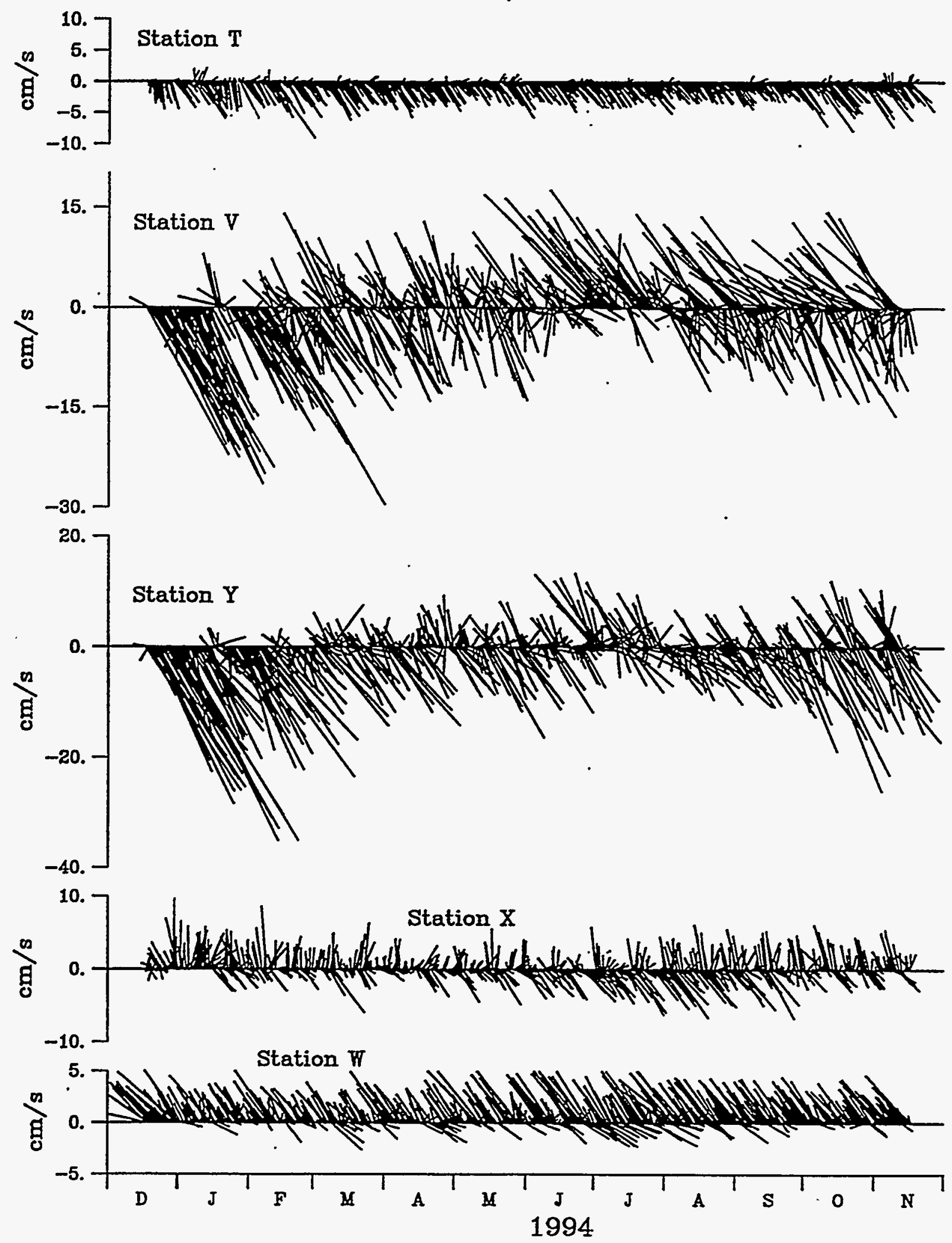
Figure 14 Straw diagram illustrating a year-long time series of 24 hour average current vectors for current stations occupied in McMurdo Sound from December 1993 to November 1994. 
Current Vector Time Series

McMurdo Sound, 24h Means
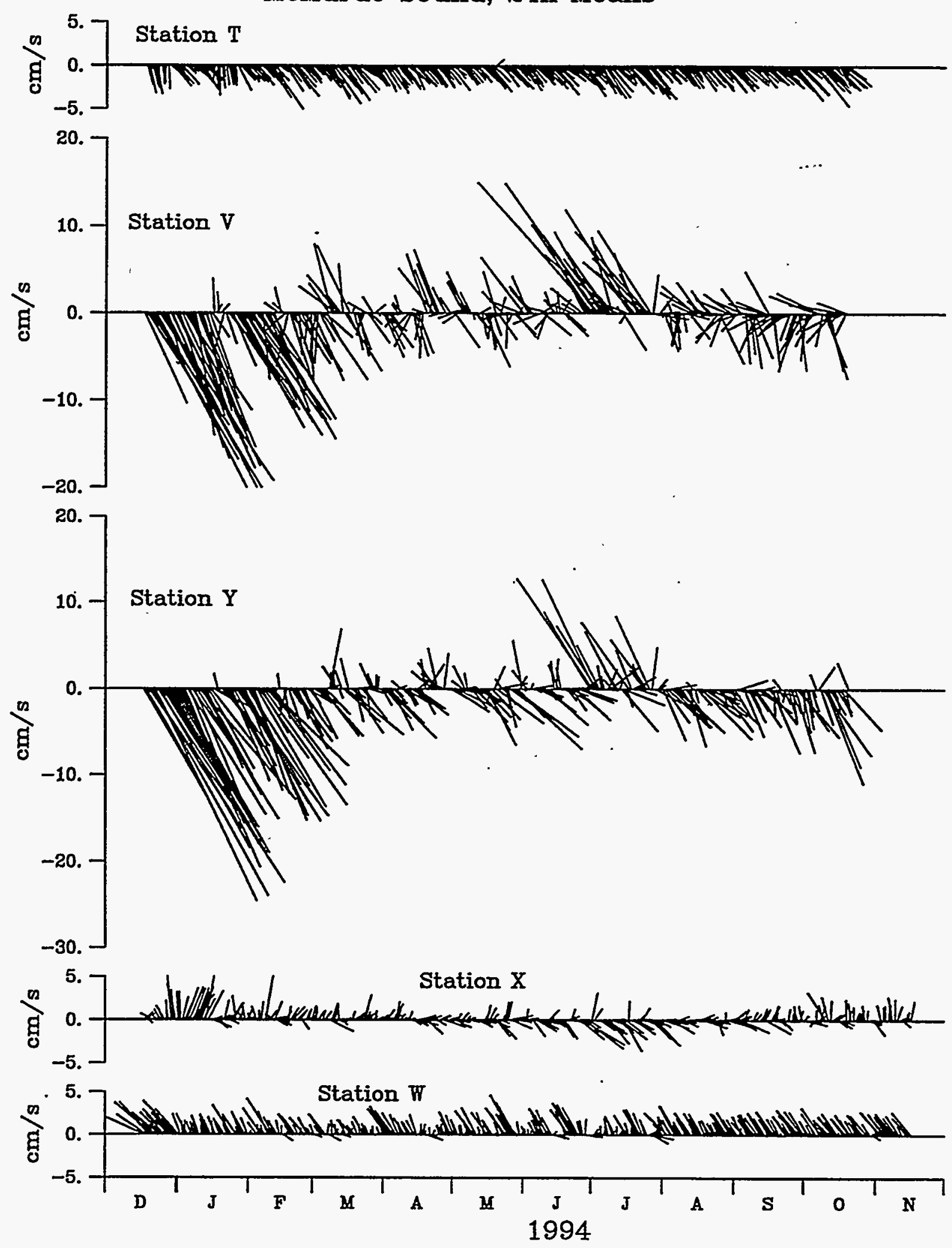


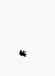


Strong southward flow in spring and summer (Station V, Y), is very similar to the pattern seen in 1992-93. A time series of two pairs of nearby stations during 1992-93 and 1993-94 are shown in Figure 15, in which interannual differences in flow are apparent. Strong NW regional flow during much of winter 1993, was confined principally to July during winter 1994. Instead, there were periods of shifting northwestward and southeastward flow from March to late June, and again from late July to mid-September, when southward flow again dominated. Comparison of time series plots of each 3 month period from November 1993 to December 1994 (6 h averages; ' Figure 16 to 19) with those from 1992-93 (Figures 22 to 25 in Barry 1994) illustrate the greater variation within seasons during 1994 than the prior year. Particularly evident in these plots is the great similarity between the transition periods between winter and summer. March through May, and September through November, 1994 were periods dominated by oscillations in flow direction, rather than the predominantly unidirectional flow (over $6 \mathrm{~h}$ averages) during other months. They also illustrate episodes of flow that can transport the wastewater plume toward the seawater intake pipe, rather than away from McMurdo Station (Station W).

Three distinct 'seasons' of flow discernable from current records obtained during 1992-93 were evident, but less clear during 1993-94. These are spring-summer (October to January), summer-fall (February to May), and fall-winter (June to September). Currents were strong and nearly continuously southeastward near Hut Pt. during the spring-summer period of both years, especially in December and January. These patterns of flow are most evident from $24 \mathrm{~h}$ averages at stations $V$ and $Y$ (Figure 14), showing consistent southeastward flow in spring/summer, northward flow in winter (principally July), and oscillatory flow during most other months. Factors influencing differences between seasons, and the timing of shifts between current regimes dominated by southward or northward flow probably include regional ice cover (e.g. SW Ross Sea), local winds (during ice-free periods), and other factors. As observed in 1992-93, currents nearer shore (Stations W, T) were less oscillatory and more persistently unidirectional. Currents at station X, the southern quadrant of the McMurdo Gyre, shifted direction greatly over periods of one to several days, especially during winter. Unlike fall and winter 1993, currents did not accelerate greatly toward the north during this period of ice formation. As in 1993, however, recurrence of the summer-fall pattern of oscillatory motion during August may be related to sea ice removal by large winter storms, perhaps in the Ross Sea polynya.

\subsubsection{Tidal Flow}

Periodic flows are currents that are cyclic in nature, just as the tides rise and fall. The same gravitational effects of planetary motions that control the cyclic rise and fall of tides, also produces cyclic currents, over periods from hours to years. Currents associated with gravitational tides are known to be a dominant forces in McMurdo Sound (Barry and Dayton 1988). Even though tidal motions are periodic, resulting in flow that oscillates in direction with little or no net transport of water, tidal currents can have important effects on transport of the McMurdo wastewater plume, even over scales of hours. Because periodic tidal motions over various temporal scales are superimposed upon each other, as well as other tidal motions (radiational tides) and aperiodic flow, actual transport of water by the sum of all driving forces may be 
Figure 15 Straw diagram illustrating 12 hour average current vectors for Stations $Q$ and $N$ from 1992-1993, and nearby Stations V and W from 1993-1994. 


\section{Current Vector Time Series}

McMurdo Sound, 12h Means, 1992-1994
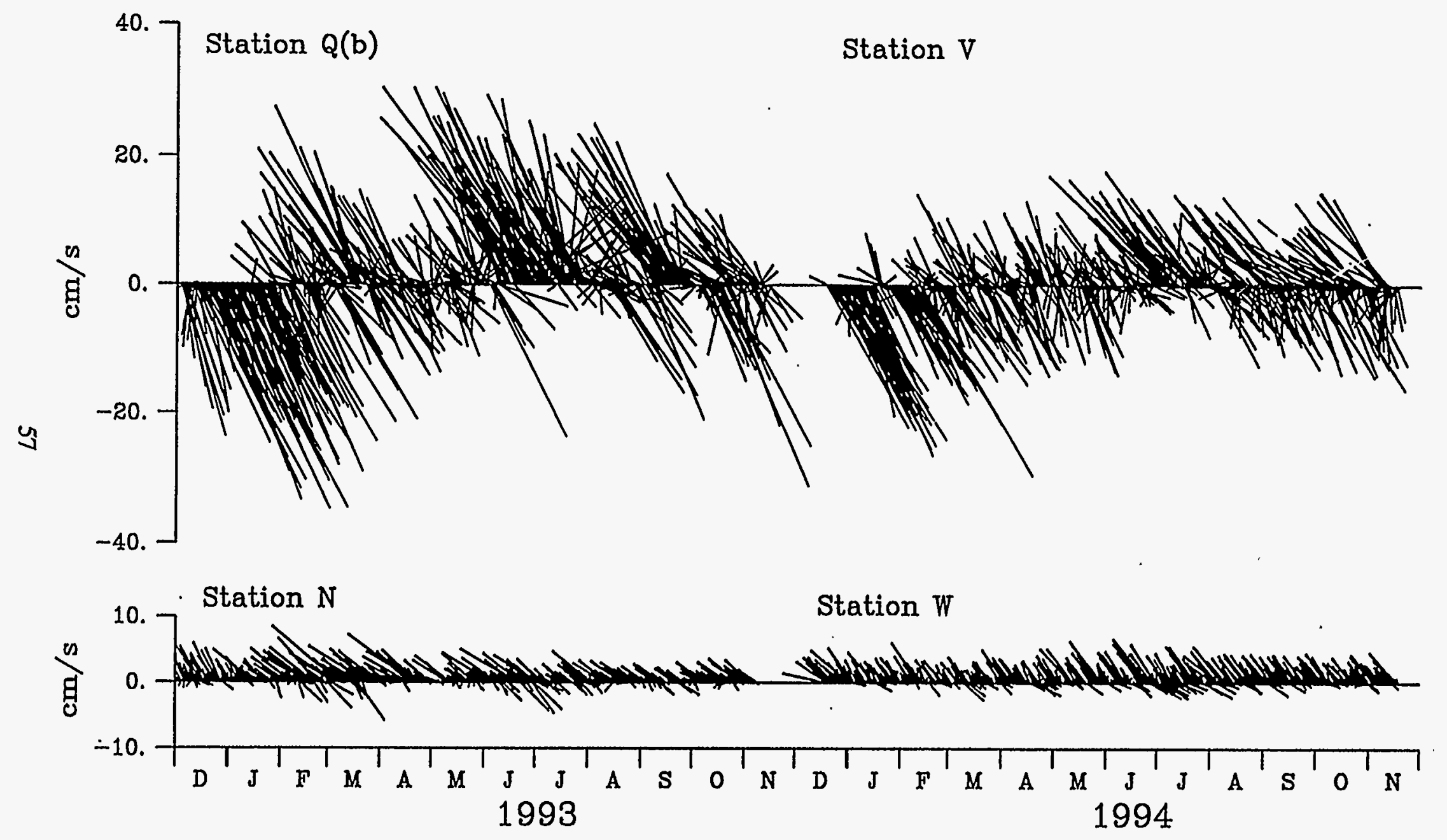
Figure 16 Straw diagram illustrating a time series of $6 \mathrm{~h}$ average current vectors at Stations in McMurdo Sound for the period December, 1993 through February, 1994. 

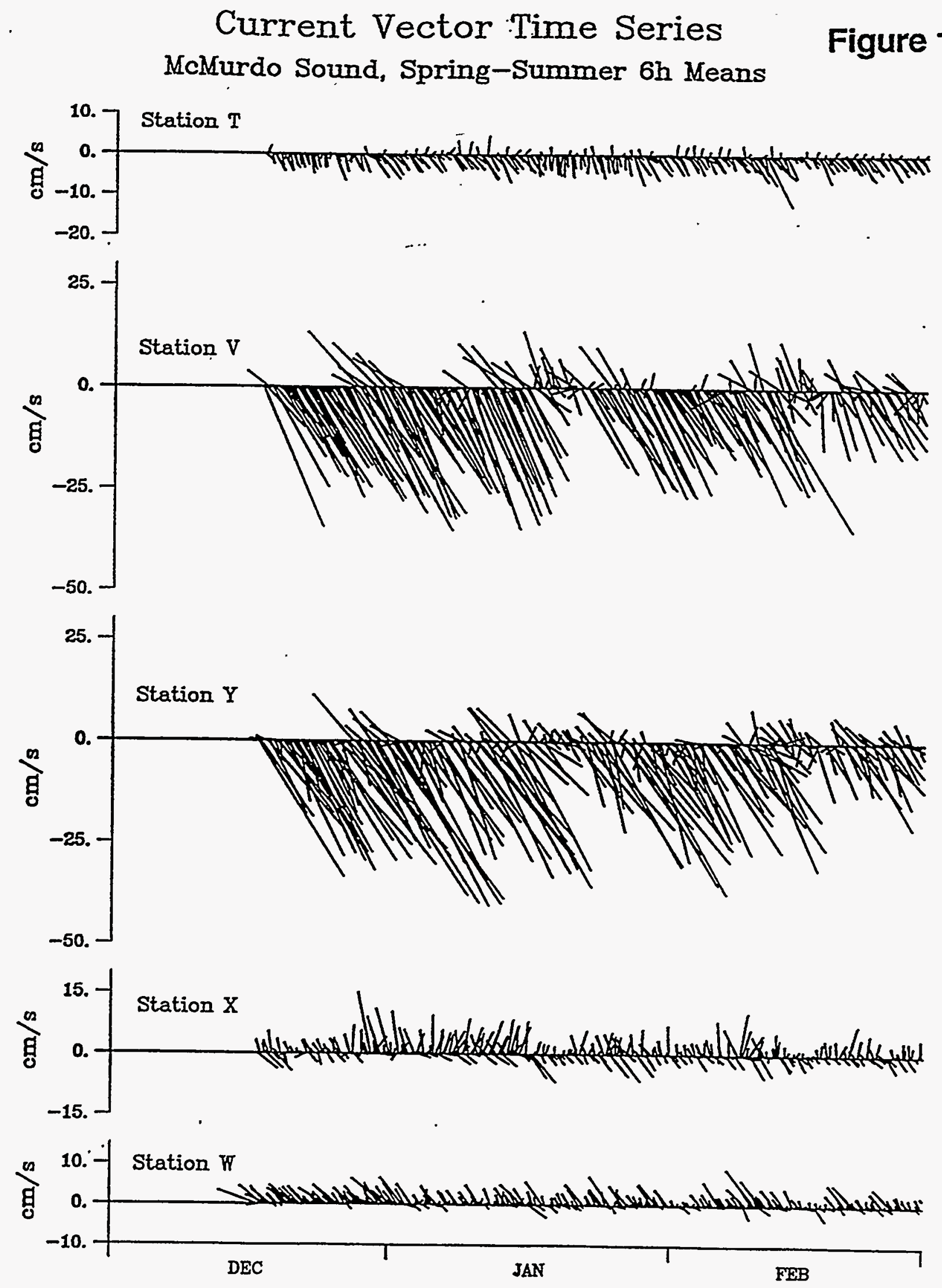
Figure 17 Straw diagram illustrating a time series of $6 \mathrm{~h}$ average current vectors at Stations in McMurdo Sound for the period March through May, 1994. 


\section{Current Vector Time Series}

Figure 17 McMurdo Sound, Summer-Fall 6h Means

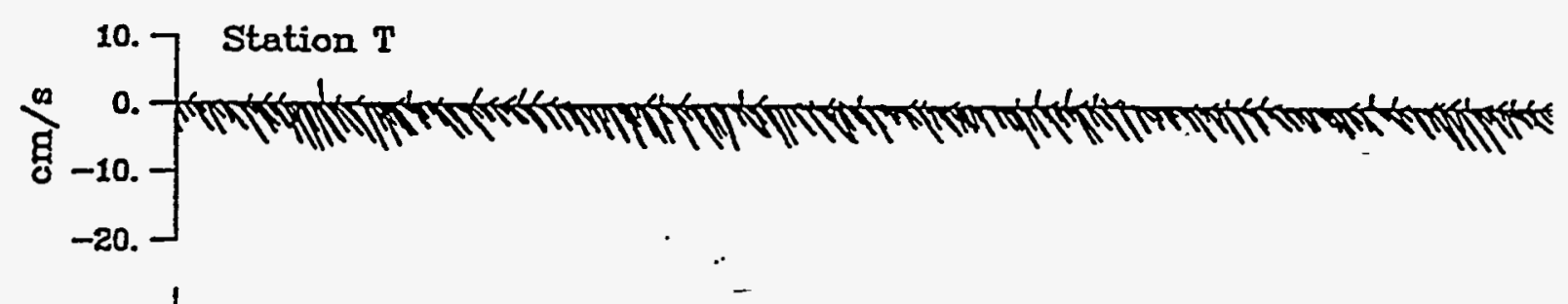
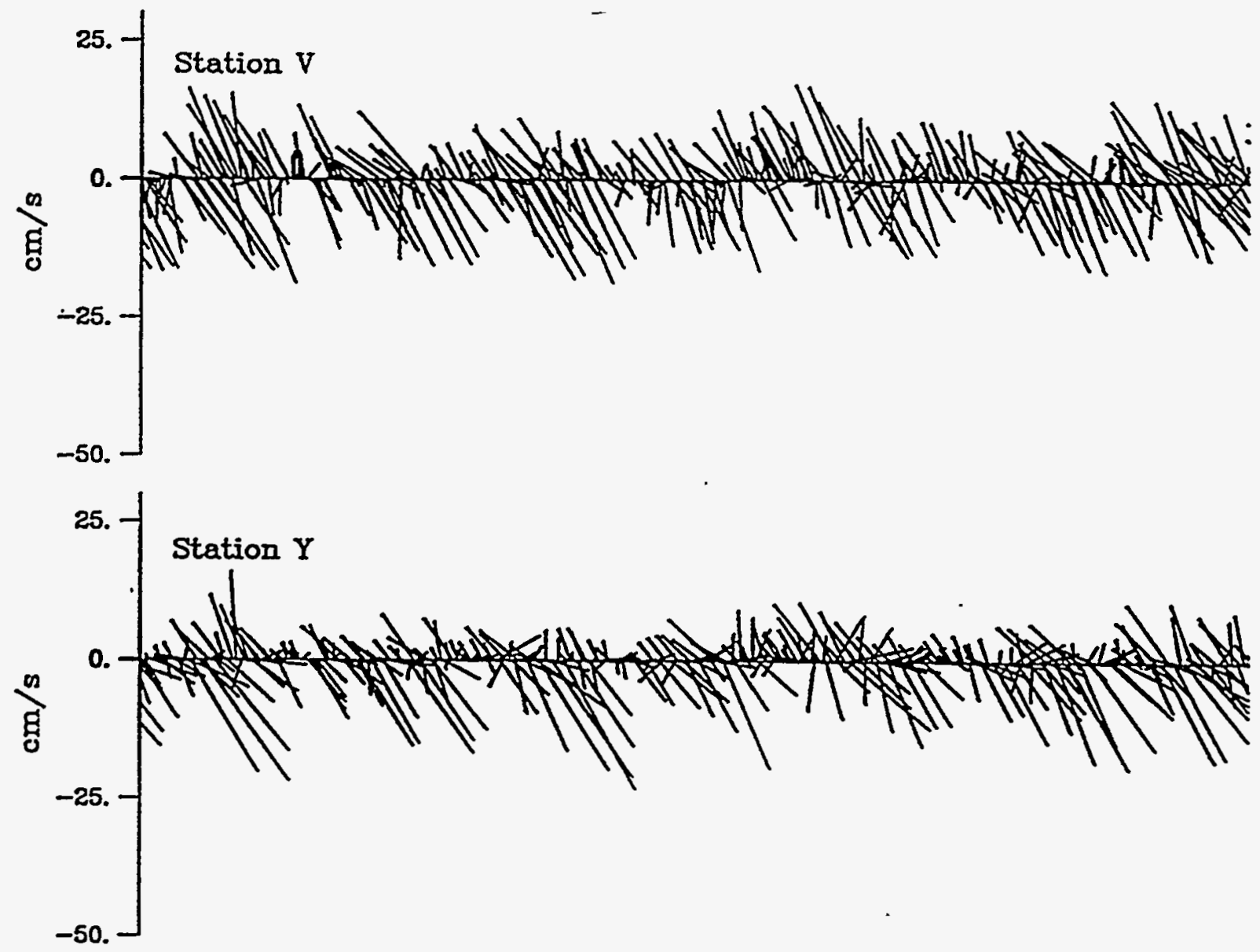

$\int_{0}^{15 .-1}$ Station $\mathrm{x}$

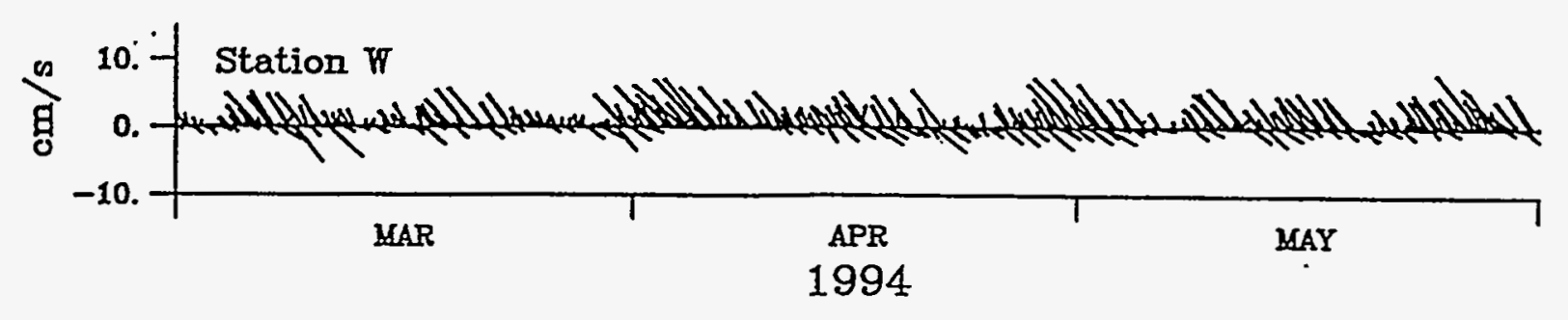


Figure 18 Straw diagram illustrating a time series of $6 \mathrm{~h}$ average current vectors at Stations in McMurdo Sound for the period June through August, 1994. 
Current Vector Time Series Figure 18 McMurdo Sound, Fall-Winter 6h Means

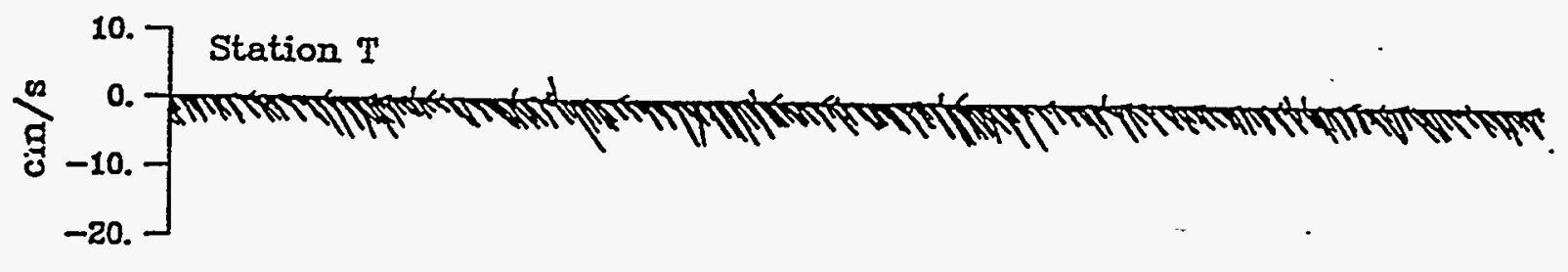

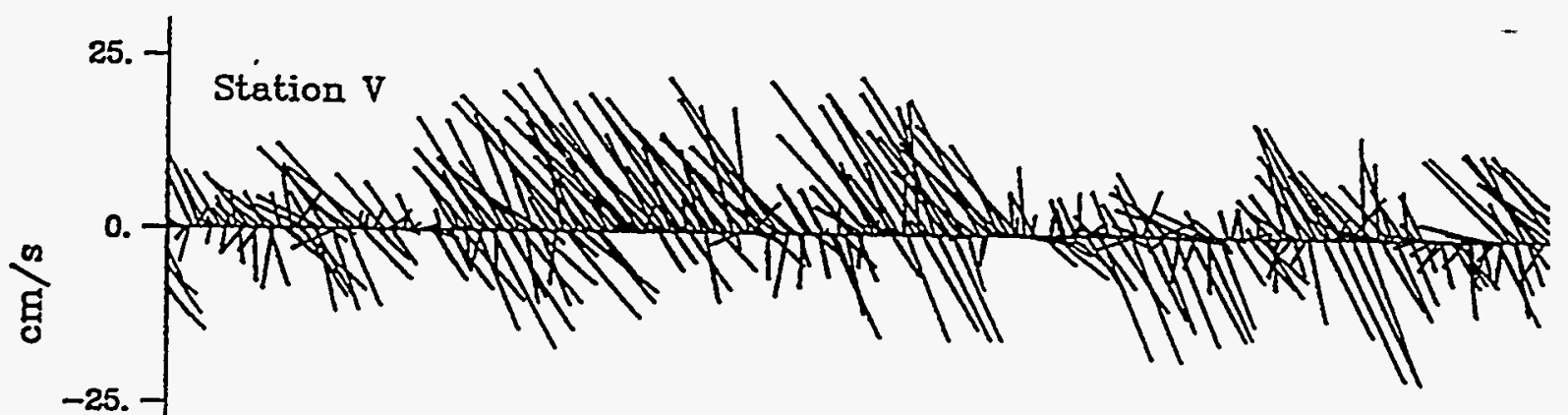

a

$-5 s$

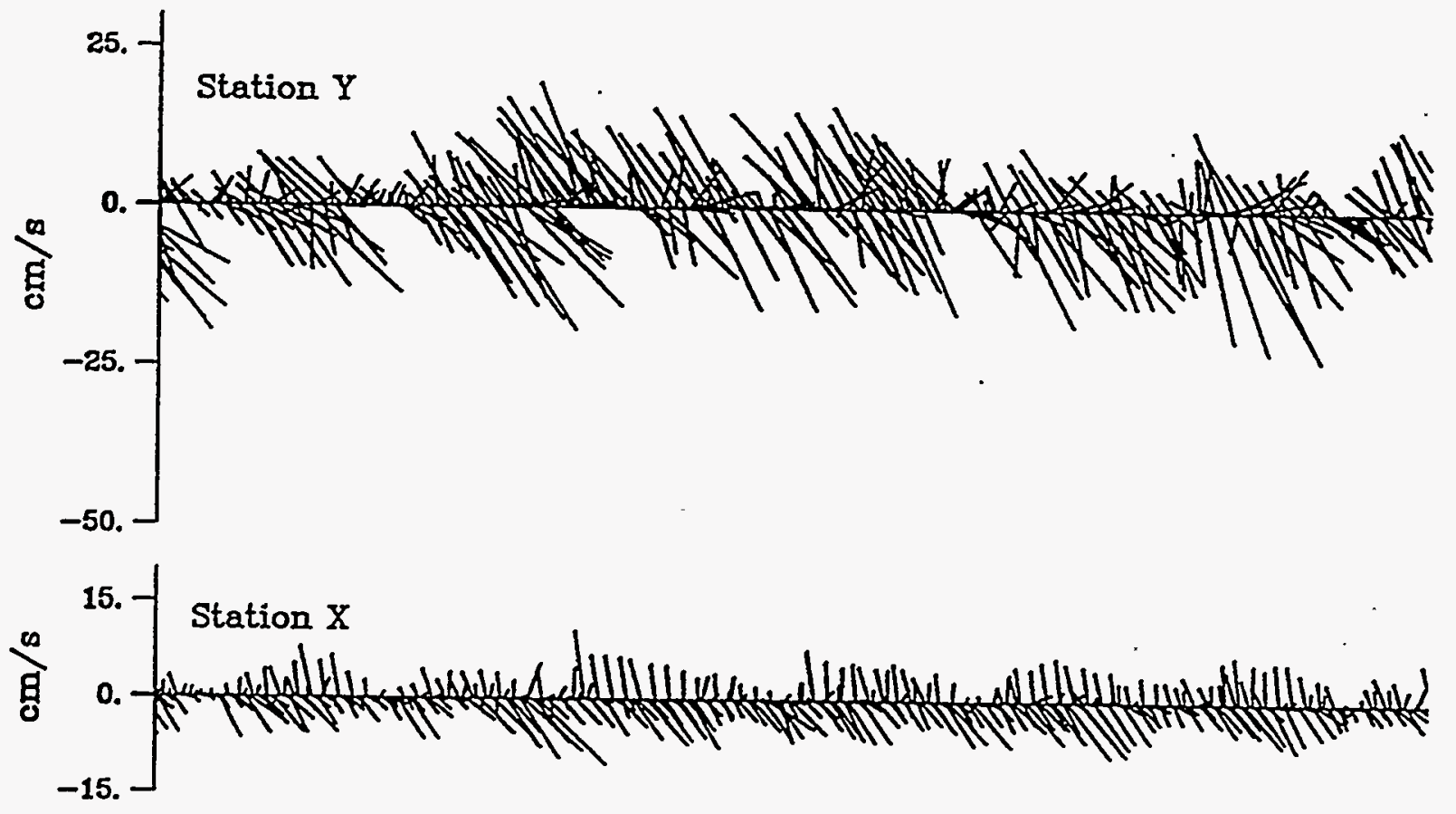

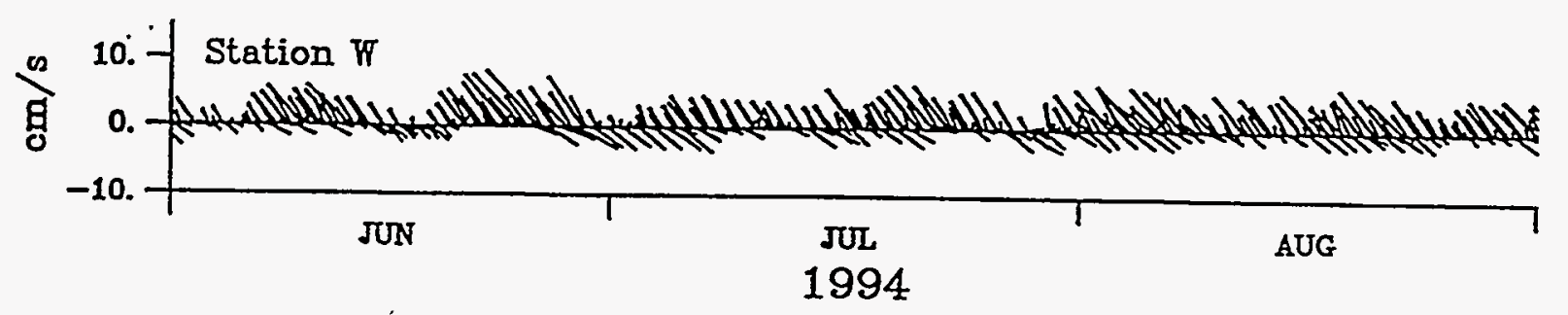


Figure 19 Straw diagram illustrating a time series of $6 \mathrm{~h}$ average current vectors at Stations in McMurdo Sound for the period September through November, 1994. 
Current Vector Time Series

Figure 19

McMurdo Sound, Winter-Spring 6h Means
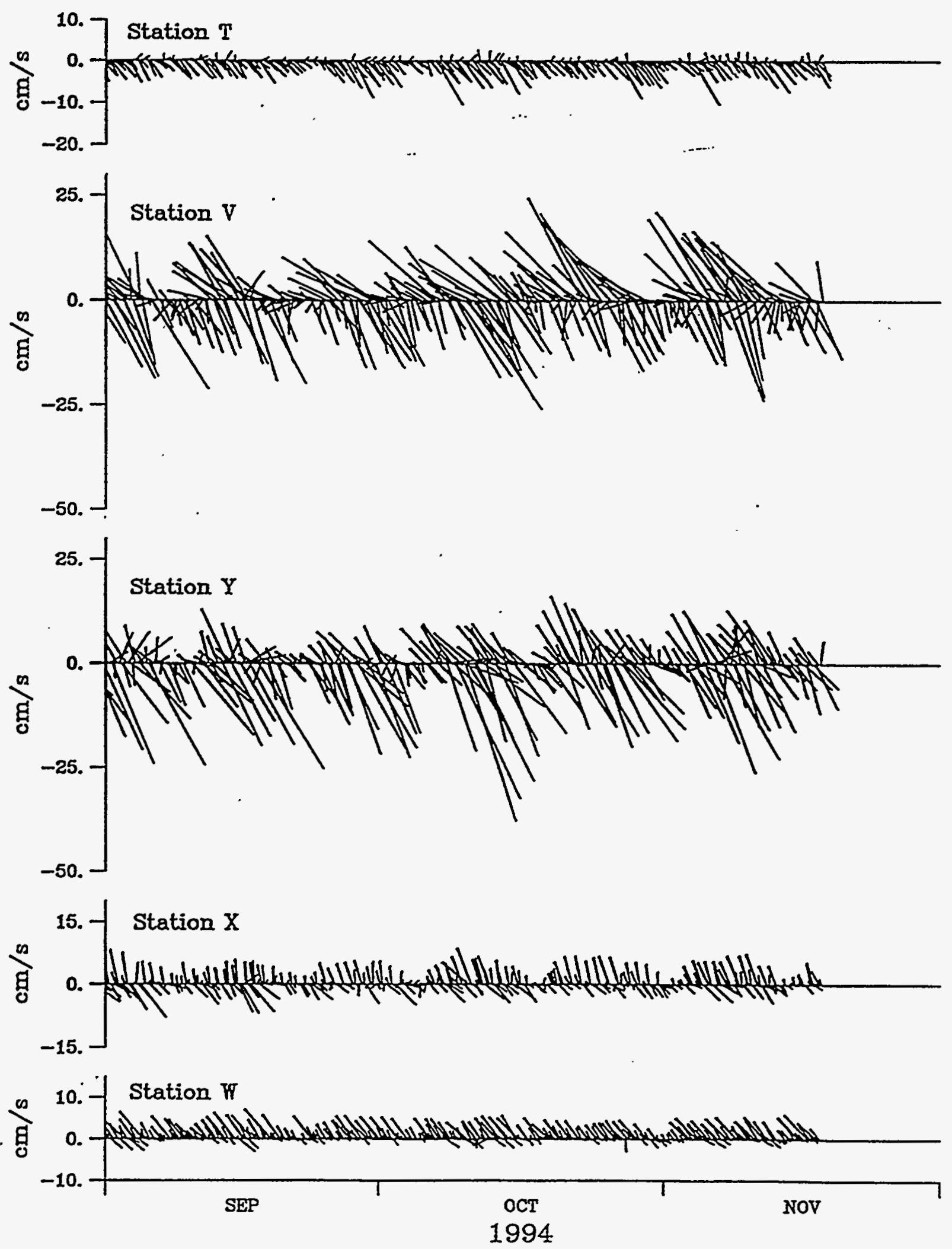
relatively continuous in a particularly direction (e.g. consistent southward regional flow during spring) or vary asymmetrically (greater flow in 1 direction of oscillation). Such variation in flow may have important effects on the induction or decay of the McMurdo gyre, or other characteristics of inshore flow, thereby effecting transport of the wastewater plume.

Spectral analyses of current records for north-south and east-west components of flow at each station during 1993-1994 indicated strong tidal influences on current speed and direction, which were nearly identical to results of similar analyses from measurements collected during 1992-1993. As expected, the dominant frequencies for cyclic flow were near $24 \mathrm{~h}$ (Figure 20 to 24), related to diurnal tidal constituents controlling astronomical, or gravitational, tidal currents. Diurnal tidal motions dominated east-west and north-south flow at all stations. Three frequencies near 1 cycle per day (or 0.04 cycles per hour) were discernable, corresponding to 3 or 4 diurnal tidal constituents $\left(\mathrm{K}_{1}, \mathrm{O}_{1}, \mathrm{P}_{1}, \mathrm{Q}_{1}\right.$ with periods of $23.93,25.82,24.07$, and 26.87 hours, respectively). Higher frequency tidal motions were also evident at all stations. Secondary and smaller peaks near in the power spectra were indicative of semi-diurnal cyclic flow $(.08$ cycles per hour), associated with semi-diurnal tidal constituents $\left(\mathrm{M}_{2}, \mathrm{~S}_{2}\right.$, and $\mathrm{K}_{2}$, with periods of 12.42 , 12.00 , and 11.97 hours, respectively). Semi-diurnal periodicity was most evident at Station $T$, for unknown reasons. Oscillatory flow with frequencies near $3 \mathrm{cpd}$ were less important overall, but still apparent, and are related to minor tidal constituents.

Dominance by diurnal and higher frequency tidal motions in periodic flow results in the greatest variation in flow (for cyclic flow) occurring on diurnal and shorter frequencies. Thus, planetary motions driving global scale ocean tides are a principal feature regulating flow in and around McMurdo Sound, and these forces produce the diurnal and shorter period oscillations in flow evident in all current records. Since these planetary motions change very little, the nearly identical results from both years of observations was expected.

Tidal variation in flow direction and speed can be seen in several figures (eg. Figs. 10 to 12). For short period observations or averages, short period tidal oscillations are evident, but current observations averaged over long periods obscure shorter period motions. For example, 6 to $24 \mathrm{~h}$ variation in flow (some associated with tidal effects) apparent in the 1 hour average time series vector diagrams (e.g. Figure 10), is obscured in the $24 \mathrm{~h}$ average data (Figure 14), because averaging all observations over $24 \mathrm{~h}$ removes (filters) variation over periods less than $24 \mathrm{~h}$. Thus, tidal variation is expressed only in figures for data averaged over periods shorter than the tidal period in question. Although simple averaging of data points (e.g. averaging all $1 \mathrm{~h}$ averages over $24 \mathrm{~h}$ ) effectively acts as a data filter, there are more effective data filters for removing tidal effects. Tidal periodicity over scales of about $30 \mathrm{~h}$ and less was filtered using more sophisticated techniques from the data for Figures 25 to 29, which show both the raw data (1h averages) and filtered data.

Oscillatory flow on frequencies less than 1 day were also evident, related to fortnightly and longer periods, but were much less energetic than observed during 1992-1993. Comparison of spectra from 1992-1993 (Barry 1994) with those for 1993-1994 (Figure 20 to 24) shows that 


\section{STATION T}

North-South $t$ _01h, FFT length 2048, Hanning window, overlap 1024

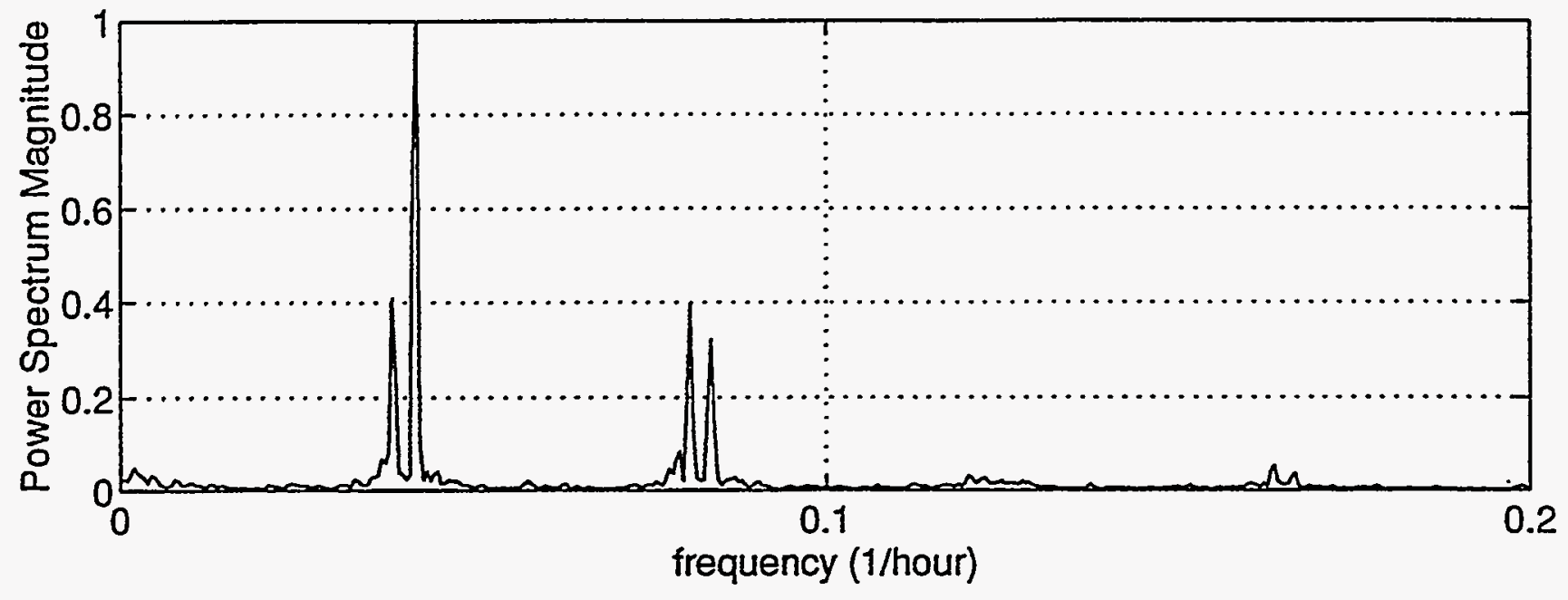

East-West t_ 01h, FFT length 2048, Hanning window, overlap 1024

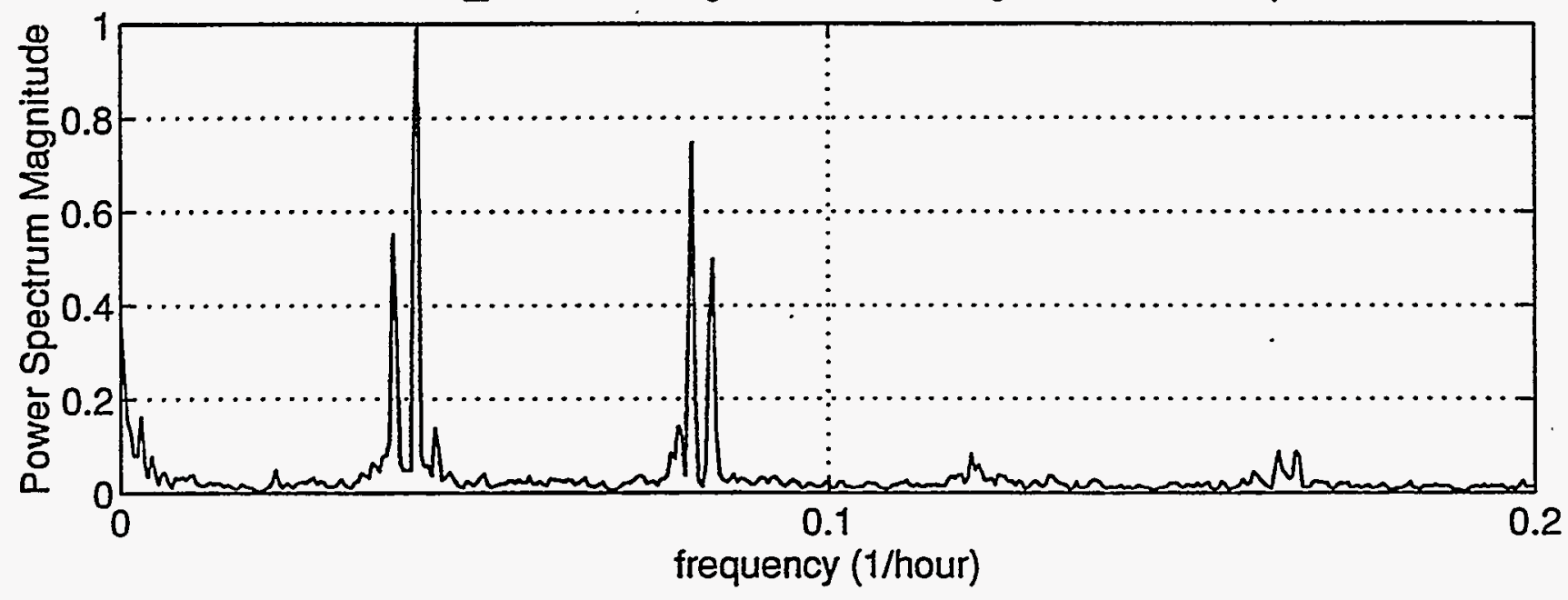

Figure 20 Power spectra for periodic flow at Station T. Power spectra are standardized to 1.0. Frequencies are in cycles per hour. See text for description of methods. a. Spectrum for north-south flow. b. Spectrum for east-west flow. 




\section{STATION W}
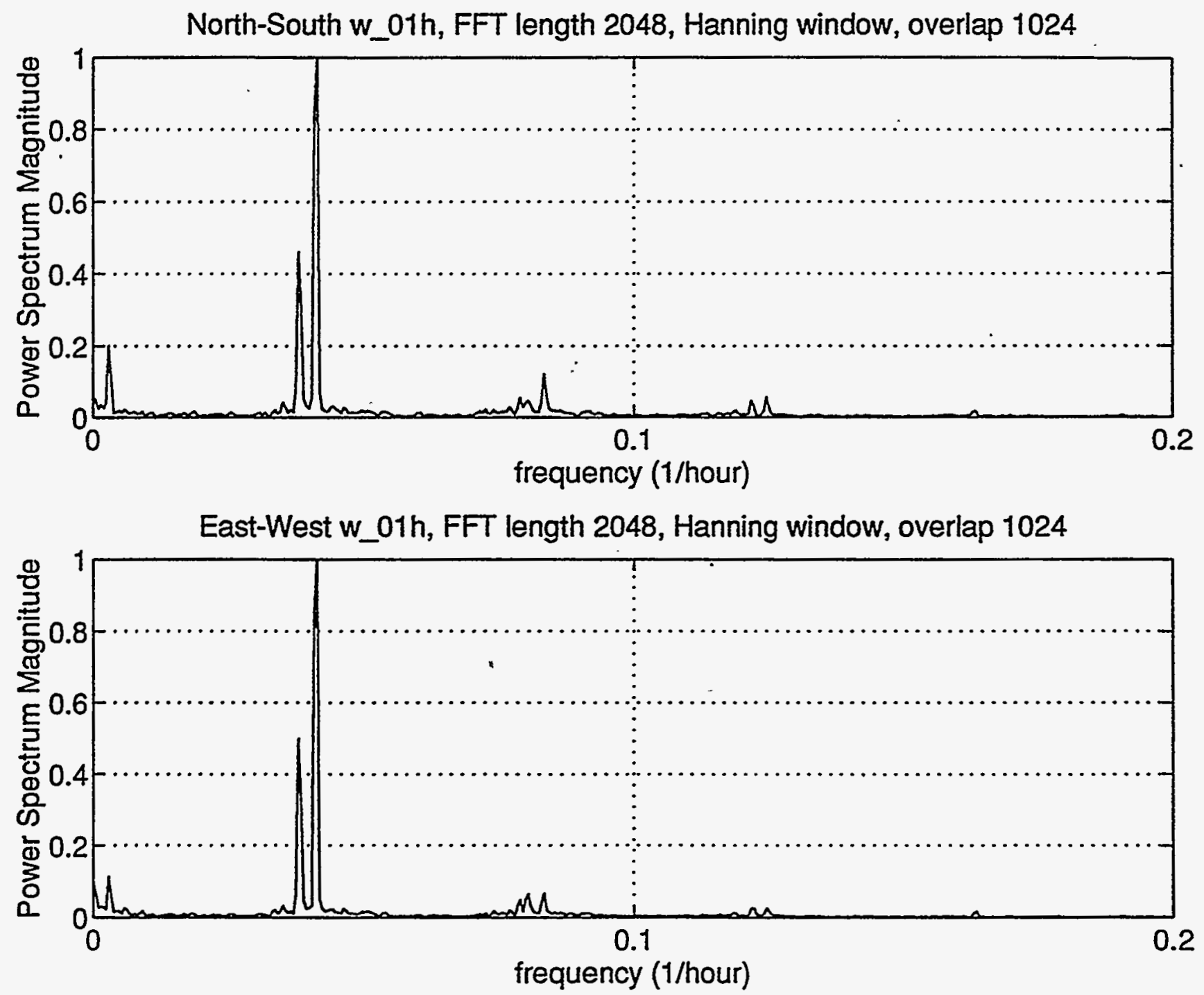

Figure 22 Power spectra for periodic flow at Station W. a. Spectrum for north-south flow. b. Spectrum for east-west flow. 


\section{STATION X}

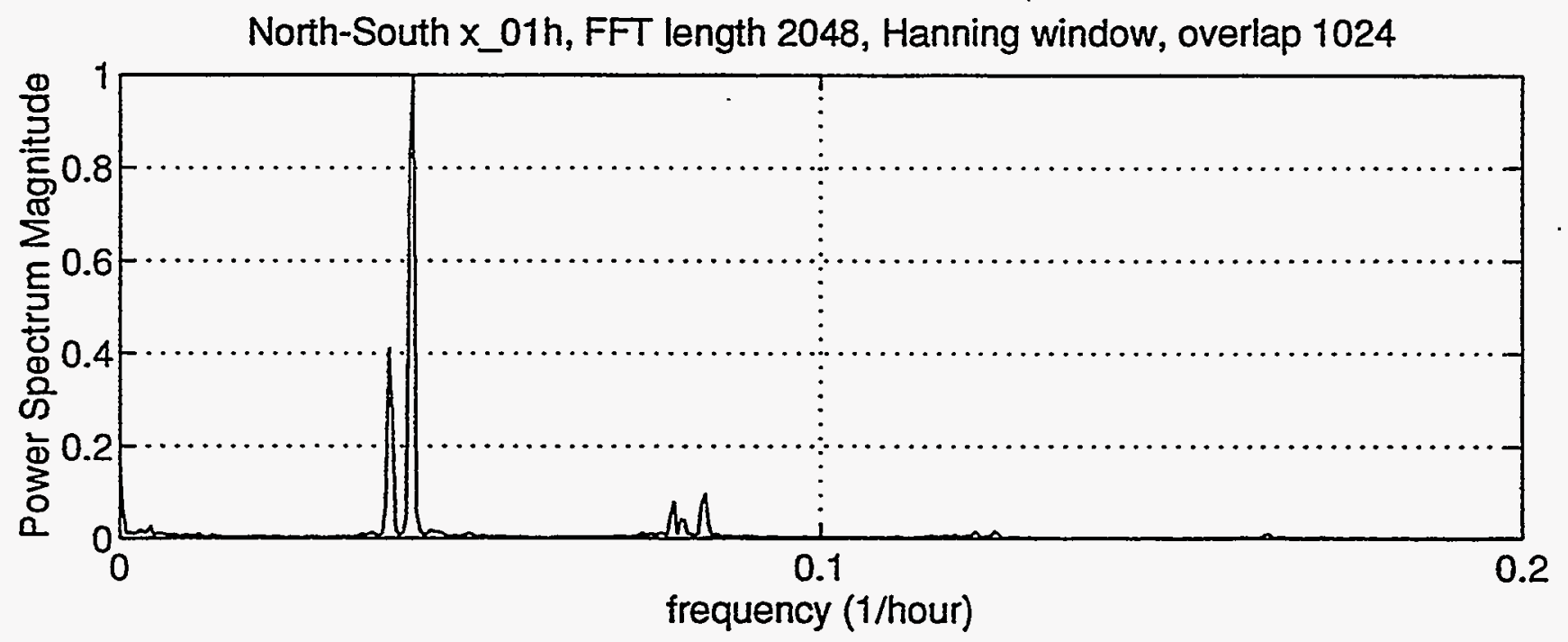

East-West $x$ _01h, FFT length 2048, Hanning window, overlap 1024

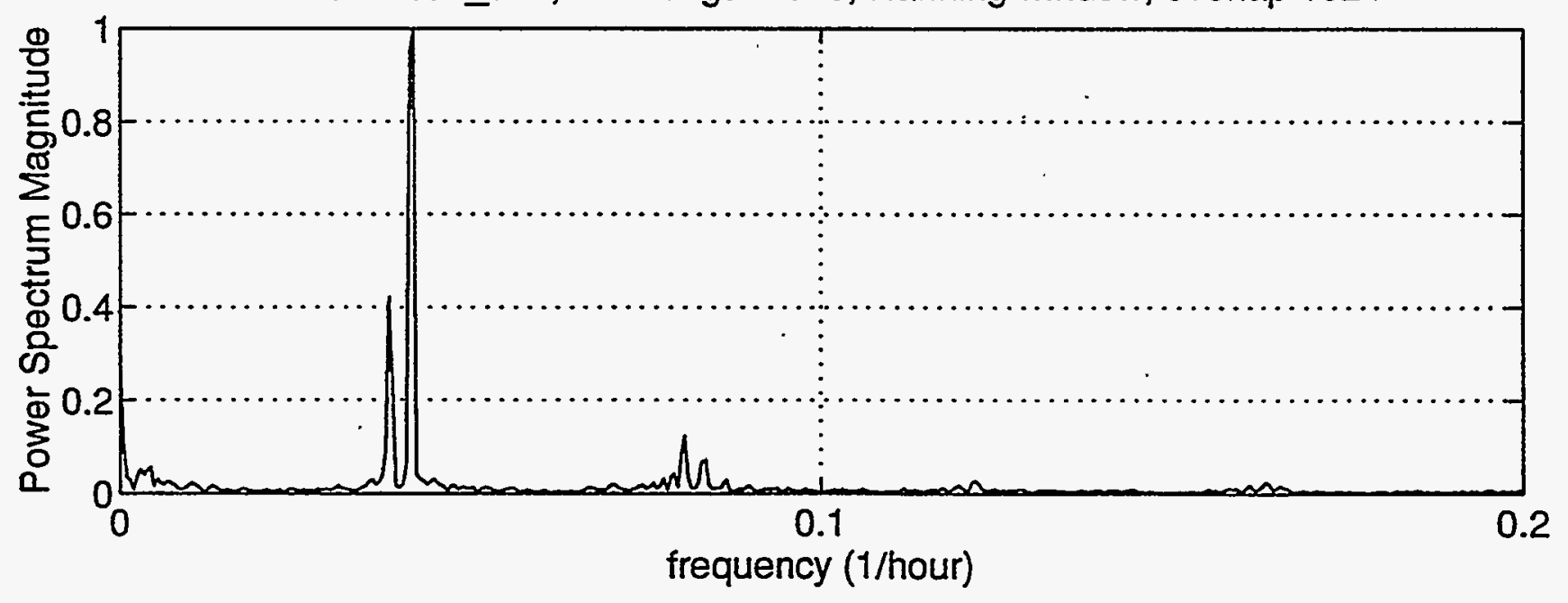

Figure 23 Power spectra for periodic flow at Station X. a. Spectrum for north-south flow. b. Spectrum for east-west flow. 


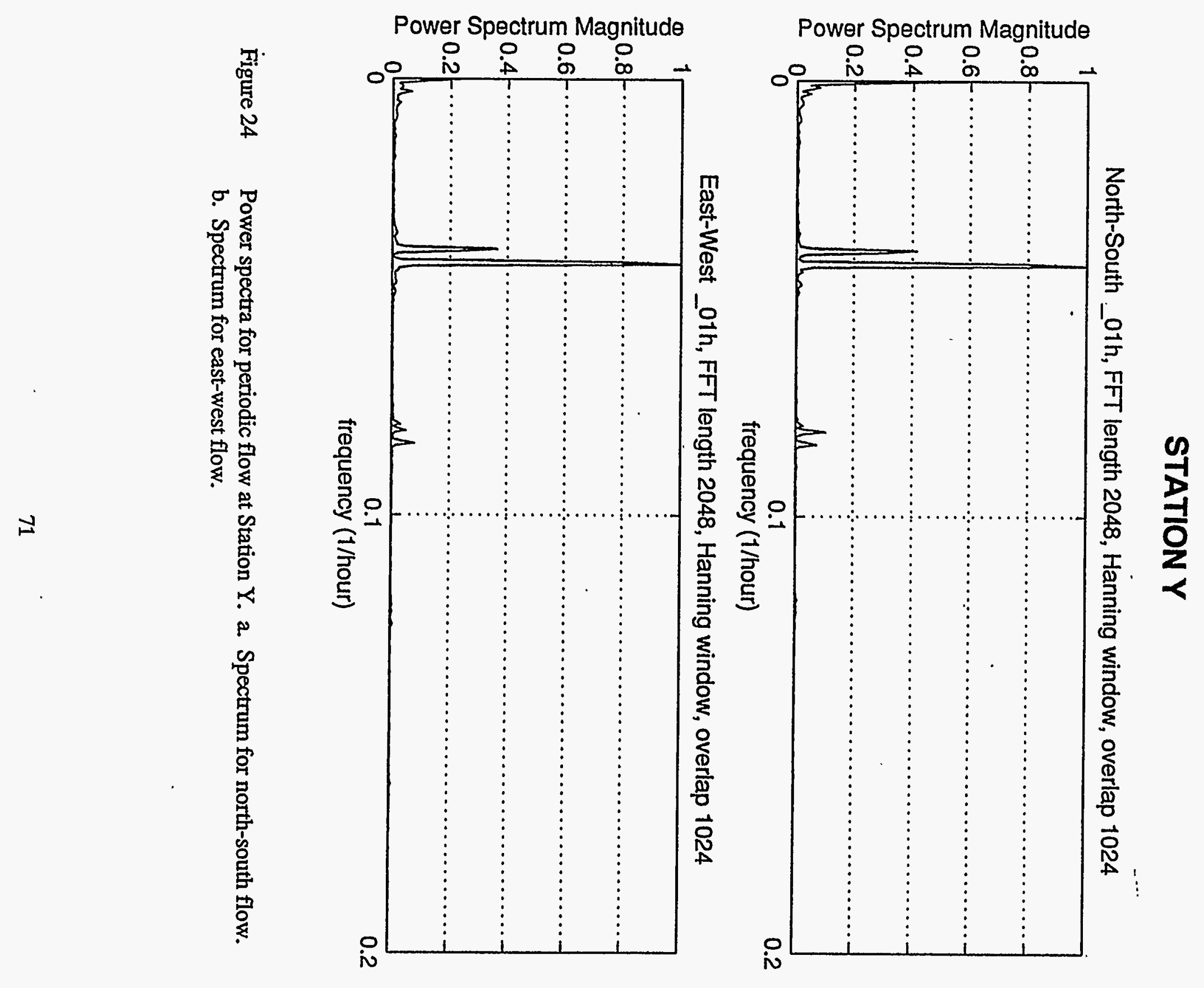


Figure 25 Time series of $1 \mathrm{~h}$ average current speeds at Station $\mathrm{T}$, including unfiltered data (gray) and low-pass filtered data (black). See text for explanation of filtering. a. North-South flow. b. East-West flow. 
Figure 25

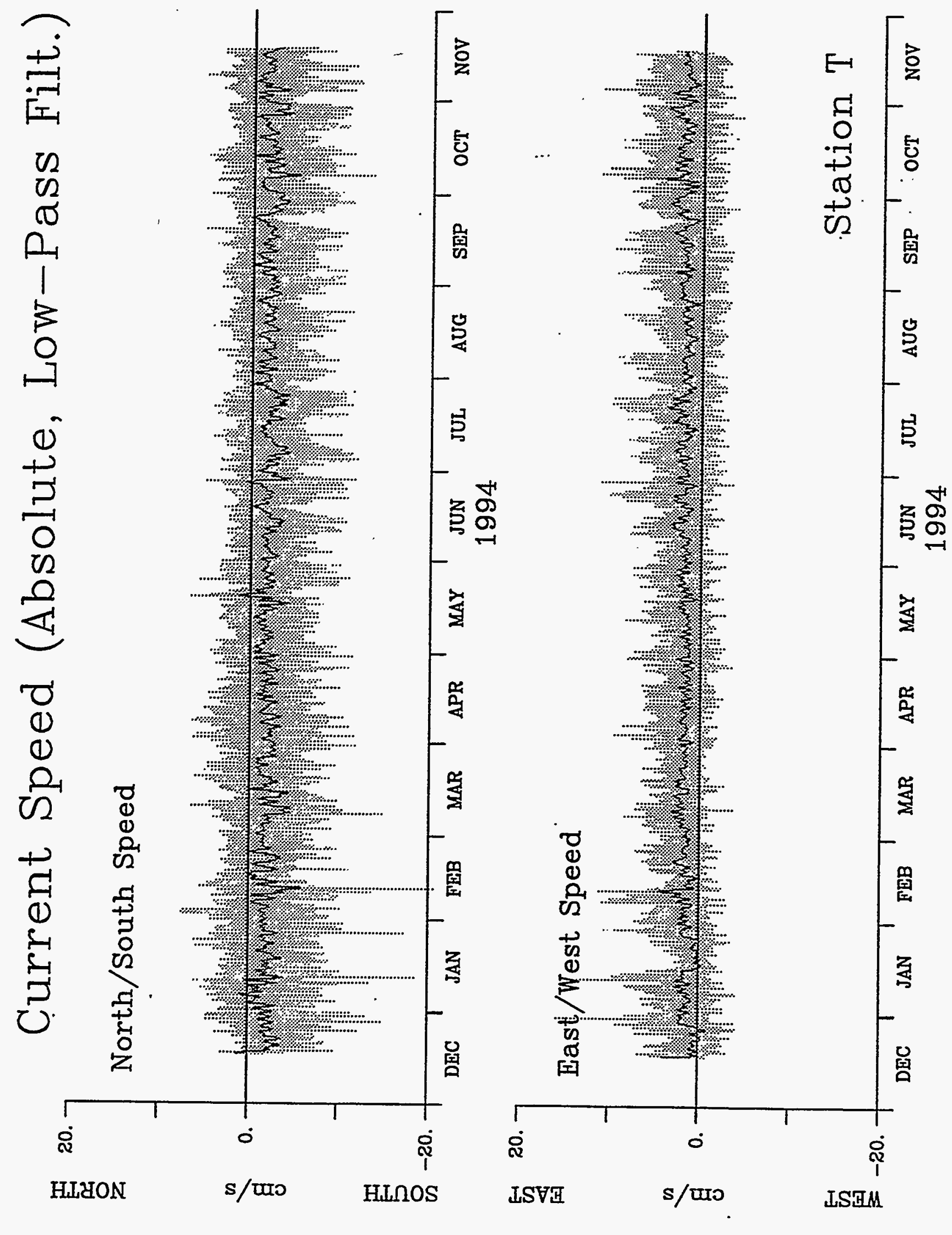


Figure 26 Time series of $1 \mathrm{~h}$ average current speeds at Station $\mathrm{V}$, including unfiltered data (gray) and low-pass filtered data (black). See text for explanation of filtering. a. North-South flow. b. East-West flow. 
Figure 26
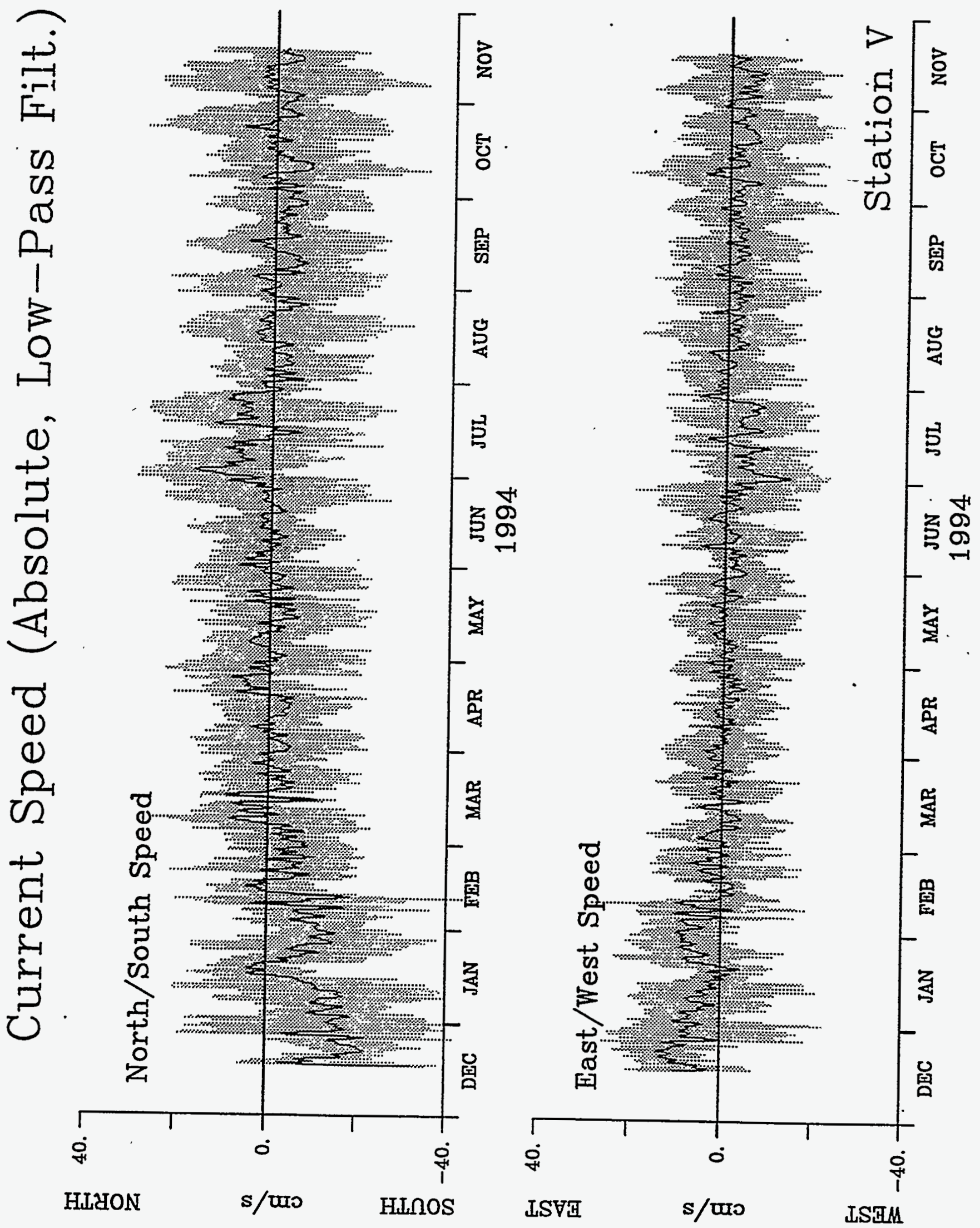
Figure 27 Time series of $1 \mathrm{~h}$ average current speeds at Station $\mathrm{W}$, including unfiltered data (gray) and low-pass filtered data (black). See text for explanation of filtering. a. North-South flow. b. East-West flow. 
Figure 27

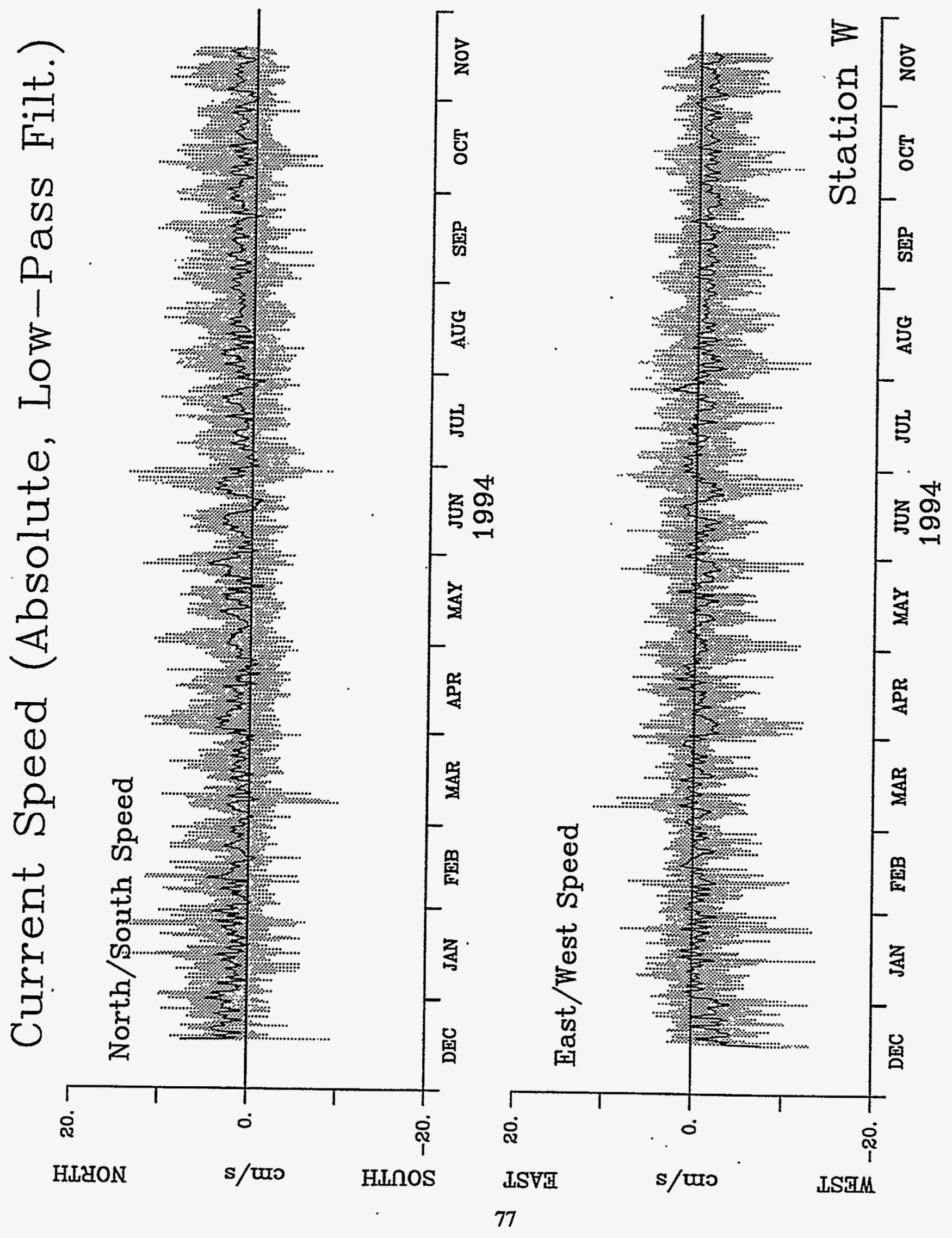


Figure 28 Time series of $1 \mathrm{~h}$ average current speeds at Station $\mathrm{X}$, including unfiltered data (gray) and low-pass filtered data (black). See text for explanation of filtering. a. North-South flow. b. East-West flow. 


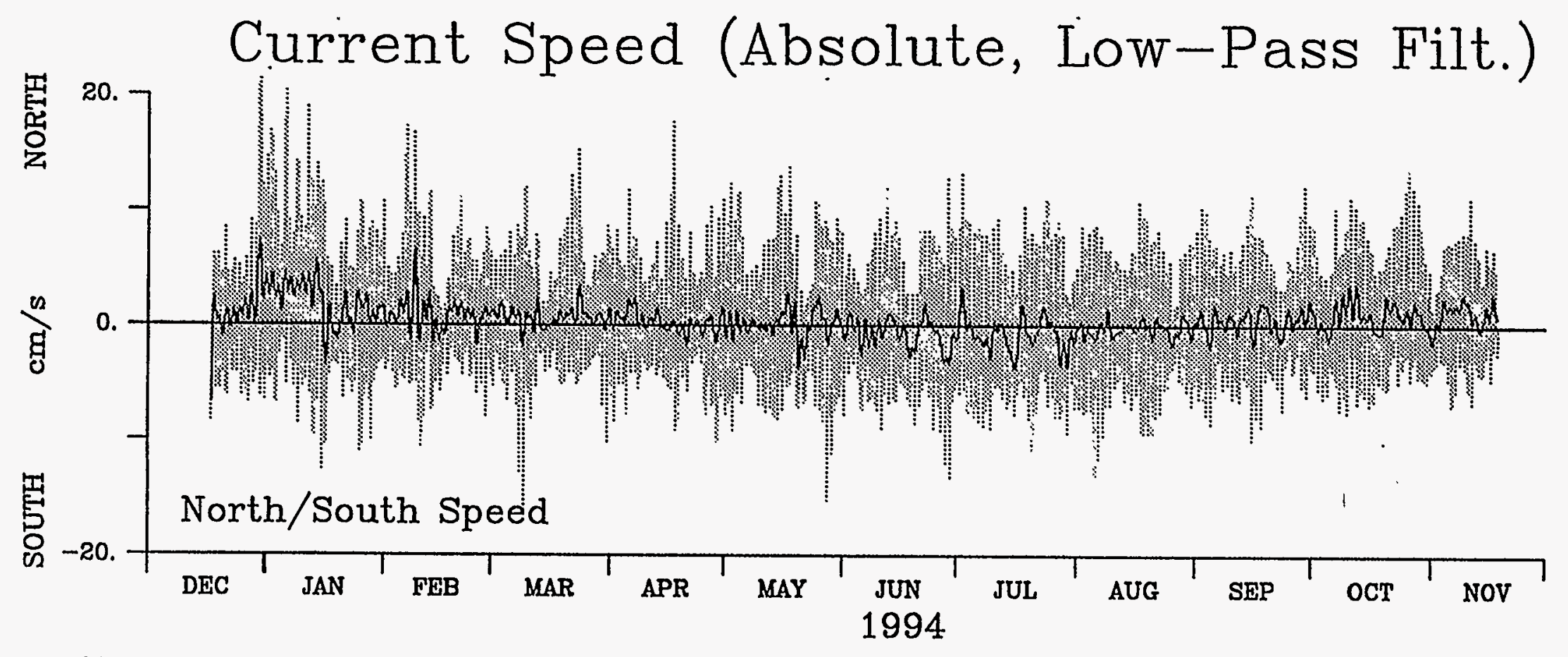

ธิ

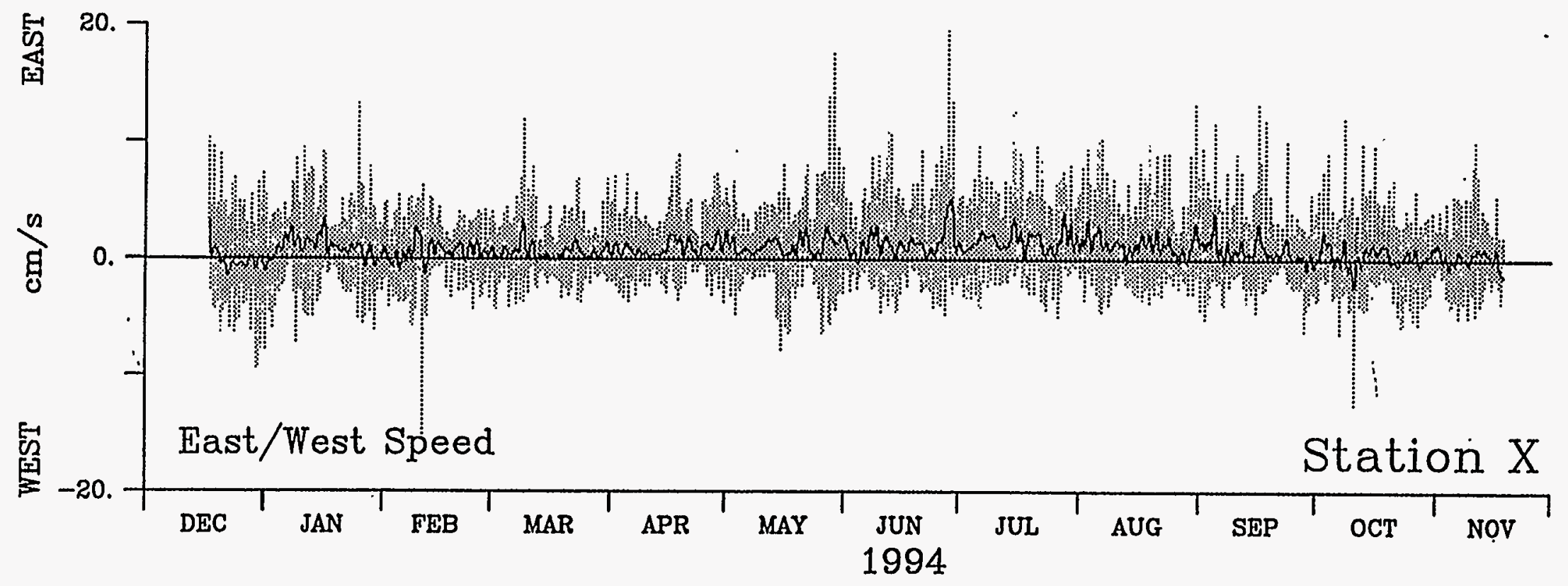

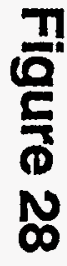


Figure 29 Time series of $1 \mathrm{~h}$ average current speeds at Station $\mathrm{Y}$, including unfiltered data (gray) and low-pass filtered data (black). See text for explanation of filtering. a. North-South flow. b. East-West flow. 

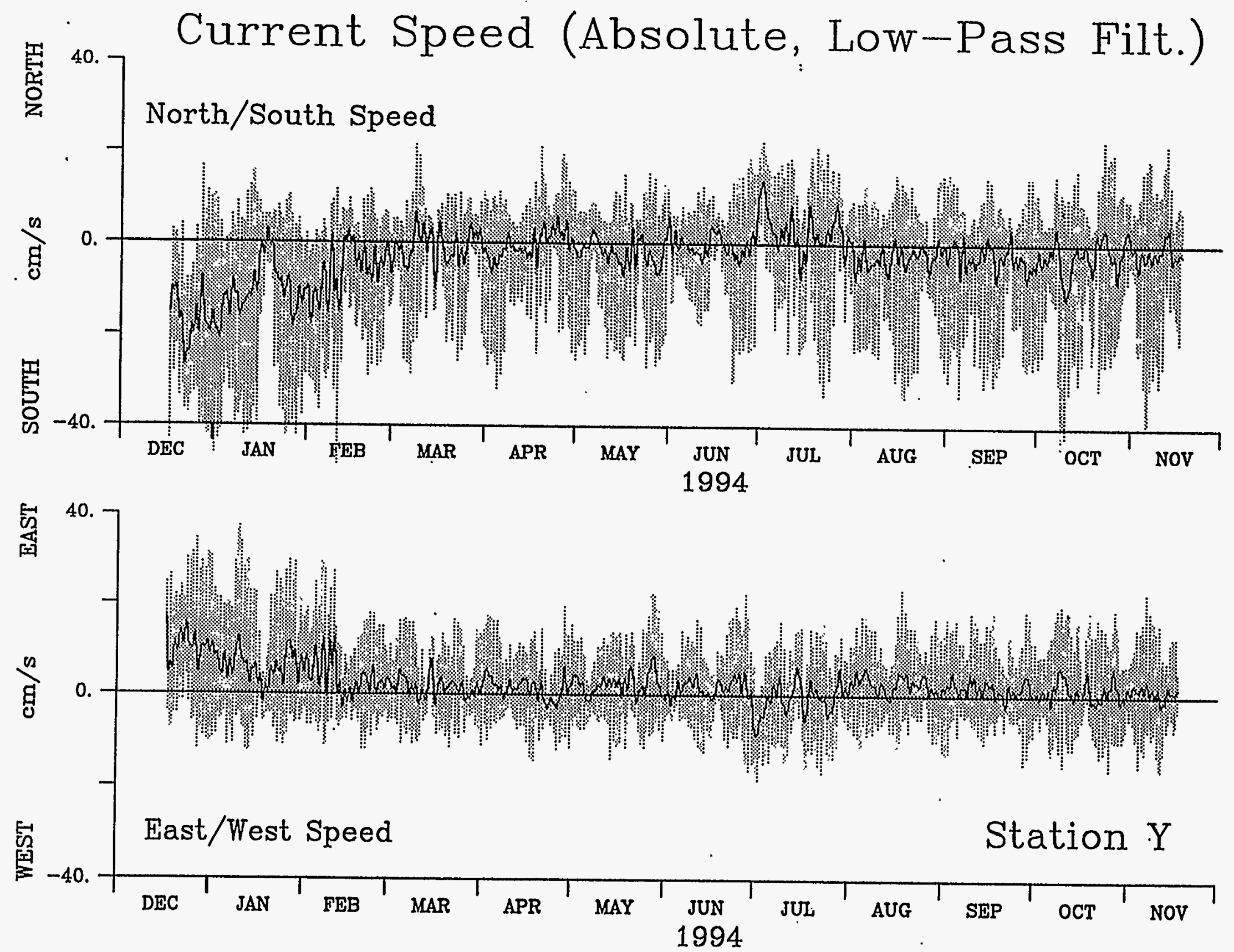
the height of the diumal motion peaks (near 0.04 cycles per hour) were generally higher for 199394, and more energy was found in lower frequencies during 1992-93. This supports the idea that seasonal motions, or low frequency (i.e. fortnightly or greater) oscillations were more important during 1992-1993.

Factors in addition to gravitational effects of planetary motions also have strong influences on cyclic patterns of flow. So-called radiational tides are related to solar radiation, either directly (solar heating), or indirectly via wind generation. Radiational tides can constitute up to $30 \%$ of gravitational tides (Pond and Pickard 1983). In McMurdo Sound, the effects of radiational tides were not strongly evident in spectral analyses for relatively short periods (e.g. fortnightly or shorter), but may be great, particularly over seasonal periods during which the role of ice cover and wind stress on surface circulation may be evident. The observation period during this study, though extending nearly 1 year, is insufficient to identify the periodic characteristics of seasonal shifts in flow. Clearly, however, seasonal shifts were an important characteristic of the flow field near McMurdo Station.

\subsection{Aperiodic Flow}

Patterns of flow unrelated to gravitational or radiational tides, or periodic flow undetectable from a 1 year current record, are less energetic than period motions, but were an important component of flow near McMurdo Station during both year-long observation periods. Overall, aperiodic flow can be estimated from the residual flow remaining after the effects of periodic motions have been removed. The easiest method of evaluating this is to average the horizontal (east-west) and vertical (north-south) components of currents over the entire data record. Table 2 lists a summary of current speeds for all stations from 1993-94. Current speeds are listed as the mean net speed (and st. dev.) and the mean absolute current speed for east-west (EW) and north-south (NS) axes. Net speed represents the mean speed overall, along the EW or NS axis, where east and north are positive. Absolute speed is the mean speed of currents along each axis, regardless of direction. Net transport by all stations surveyed during the 1993-94 observations fit a counter-clockwise gyral pattern representative of the McMurdo Gyre. In addition, net flow at Station T suggest southeastward alongshore flow, which also fits the pattern expected if the McMurdo Gyre dominated overall net transport. Absolute current speeds were greatest for the offshore stations $(\mathrm{V}, \mathrm{Y}$ ) where current speeds averaged near 6 and $8.5 \mathrm{~cm} / \mathrm{s}$ along east/west and north/south axes, respectively. Absolute speeds at other stations consistently averaged near $3 \mathrm{~cm} / \mathrm{s}$ along both axes.

\subsection{Progressive Vector Diagrams}

Year-long averages of net flow do not adequately represent general conditions over time scales important to transport of the wastewater plume. Progressive vector diagrams for the yearlong observations during 1993-94 at stations (T, V, W, X, and Y) illustrate variation in the 
current field within and between months much more clearly than most other data presentations. Progressive vector diagrams represent a time series of current vectors (e.g. straw diagram current vectors), attached 'head-to-tail'. Thus, rather than a straw diagram with current vectors organized in series along a time axis, a progressive vector diagram represent the path of a water parcel during the measurement period, assuming that it flows in the direction and speed at which the current meter is positioned. This is impossible in many cases, however, since total transport approaches $1000 \mathrm{~km}$ or more over the observation period. Nevertheless, progressive vector diagrams illustrate quite clearly temporal changes in speed and direction of currents.

Progressive vector diagrams based on 3 hour vector averages for all currènt observations during 1993-94 (Figures 30 to 34) indicate that the general pattern of flow for offshore stations (Stations Y, V) was strong and southwestward during December through early March. Flow then changed abruptly to a regime of oscillating northward and southward flow, which persisted until mid-June at Station V (Figure 30a), and until at least the end of July at Station Y (Figure 31a). Recall that these two stations are most representative of regional circulation. Flow at both stations was generally north to northwestward in July. Through the remainder of the year, however, flow differed between stations, with net southwestward flow at Station V, and southeastward flow at Station Y. At both stations, the principal motions were aligned along northwest - southeast or north - south axes, as shown in Figures 30b and 31b which show a closeup of a portion of the year. Elliptical current patterns (Figure 31b) associated with inertial currents are related to daily tidal motions. Differences in net drift late in 1994 were probably related both the deflection of southward and northward flow to the west near Station V, and the eastward bias of currents (particularly southward currents) near Station $Y$ by the McMurdo Gyre.

Flow at Station $\mathrm{X}$, on the southern quadrant of the McMurdo Gyre, moved generally toward the northeast to east over the year, even though principal daily motions (seen as the sawtooth pattern on Figure 32) were along a southeast - northwest axis. Presence of the McMurdo Gyre was probably responsible for the net shoreward drift.

Station W, near the present outfall site, was characterized by fairly consistent and sluggish net drift toward the north northwest (Figure 33a), but also showed considerable daily and monthly oscillation in flow along a northwest - southeast axis, including episodes of southeastward flow (Figure 33b) sufficient to deliver the wastewater plume to the jetty area. Close inspection of currents near the outfall during October 1994 (Figure 33c) show much less energetic and less oscillatory flow, with a lesser chance of plume transport to the jetty area.

Flow on the northern side of Hut Pt. had not been investigated in earlier years, and Barry (1994) speculated that a clockwise gyre north of Hut Pt. may spin up during periods of northward flow. The pattern of flow at Station T (Figure 34a) was very consistent toward the southeast all year. In addition there was considerable daily oscillation in current speed, and somewhat less variation in current direction, principally over daily periods (Figure 34b). This pattern is consistent with southeastward regional flow along the Hut Pt. Peninsula, and a clockwise gyre north of Hut Pt., caused by northward regional flow. 


\section{Station V 1993-1994 Progressive Vector Diagram}

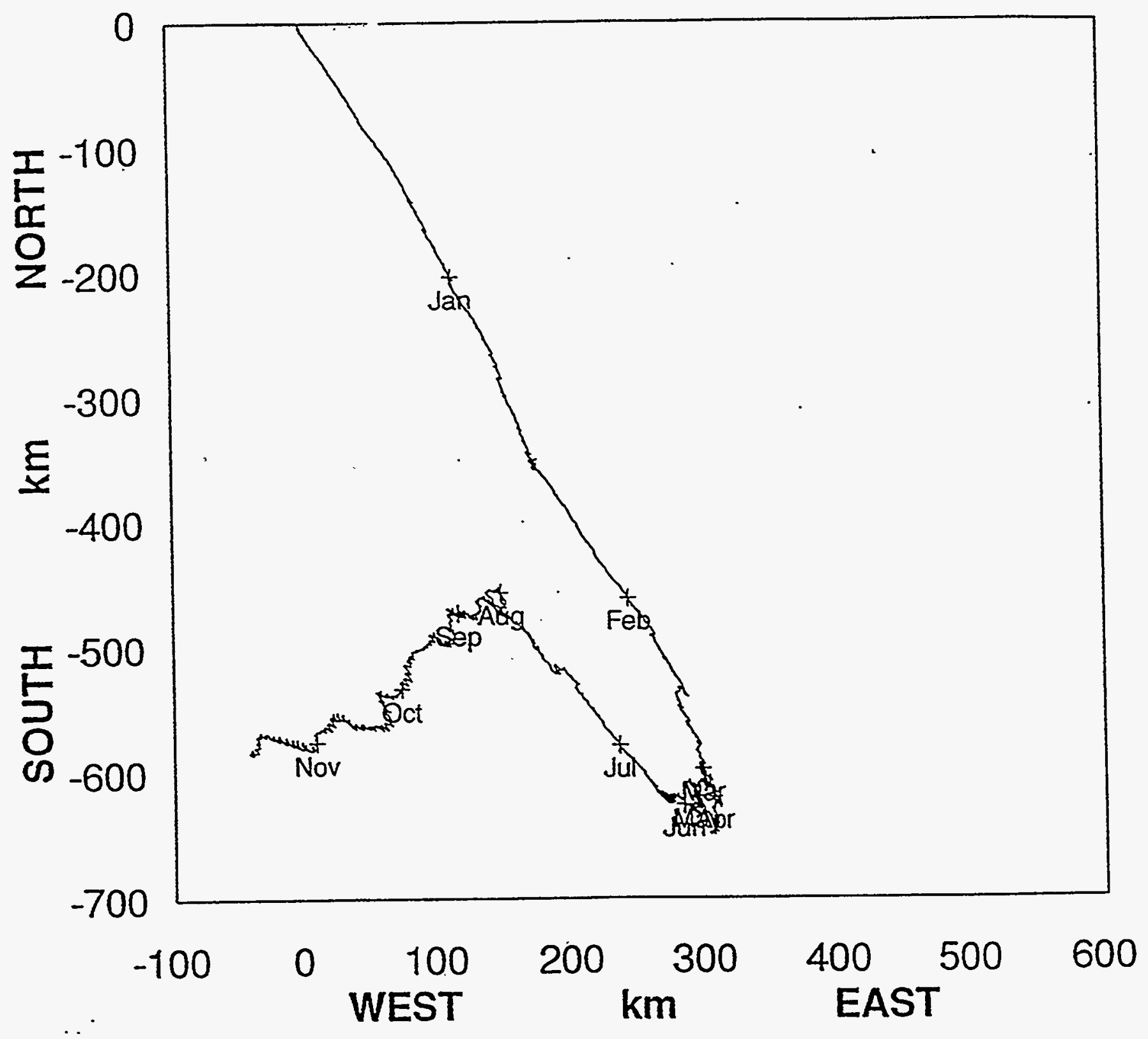

Figure 30a Progressive vector plot for current vectors (3 h means) at Station V, December 1993 to November 1994 


\section{Station V 1993-1994 Progressive Vector Diagram}

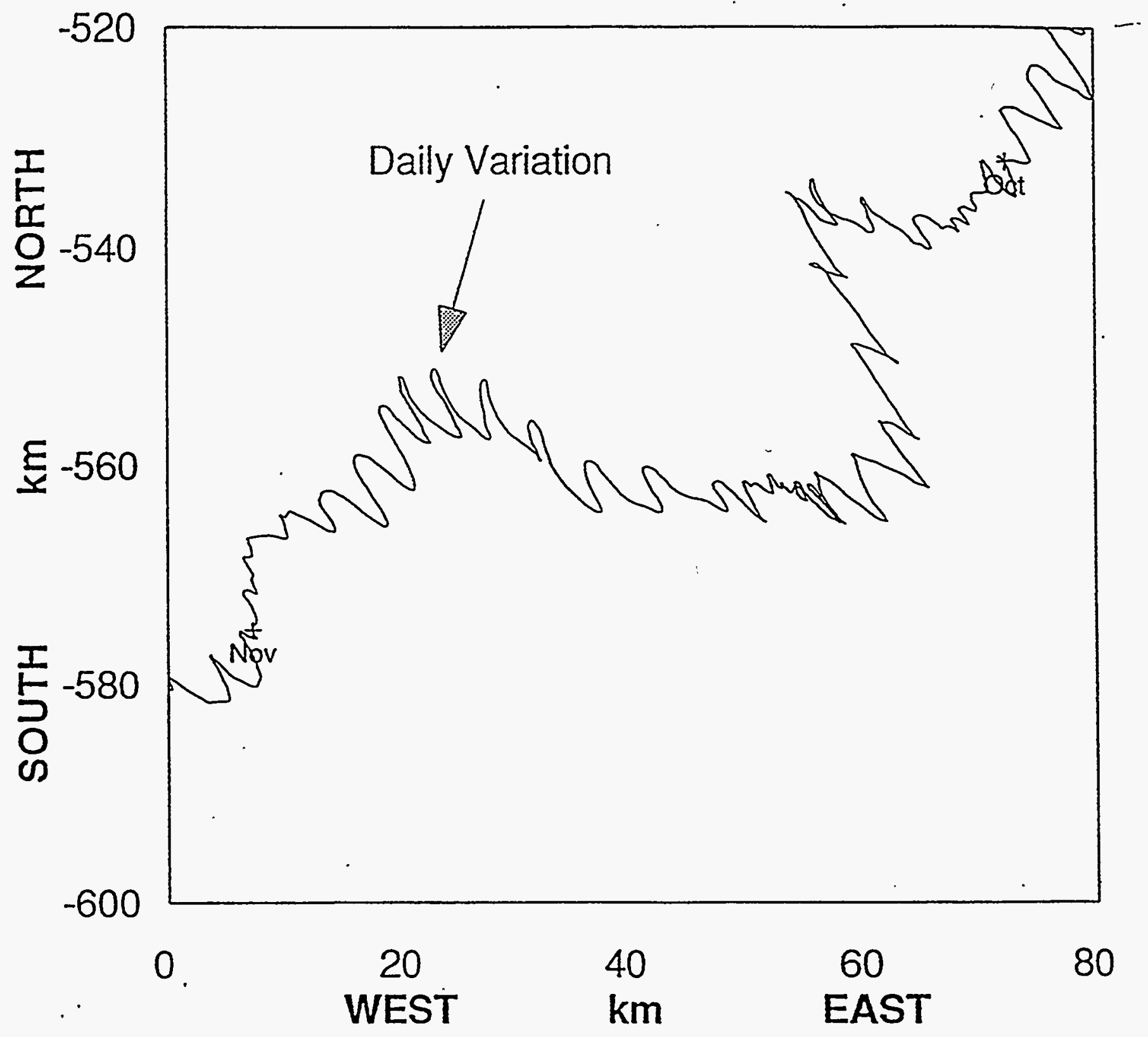

Figure 30b. Progressive vector plot for current vectors (3 h means) at Station V, October, 1994 


\section{Station Y 1993-1994 \\ Progressive Vector Diagram}

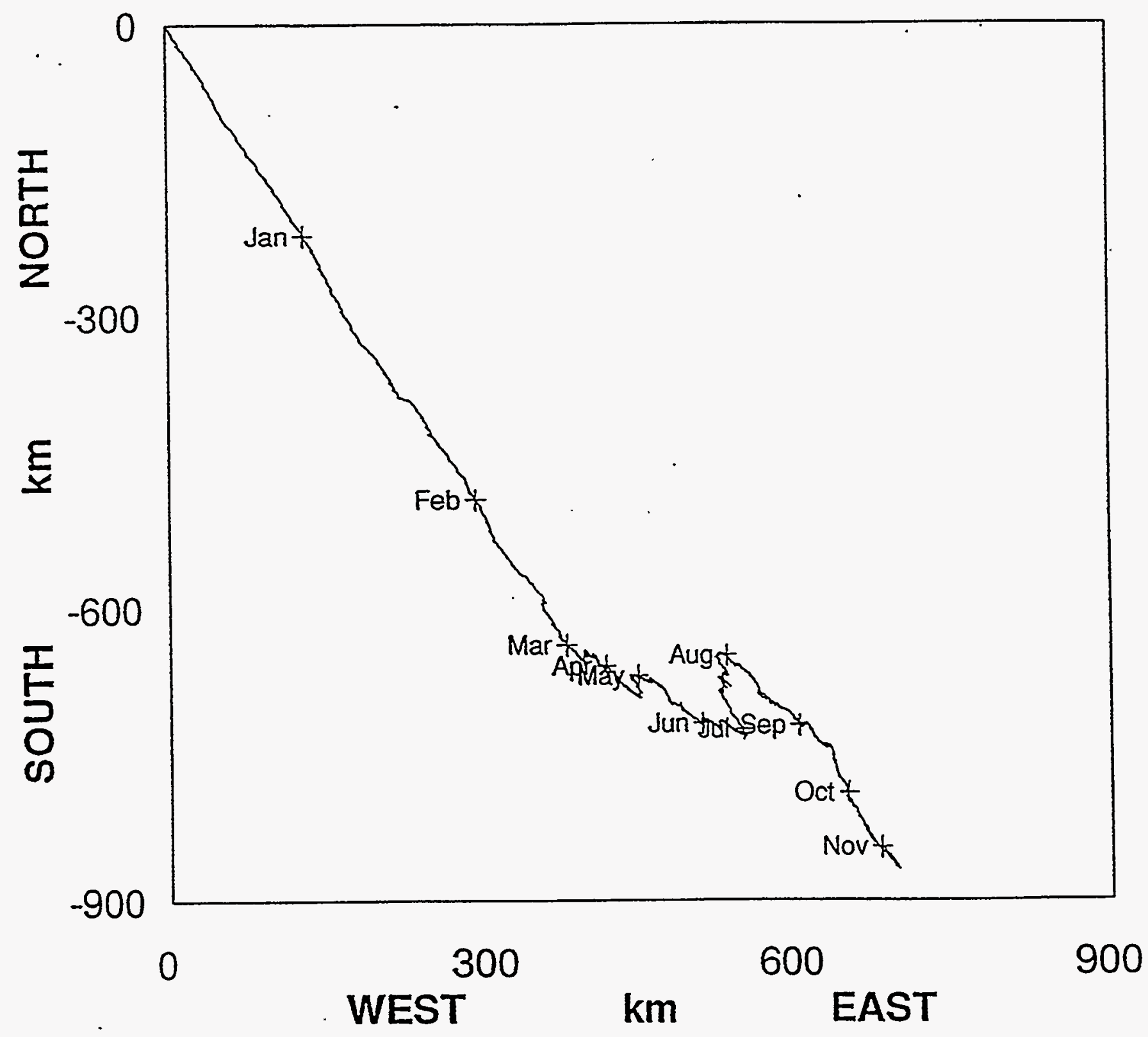

Figure 31a Progressive vector plot for 3 h mean current vectors at Station Y, December 1993 through November 1994 


\section{Station Y 1993-1994 Progressive Vector Diagram}

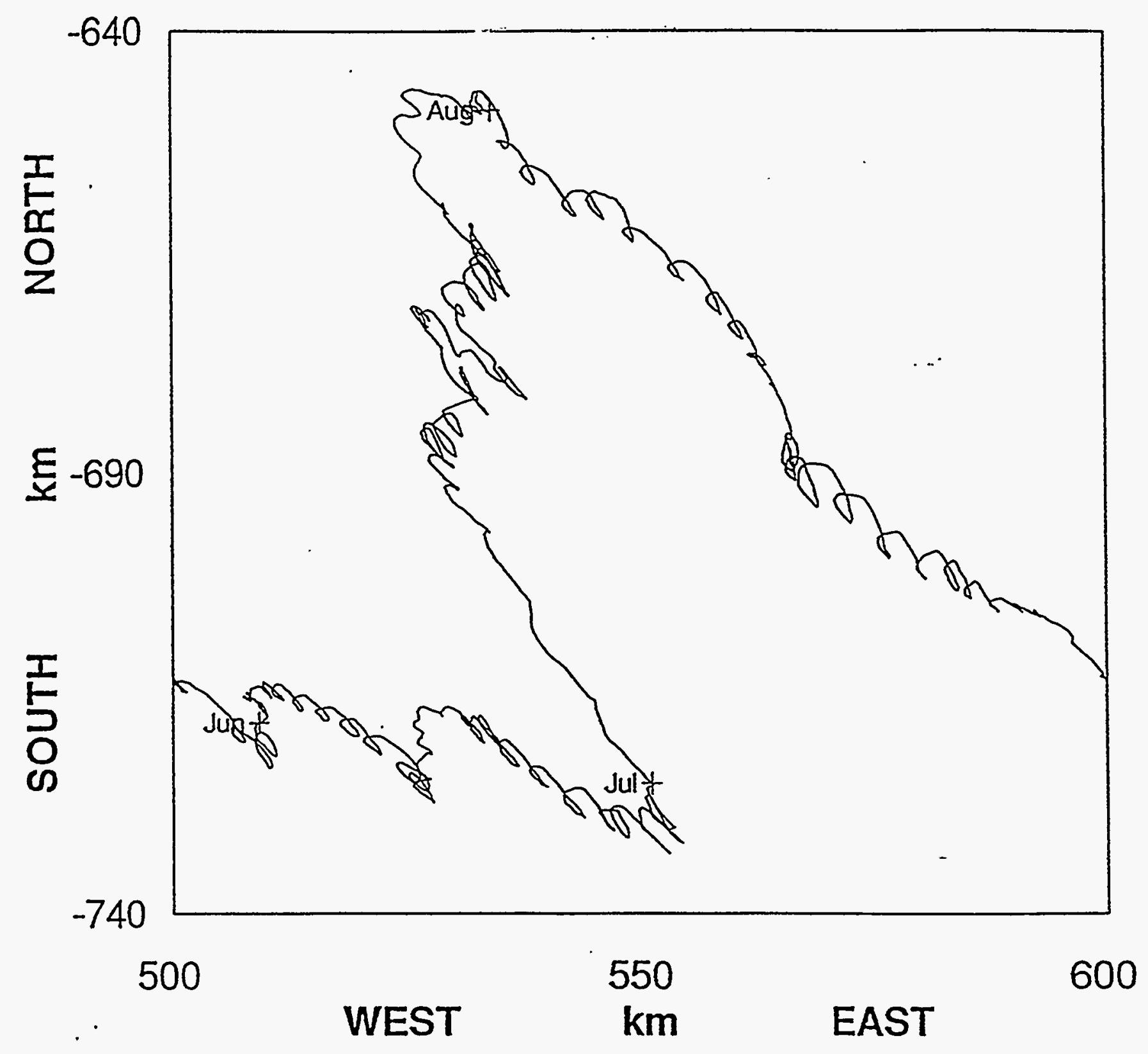

Figure 31b. Progressive vector plot for $3 \mathrm{~h}$ mean current vectors at Station $Y$, June through August, 1994. 


\section{Station X 1993-1994 \\ Progressive Vector Diagram}

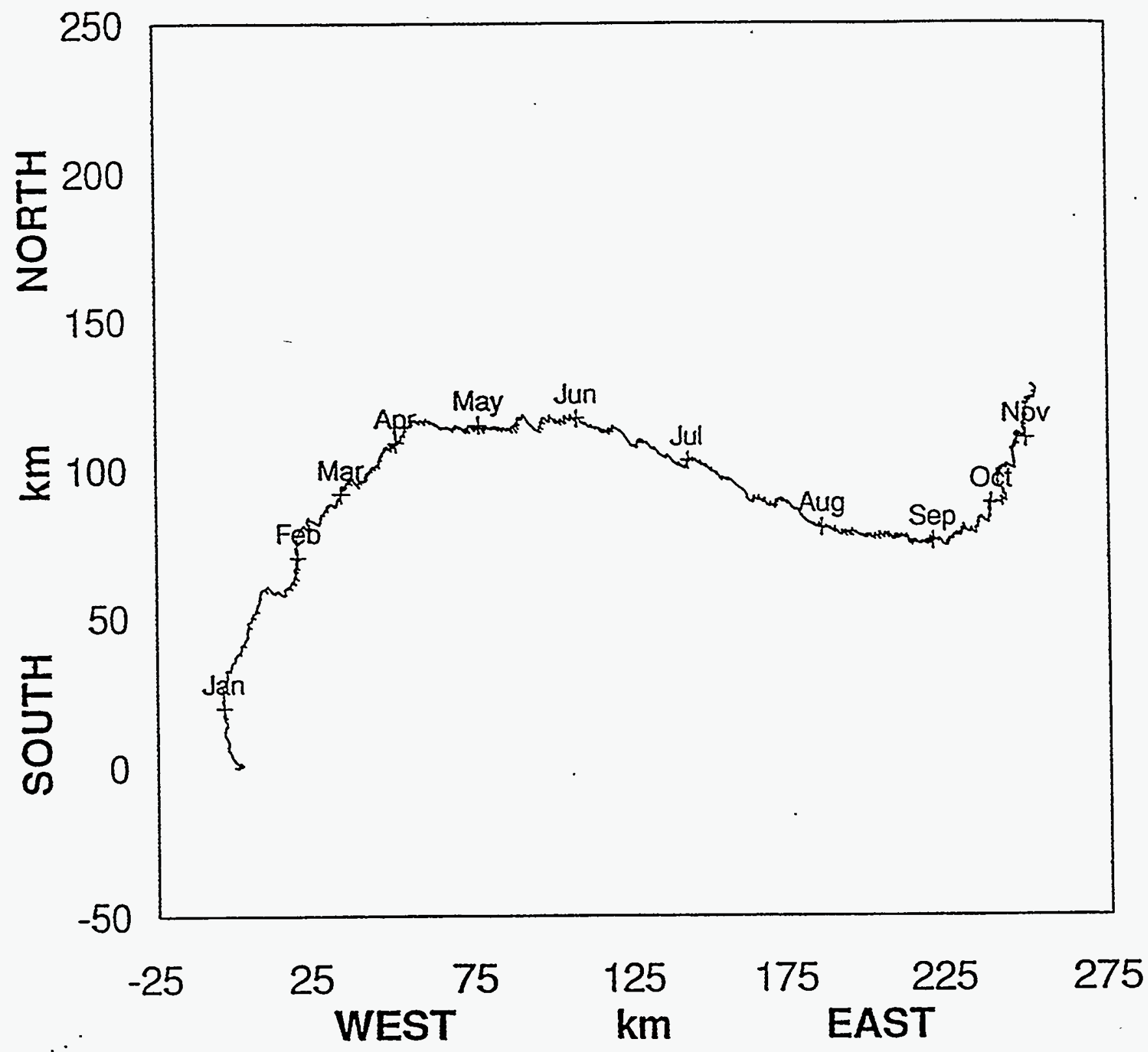

Figure 32 Progressive vector plot for $3 \mathrm{~h}$ mean current vectors at Station $\mathrm{X}$ from December 1993 through November 1994. 


\section{Station W 1993-1994 Progressive Vector Diagram}



Figure 33a Progressive vector plot for 3 h mean current vectors at Station W, December 1993 through November 1994. 


\section{Station W 1993-1994 Progressive Vector Diagram}

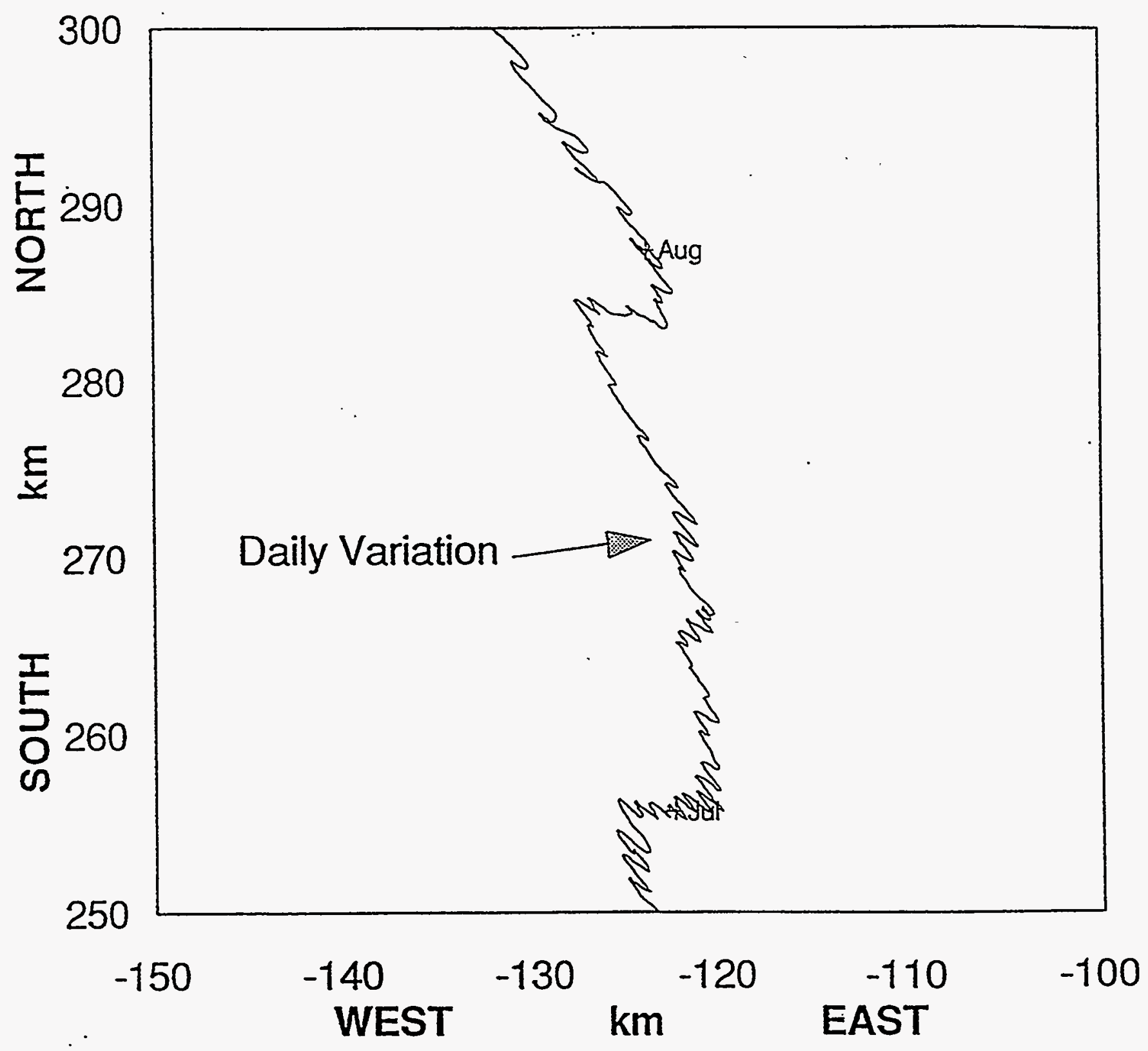

Figure 33b Progressive vector plot for $3 \mathrm{~h}$ mean current vectors at Station W, August, 1994. 


\section{Station W 1993-1994 Progressive Vector Diagram}

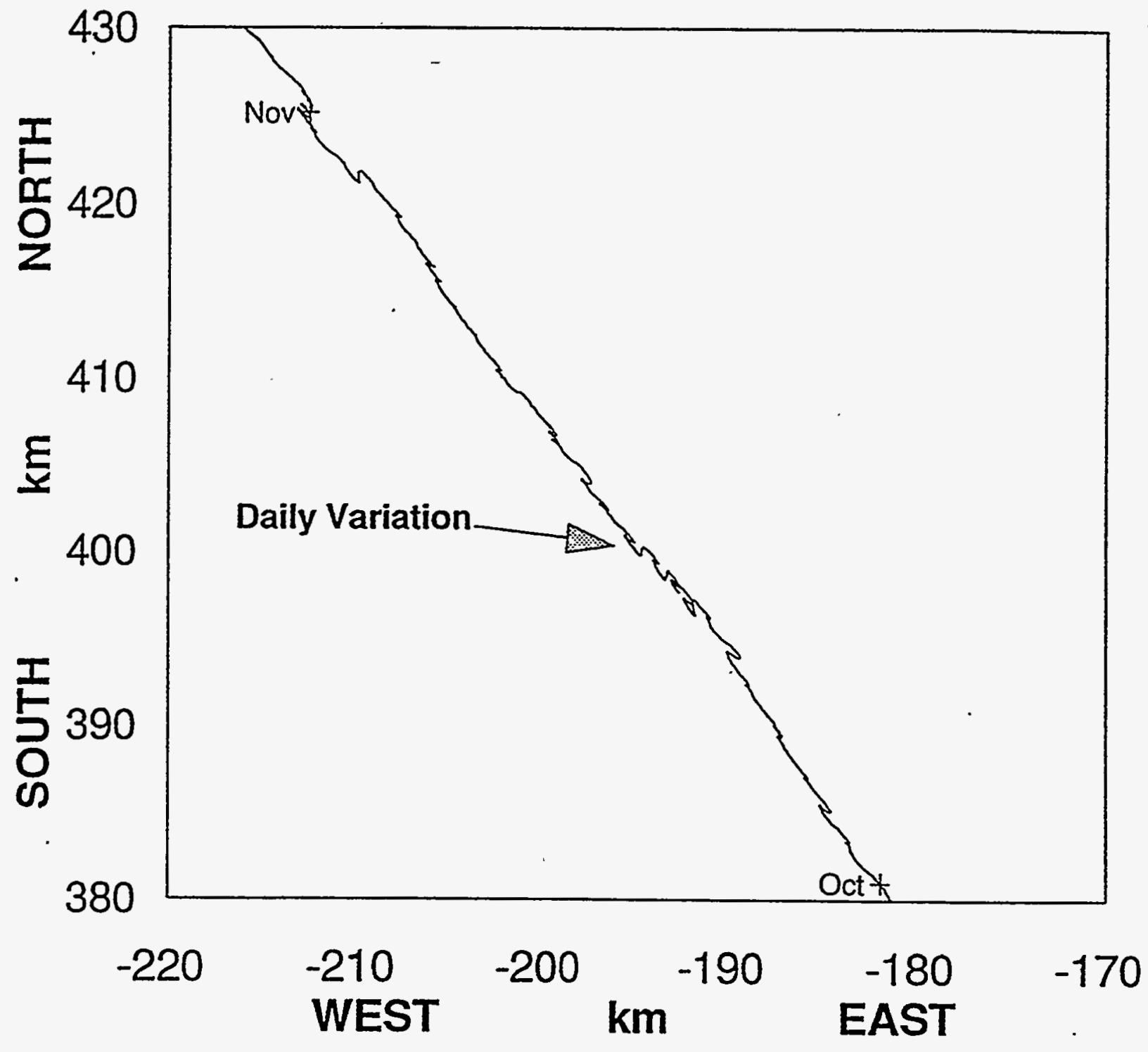

Figure 33c Progressive vector plot for $3 \mathrm{~h}$ mean current vectors at Station W, October, 1994. 


\section{Station T 1993-1994 Progressive Vector Diagram}



Figure 34a Progressive vector plot for $3 \mathrm{~h}$ mean current vectors at Station T, December 1993 through November 1994. 


\section{Station T 1993-1994 Progressive Vector Diagram}

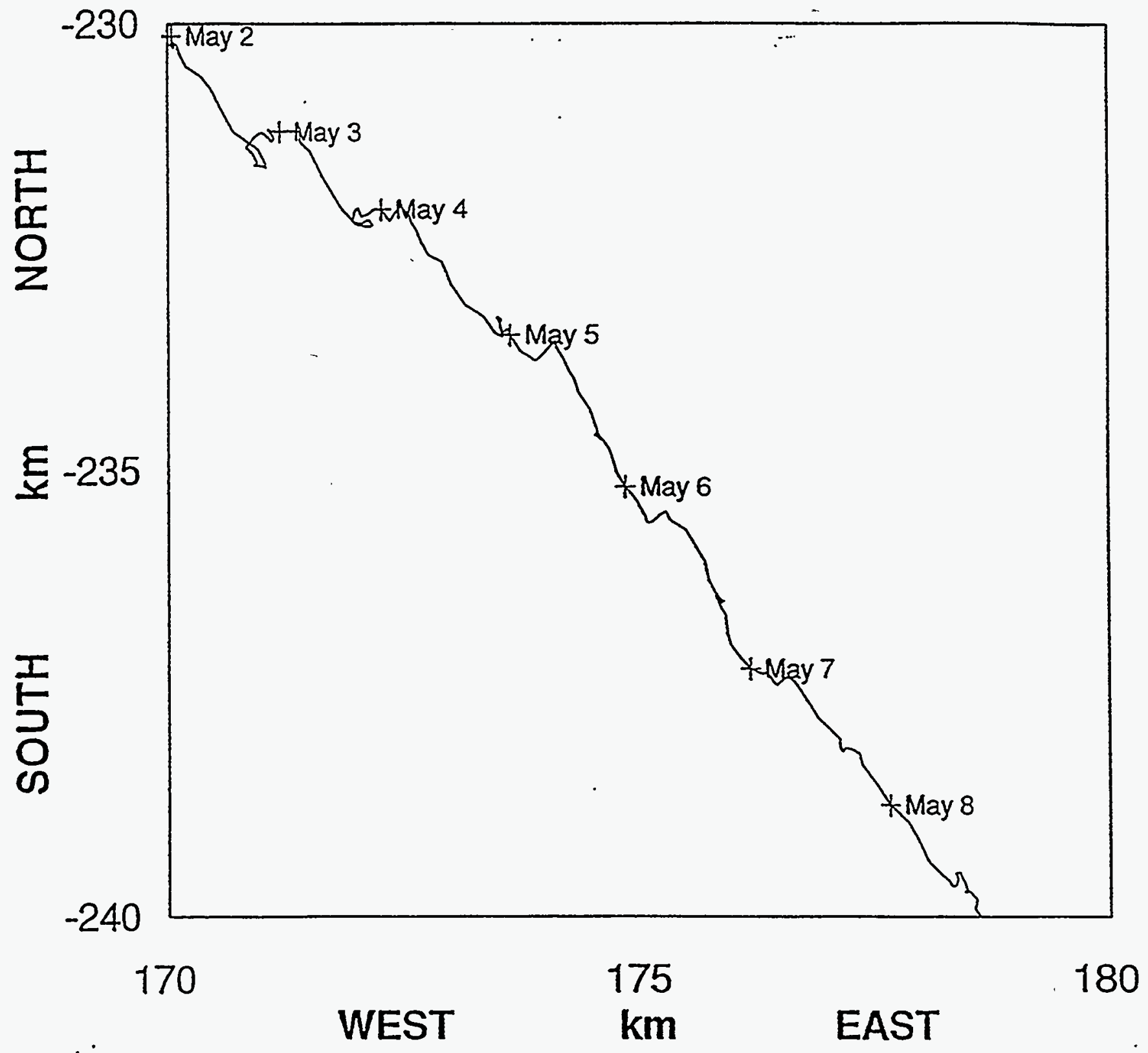

Figure 34b Progressive vector plot for $3 \mathrm{~h}$ mean current vectors at Station T, early May, 1994. 


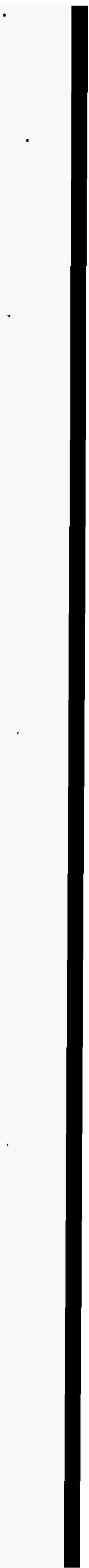


The overall pattern of flow shown by progressive vector diagrams were quite similar between nearby stations during 1992-1993 and 1993-1994, except for the more intense northwestward flow during June and September of 1993. Station P from 1992-1993 (Figure 35 in Barry 1994) and Station V from 1993-1994 (Figure 30) both show strong seasonal shifts in flow, but more strongly northwestward flow in winter, 1993. It is possible that differences in ice cover over regional or larger scales may have produced these differences.

\subsection{Effects of Ice Cover and Wind Stress on McMurdo Sound Currents}

Ice cover and wind are likely to have very strong influences on surface currents in McMurdo Sound, over local to large (e.g. $1000 \mathrm{~km}$ ) scales. The large seasonal shifts in current patterns are evidence of shifts in forces regulating flow in McMurdo Sound. While data are not readily available to measure accurately the timing and extend of sea ice cover, its removal near the beginning of February 1993, coincided with a marked shift in the prevailing pattern of flow near Hut Point, suggesting the shift was a regional pattern. Week-long or longer episodes of prevailing S or NW flow during Fall and early Winter 1993 may be associated with changes in wind stress regulated by the formation and removal of areas of sea ice near Ross Island and McMurdo Station. Similarly, the rapid NW flow in June and July 1993, followed abruptly by a return to oscillatory and generally southward flow in August, could easily be ice-related. Sea ice was developing through fall 1993, and may have reached near maximum development around Ross Island by the beginning of June, only to be removed by a harsh winter storm of early August. Ice cover during 1993-1994 was far more extensive than the prior year, and may have influenced the flow pattern near McMurdo Station. Further research is required to evaluate this hypothesis. 
Figure 35 Map of McMurdo Sound near McMurdo Station indicating proposed wastewater pipeline and outfall sites. Black line indicates the proposed pipeline path. Light brown area indicates the region with optimal current flow patterns for waste dispersal away from McMurdo Station. 


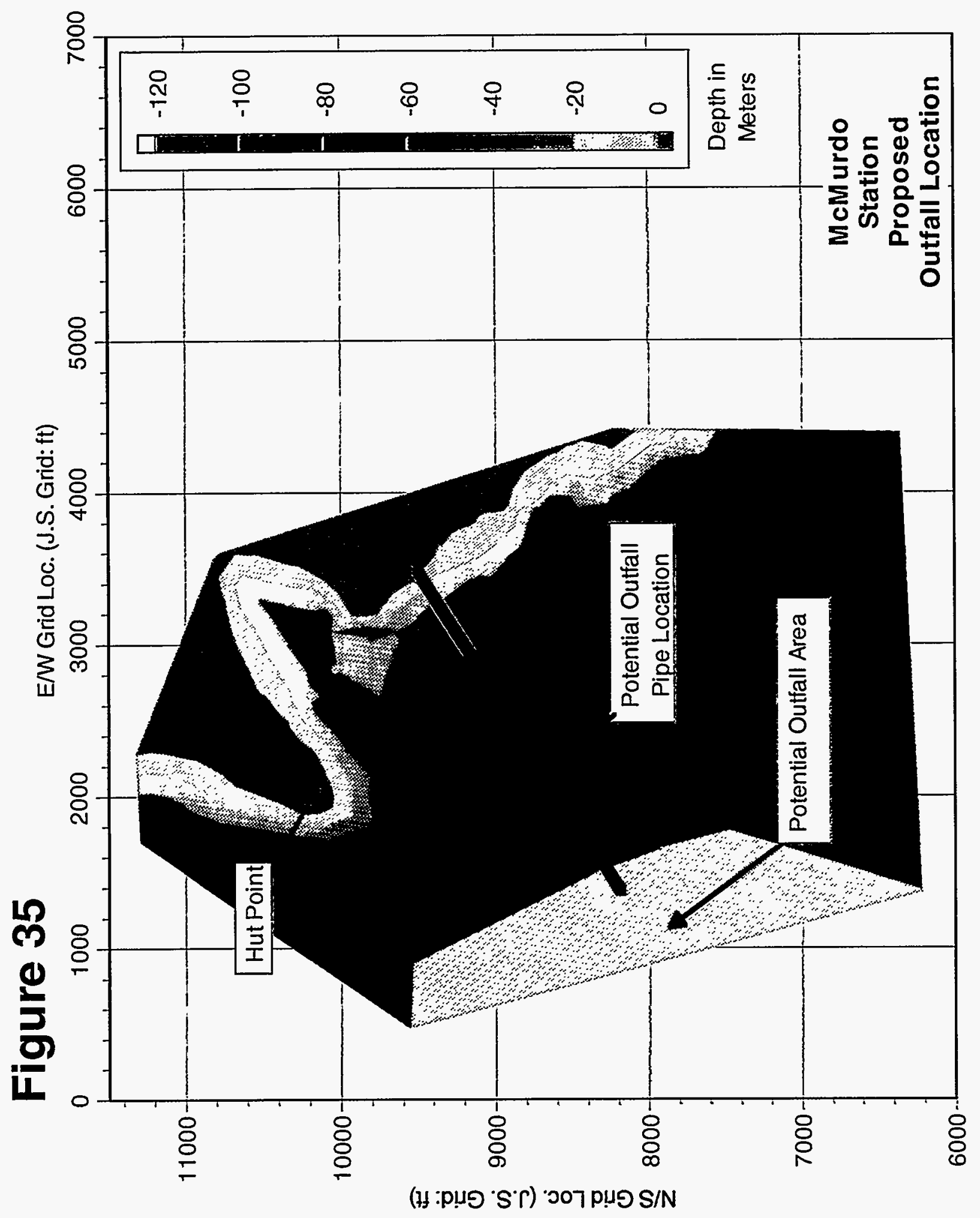





\section{DISCUSSION}

\subsection{Relationship of Current Patterns to Wastewater Plume Dispersal}

Year-long observations of currents in the vicinity of McMurdo Station from December 1992 to November 1994 included 2 years of observation during periods of high änd low ice cover in McMurdo Sound. Observations during all seasons revealed large variation in ocean currents that had not been identified from data collected solely during spring and early summer. Spring and early summer studies during 1991 and 1992 showed that the regional pattern of flow was generally southward along the Hut Point peninsula, and generated a counter-clockwise eddy adjacent to McMurdo Station (McFeters et al. 1993). Flow in this eddy transports the wastewater plume from the present outfall towards Hut Point, where it presumably is partially recirculated near McMurdo Station in the McMurdo Gyre, and partially entrained in southward flow passing Hut Point and dispersed away from McMurdo Station. The transport mechanism does not transport solids that settle to the bottom in the outfall area, where low current speeds dominate (Table 2, Barry 1994). Importantly, episodes of current reversal along McMurdo Station, which persisted for 12 to $24 \mathrm{~h}$, were evident in current records approximately monthly during spring 1992-1993, resulting in plume transport to the SE towards the seawater intake. Such episodes were even more frequent during 1993-1994. This mechanism is probably responsible for the high coliform bacterial densities near the seawater intake area (Howington et al. 1992, McFeters et al. 1993). Because the distance between the present outfall and the seawater intake pipes at the jetty are so near to one another $(-500 \mathrm{~m})$, it requires only a short period of southeastward flow from the outfall near Station $W$ to the jetty. To transport wastewater this distance requires only 6 hours for a current running SE at $2.5 \mathrm{~cm} / \mathrm{s}$ (the average current speed near the outfall).

In comparing patterns of flow between 1992-1993 and 1993-1994, it is apparent that the general pattern of seasonal shifts in net flow on a regional scale is somewhat similar between years, but the timing, strength, and variability of flow within seasons, and especially over daily periods, varies greatly with time. This was strongly evident in 1993-94 when daily oscillations in flow were much more frequent year-round, than during the prior year. Moreover, episodes of current reversals which may have influenced dispersal of the wastewater plume were common in 1994 during most seasons. Thus, although general patterns of net flow are similar over seasonal scales, but shorter period patterns are shown to be quite difficult to predict. Such variability should be considered with regard to repositioning the wastewater outfall.

Barry (1994) emphasized the importance of coupling of diurnal current motions with longer period changes in regional flow. For example, if diurnal tidal oscillations in current speed and direction are superimposed on a fairly rapid southward large scale flow along the Hut Point Peninsula, the combined current will be a pulsed southward flow, oscillating from sluggishly (e.g. near $3 \mathrm{~cm} / \mathrm{s}$ ) southward (when the tidal flow opposed the larger scale flow), to rapidly southward 
when tidal flow reverses (e.g. $20 \mathrm{~cm} / \mathrm{s}$; see Figure 26 in Barry 1994, Station A). During these periods, the McMurdo gyre should be relatively persistent and transport near the present outfall will be towards Hut Pt. This was the general pattern during spring 1992-1993, as well as other periods where general southward flow dominated. However, if the larger scale flow is weakly southward, as seen during much of 1993-1994, northward periods of tidal oscillation can result in net northward flow near Hut Point, which apparently disrupted the McMurdo Gyre and transported the wastewater plume to the SE. Likewise, tidal oscillations superimposed on net northward regional flow may also have important consequences near McMurdo Station.

Coupling of several scales of variation can result in episodes of current reversal along the McMurdo Station shoreline, with sufficient magnitude to disperse the wastewater plume near McMurdo Station, rather than transport much of it offshore. Figures 25 to 29 illustrate coupling of tidal and aperiodic flow. For each station, hourly current speeds are shown in gray for north/south and east/west directions of flow. Net current speeds for hourly data with tidal motions of $30 \mathrm{~h}$ and less filtered out are shown in black. Thus, the black lines indicate the pattern of transport over short periods, after tidal oscillations are removed. At Stations V and $\mathrm{Y}$, which represent regional flow (Figure 26, 29), tidal fluctuations were somewhat stronger than the prior year (1992-1993). The most apparent features include the strong tidal variation, resulting in net southeastward flow of December and January, and periods of persistent northwestward flow during part of winter. At the same time, filtered net flow at Station W (Figure 27), was mostly . northwestward, with occasional shifts (e.g. mid-February) to the southeast apparent on the filtered data (black line). Flow at Station $W$ was more strongly northward overall, than nearby at Station $N$ during 1992-1993. Moreover, short period changes in flow (1 to $6 \mathrm{~h}$ ) were stronger in 1993-94 than the prior year, and may have resulted in more frequent transport of the sewage plume towards the seawater intake area. Alternatively, Station W may have more energetic currents because it is slightly further offshore than Station N (1992-1993 data).

The frequency of reversal events, or any event (defined as a current observation at Station $W$ with sufficient speed to transport the plume $500 \mathrm{~m}$ to the $\mathrm{SE}\left[120^{\circ}-165^{\circ}\right]$ ) sufficient to impact the intake area ranged from 2.5 to $14.8 \%$ (for 3 and $6 \mathrm{~h}$ data averages, respectively) in 19931994, compared with 1.2 to $6.7 \%$ in 1992-1993. For all $3 \mathrm{~h}$ mean data at Station W, $2.5 \%$ of 2685 total observations were both toward the SE and $4.6 \mathrm{~cm} / \mathrm{s}$ or greater. For $6 \mathrm{~h}$ data averages, flow was to the SE $32 \%$ of the time, compared with $18.3 \%$ for $1992-1993$. Flow was sufficiently rapid to transport the plume $500 \mathrm{~m}$ to the intake area $14.8 \%$ of the time, in 1993-1994, nearly 3 times the frequency of 1992-1993. For $12 \mathrm{~h}$ averages, the plume could move to the SE at least $500 \mathrm{~m} 4.0 \%$ of the time. Thus, although SE flow near the outfall comprises a minority of the flow patterns in that areas, these events are clearly an important component of the flow field capable of relatively frequent impacts to the intake area. This was true for both years of observation, but the noteworthy pattern of 1993-1994 is the greater oscillatory motion over 6 to 12 hour periods, compared to 1992-1993.

Analysis of current meter data from the period October 1, 1994 to February 15, 1995, indicated that a transport events to the SE were less frequent during this period, when McMurdo 
Station has the highest population, and thus, greatest wastewater releases, than during the entire year. For 3 hour average current vectors, flow was sufficiently strong to the SE to transport the plume $500 \mathrm{~m}$ only $0.7 \%$ of the time. Using $6 \mathrm{~h}$ averages, this percentage was $2.8 \%$. Thus, SE transport events occurred less frequently during the spring/ summer period than the remainder of the year. The summer reduction in SE transport was also evident in 1993-1994, when such events occurred in 1.8 percent of all spring/summer observations ( $3 \mathrm{~h}$ averages), compared to $2.5 \%$ for the entire year. This pattern is likely related to the more persistent southward regional flow in summer, which stabilizes the McMurdo Gyre.

\subsection{Recommendations for Wastewater Outfall Relocation}

The ideal location for a wastewater release site is one providing the maximum likelihood of entrainment of the wastewater plume in currents that disperse the plume downstream and offshore from McMurdo Station. In addition, a site of high current speeds is preferable to one of low speeds, owing to the greater potential for resuspension and dispersal of sinking particulate material. Near McMurdo Station, this requires the site to be outside the McMurdo Gyre, so that the plume is not entrained in the gyre and transported inshore. Figure 35 shows an area potentially appropriate for the outfall site. The boxes indicate regions thought to be minimally away from the McMurdo Gyre to prevent entrainment of the plume. The proposed locations should be compared to maps indicating the seasonal pattern of flow near the station. In particular, inspection of the spring-summer map (Figure 7) shows the transition zone between the inner and outer portions of the McMurdo Gyre (Stations J, $\mathrm{K}$, and L) during a 1 month-long current record from 1992. Station $J$ was clearly in the inner side of the gyre (during the summer observation period), and station $\mathrm{L}$ was in the outer portion of the gyre. Station $\mathrm{K}$ was located in the central transition zone of the gyre. The gyre very likely varies considerably in its size and position. To maximize dispersal away from McMurdo Station, the outfall should be positioned at least as far offshore as Station $L$, and preferably much further, since flow from Station L probably turns towards the coast as part of the McMurdo Gyre. The advantage of positioning the outfall directly offshore from Hut Point, in addition to distance from the McMurdo gyre, is the higher current speeds in this area, and potential for dispersal of solids. A negative aspect of this site is the potential for entrainment of wastewater into the plume: because Hut Point is the point of generation for the gyre, the nearer to Hut Point the outfall is placed, the greater the likelihood for entrainment in the gyre. Nevertheless, any site outside the gyre is preferable to the present location. Again, the maximum distance offshore is the preferred location. Variation in flow may result in plume transport inshore, even from offshore of this location. During the winters of 1993 and 1994, there were periods when the regional flow appeared to be directed nearly from the SW, which will transport offshore waters directly towards McMurdo Station. Under such conditions it would be difficult to position the outfall pipe anywhere within several $\mathrm{km}$ of McMurdo Station and prevent some plume transport to the McMurdo vicinity. However, during periods of regional flow in directions from about 160 to 360 degrees true, the plume should be dispersed away from McMurdo Station from the proposed outfall location. 
An additional consideration for outfall positioning is the pipeline track, which should optimally continue downslope with no upsloping sections. Although the bathymetric map (Figure 5 ) is quite coarse in scale, it was used to identify the generally preferred pipeline track. This track may be modified according to results of a more detailed bathymetric survey. 


\section{REFERENCES}

Barry, JP 1988. "Hydrographic patterns in McMurdo Sound, Antarctica and their relationship to local benthic communities". Polar Biology 8, 377-391

Barry, JP 1994. “Ocean current observations near McMurdo Station, Antarctica from 1991 to 1993: Relation to wastewater discharge dispersal” Report Number EGG-CIET-11280 to Idaho National Engineering Laboratory, 88p.

Barry, JP and Dayton, PK, 1988. "Current patterns in McMurdo Sound, Antarctica and their relationship to local biotic communities". Polar Biology 8, 367-376.

Barry, JP, PK Dayton, RB Dunbar, and A Leventer 1990 "Winter oceanographic observations in McMurdo Sound, Antarctica". Ant.J. U.S., 25, 106-107.

Bromwich, DH, JF Carrasco, Z Liu, and R-Y Tzeng 1993. "Hemispheric atmospheric variations and oceanographic impacts associated with katabatic surges across the Ross Ice Shelf, Antarctica". J. Geophys. Res. - Atmospheres, in press.

Dayton, PK 1989. "Interdecadal variation in an Antarctic sponge and its predators from oceanographic climate shifts:. Science 245, 1484-1486.

Dunbar RB and Leventer A, 1991. "Circulation in eastern McMurdo Sound, Antarctica, January through November 1990". Ant.J. U.S., 26, 117-119.

Doake, CSM 1978. "Dissipation of tidal energy by Antarctic ice shelves". Nature 275, 304-305.

Gilmour, AE, WJP MacDonald, FG VanderHoeven 1960. "Ocean currents in McMurdo Sound". Nature 4740, 867.

Gilmour, AE, WJP MacDonald, FG VanderHoeven 1962. "Winter measurements of sea currents in McMurdo Sound". NZ J Geol. Geophys. 5, 778-789.

Heath, RA 1971. "Circulation and hydrology under the seasonal ice in McMurdo Sound, Antarctica". NZ J. Mar. Freshwater Res. 5, 479-515.

Heath, RA 1977. "Circulation across the Ice Shelf Edge in McMurdo Sound, Antarctica": In: Dunbar JM (ed) Polar Oceans. Proc. Polar Oceans Conf., pp 129-149.

Hodgson TV 1907. "On collecting in Antarctic Seas". Natural history, vol III. Zool. Bot.

Holdsworth, G 1977. "Tidal interaction with ice shelves". Annales de Geophysique t.33 fasc 1/2, 
pp 133-146.

Howington, JP, GA McFeters, JP Barry, and JJ Smith 1992. "Distribution of the McMurdo Station Sewage Plume". Marine Pollution Bulletin, 25, 9-12, 324-327.

Jacobs, SS, RG Fairbanks, and Y Horibe 1985. "Crigin and evolution of water masses near the Antarctic continental margin: evidence from $\mathrm{H}_{2}{ }^{18} \mathrm{O} / \mathrm{H}_{2}{ }^{16} \mathrm{O}$ ratios in seawater". Pages $59-86$ in: Oceanology of the Antarctic Continental Shelf, SS Jacobs (editor), Antarctic Research Series, v. 43. American Geophysical Union.

Lewis, EL and RG Perkin 1985 "The winter oceanography of McMurdo Sound, Antarctica". Pages 145-166 in: Oceanology of the Antarctic Continental Shelf, SS Jacobs (editor), Antarctic Research Series, v. 43. American Geophysical Union.

Littlepage, ЛL 1965. "Oceanographic investigations in McMurdo Sound, Antarctica". In, Llano G(ed) Biology of Antarctic Seas, vol II. American Geophysical Union, pp 145-166.

MacAyeal, DR 1984. "Thermohaline circulation below the Ross Ice Shelf: A consequence of tidally induced vertical mixing and basal melting". J. Geophy. Res, 89, 597-606.

McFeters, GA. 1993. "Progress report for studies of coliform bacterial counts and currents near the McMurdo Station wastewater outfall". NSF grant to T-325.

McFeters, GA, JP Barry, and JP Howington 1993. "Distribution of enteric bacteria in Antarctic seawater surrounding a sewage outfall". Water Res. 27, 645-650.

Pillsbury, RD and SS Jacobs, 1985. "Preliminary observations from long-term current meter moorings near the Ross Ice Shelf, Antarctica". Pages 87-108 in: Oceanology of the Antarctic Continental Shelf, SS Jacobs (editor), Antarctic Research Series, v. 43. American Geophysical Union.

Pond, S and GL Pickard 1983. Introductory Dynamical Oceanography, 2nd edition. Pergamon Press, Oxford.

Raytheon Service Company 1983. "Report on the McMurdo Station water quality study", Unpubl. Rep ITT Antarctic Serv.

Tressler, WL and Am Ommundsen 1962. "Seasonal oceanographic studies in McMurdo Sound, Antarctica". USN Hydrographic office Technical Report 125. 
Appendix A

COMPUTER-BASED TIME SERIES OF MCMURDO SOUND CURRENT VECTORS

A-1 



\section{Appendix A}

\section{COMPUTER-BASED TIME SERIES OF MCMURDO SOUND CURRENT VECTORS}

\section{A-1. DESCRIPTION OF VECTOR DISPLAY PROGRAM}

This program was distributed last year, with both the data and program on 1 data diskette. This year I have provided data files from the 1993-1994 observations, including 3, 6, and 12 hour average data.

With considerable support from Sean Callahan of the Crary Science Facility at McMurdo Station, we developed a computer program to display time series observations of current vectors for all current meter records from 1991 to 1993 . This program (VECTOR), reads data files for 1, $3,6,12$, or 24 hour mean current vectors for all stations, and provides a graphic display on a DOS-based computer terminal. VECTOR is useful in inspecting patterns of flow, and particularly variation in flow over time. Individual vectors corresponding to observations from each station at each time period are displayed simultaneously to provide an instantaneous synoptic view of currents near McMurdo Station. The time series can be paused, accelerated, or slowed, depending on the desired rate of inspection. As time series of data for each station are completed, a mean overall vector average is displayed in a different color to allow discrimination between these and instantaneous vectors. VECTOR is provided on a $3.5^{\prime \prime}$ floppy disk, and is accompanied by data files comprising 6,12 , and $24 \mathrm{~h}$ averages.

VECTOR is initiated by copying all files on the diskette to a hard drive (though it will run from the floppy), and typing the command "vector". The program will initiate, and list all available data files. Choose the file type $(6,12$ or $24 \mathrm{~h}$ averaged data) by typing the appropriate code (e.g. *.12h for 12 hour averages). You may also select individual files by their specific names. Press the return key when finished with data selection (select only 1 type of data $: 6,12$, or $24 \mathrm{~h}$ averages), and VECTOR will read all appropriate data files and begin displaying data. Current vectors will be displayed as they are available for each station, according to the time clock, which begins at the beginning of the available data, and increments in time according to the data type (i.e. 6,12 or $24 \mathrm{~h}$ ).

\section{A-2. DESCRIPTION OF VECTOR KEYBOARD CONTROLS}

Keyboard controls can be used to modify the display rate and other characteristics of the VECTOR program. These keyboard controls can be used in upper or lower case, and have immediate effects on program display features. When the program is complete, it will flicker, with blue current averages displayed for each station or data file. Data averages displayed at the end of each data series are not affected by advancing the time clock (e.g. M). 


\section{A-2.1 Keyboard Controls}

\section{VECTOR - Start Program}

Space bar Pause or resume operation

$+$

$-$

$>$

$<$

$\mathrm{D}$

M

$\mathrm{Y}$

$\mathrm{R}$
Speed clock by factor of 2

Slow clock by factor of 2

Increase Current Vector Scale

Decrease Current Vector Scale

Advance clock by 1 day

Advance clock by 1 month

Advance clock by 1 year

Redraw coastline 